
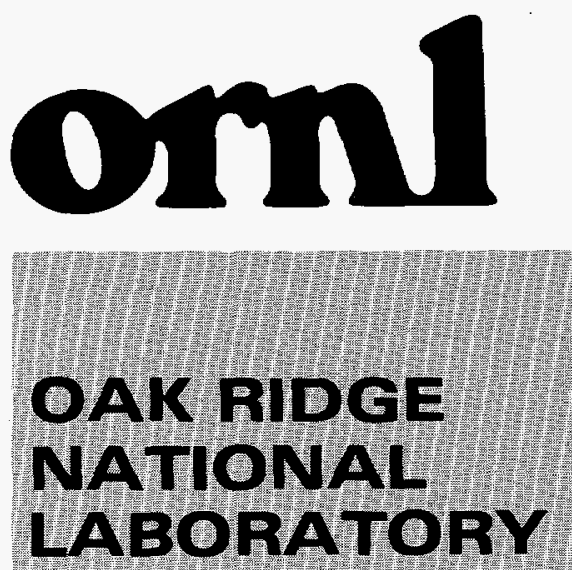

MAGTHN MAGUETRA
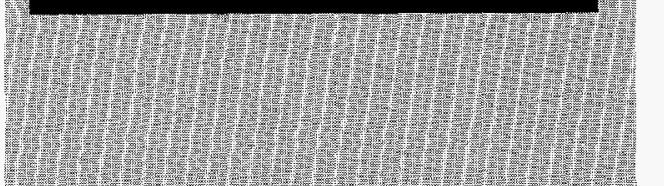

ORNL-6618/s1

6. $9 ?$ ? 138

391

\title{
ANSL-V: ENDF/B-V Based Multiqroup Cross-Section Libraries for Advanced Neutron Source Reactor Studies Supplement 1
}

\author{
R. Q. Wright \\ J. P. Reneir \\ J. A. Bucholz
}

August 1995

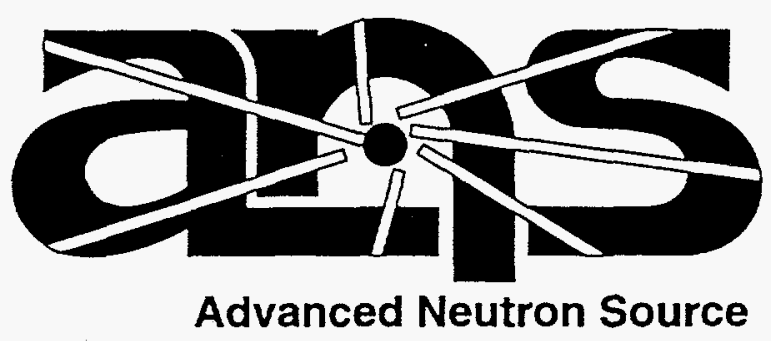

MANAGED BY

MARTIW MARIETTA ENERGY SYSTEMS, INC.

FOR THE UNITED STATES

Mha. -R

DEPARTMENT OF ENERGY 
This report has been reproduced directly from the best available copy.

Available to DOE and DOE contractors from the Office of Scientific and Technical Information, P.O. Box 62, Oak Ridge, TN 37831; prices available from (615) 576-8401, FTS 626-8401.

Available to the public from the National Technical Information Service, U.S. Department of Commerce, 5285 Port Royal Rd., Springtield, VA 22161.

This report was prepared as an account of work sponsored by an agency of the United States Government. Neither the United Stales Government nor any agency thereof, nor any of their employees, makes any warranty, express or implied, or assumes any legal liability or responsibility for the accuracy, completeness, or usefulness of any information, apparatus, product, or process disclosed, or represents that its use would not infringe privately owned rights. Reference herein to any specific commercial product, process, or service by trade name, trademark, manufacturer, or otherwise, does not necessarily constitute or imply its endorsement, recommendation, or favoring by the United States Government or any agency thereof. The views and opinions of authors expressed herein do not necessarily state or reflect those of the United States Government or any agency thereof. 
Computational Physics and Engineering Division

\title{
ANSL-V: ENDF/B-V BASED MULTIGROUP CROSS-SECTION LIBRARIES FOR ADVANCED NEUTRON SOURCE (ANS) REACTOR STUDIES SUPPLEMENT 1
}

\author{
R. Q. Wright, J. P. Renier, and J. A. Bucholz
}

Date Published: August 1995

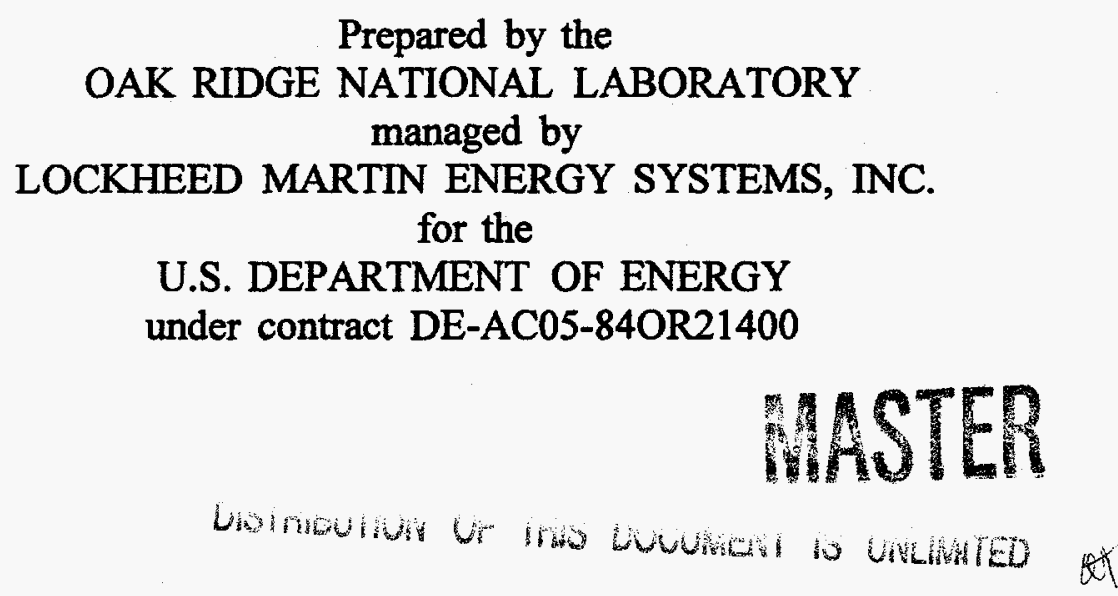




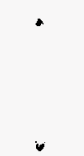




\section{CONTENTS}

LIST OF TABLES $\ldots \ldots \ldots \ldots \ldots \ldots \ldots \ldots \ldots \ldots \ldots \ldots \ldots \ldots \ldots \ldots$

ACRONYMS $\ldots \ldots \ldots \ldots \ldots \ldots \ldots \ldots \ldots \ldots \ldots \ldots \ldots \ldots \ldots \ldots \ldots \ldots \ldots$

ABSTRACT $\ldots \ldots \ldots \ldots \ldots \ldots \ldots \ldots \ldots \ldots \ldots \ldots \ldots \ldots \ldots \ldots \ldots \ldots$

1. INTRODUCTION $\ldots \ldots \ldots \ldots \ldots \ldots \ldots \ldots \ldots \ldots \ldots \ldots \ldots \ldots \ldots \ldots \ldots$

2. ANSL-V LIBRARY SPECIFICATIONS $\ldots \ldots \ldots \ldots \ldots \ldots \ldots \ldots \ldots \ldots$

3. METHODOLOGY USED TO GENERATE CROSS-SECTION LIBRARIES $\ldots \ldots \ldots \ldots$

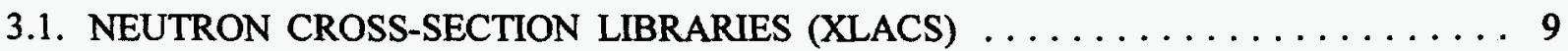

3.2. GAMMA-RAY INTERACTION CROSS SECTIONS (SMUG) $\ldots \ldots \ldots \ldots \ldots \ldots \ldots$

3.3. GAMMA-RAY PRODUCTION CROSS SECTIONS (LAPHNGAS) $\ldots \ldots \ldots \ldots \ldots 11$

3.4. ANSL-V COUPLED 99N/44G NEUTRON-GAMMA LIBRARY (UNITAB) $\ldots \ldots \ldots 11$

3.5. ANSL-V COUPLED 39N/44G NEUTRON-GAMMA LIBRARY (MALOCS) $\ldots \ldots . .11$

4. FUNCTIONS OF THE OTHER AMPX MODULES $\ldots \ldots \ldots \ldots \ldots \ldots \ldots \ldots$

4.1. TREATMENT OF DELAYED FISSION GAMMAS $\ldots \ldots \ldots \ldots \ldots \ldots \ldots \ldots \ldots$

4.2. RENORMALIZATION OF 2-D ARRAYS (COMET) $\ldots \ldots \ldots \ldots \ldots \ldots \ldots \ldots$

4.3. ADJUST THERMAL SCATTERING MATRICES (FRESH) $\ldots \ldots \ldots \ldots \ldots \ldots \ldots$

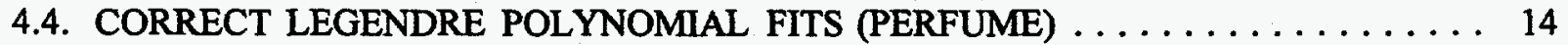

4.5. ANSL-V CROSS-SECTION LIBRARY CHECKING (RADE) . . . . . . . . . . 15

4.6. MODULE TO CONVERT MASTER CROSS-SECTION LIBRARIES FROM BCD TO BINARY FORMAT (OR VICE VERSA): AIM $\ldots \ldots \ldots \ldots \ldots \ldots \ldots$

4.7. A CAUTIONARY NOTE REGARDING PHOTONEUTRONS $\ldots \ldots \ldots \ldots \ldots$

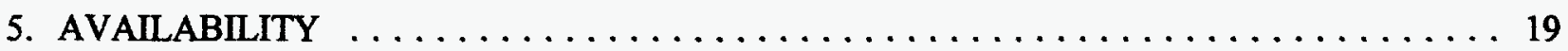

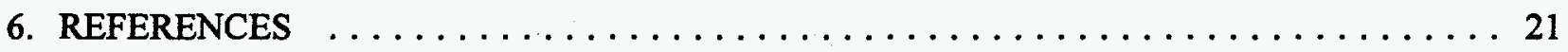

APPENDIX A: UPDATE TO ANSL-V COUPLED NEUTRON-GAMMA

LIBRARY (JUNE 1991) . . . . . . . . . . . . . . 23

APPENDIX B: SUMMARY OF ANSL-V LIBRARY DATA $\ldots \ldots \ldots \ldots \ldots \ldots$

APPENDIX C: ANSL-V LIBRARY: AMPX INPUT DATA FILES $\ldots \ldots \ldots \ldots \ldots \ldots$ 



\section{LIST OF TABLES}

Table

Page

1 Neutron group energy boundaries for the 99 -group ANSL-V library $(\mathrm{eV}) \ldots \ldots \ldots$

2 Photon group energy boundaries for ANSL-V library $(\mathrm{eV}) \ldots \ldots \ldots \ldots \ldots \ldots \ldots$

3 Broad-group energy boundaries for 39 -group library $(\mathrm{eV}) \ldots \ldots \ldots \ldots \ldots \ldots$

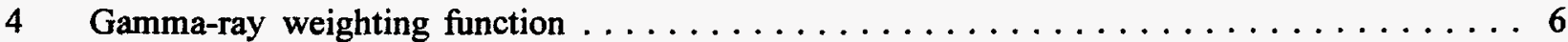

5 Summary of AMPX modules used for ANSL-V generation $\ldots \ldots \ldots \ldots \ldots \ldots \ldots$

6 Materials taken from LENDL library $\ldots \ldots \ldots \ldots \ldots \ldots \ldots \ldots \ldots \ldots$

7 Cross-section checks performed by RADE on AMPX master interface files $\ldots \ldots \ldots \ldots 15$

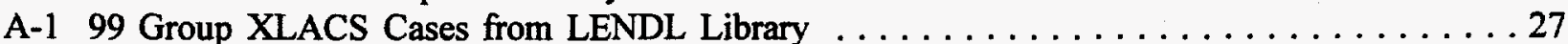

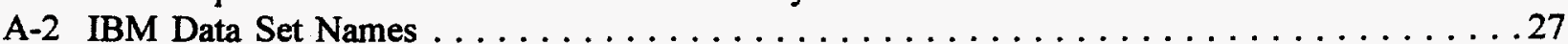

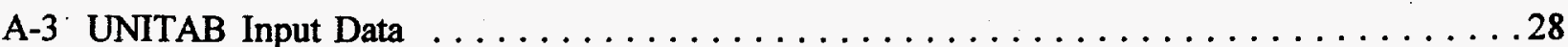

A-4 Gamma Ray Production Process 102 for B-11, Total Energy and Cross Section . . . . . . 29

B-1 Brief summary of data for all 138 nuclides in the $99 \mathrm{n} / 44 \mathrm{~g}$ and $39 \mathrm{n} / 44 \mathrm{~g}$

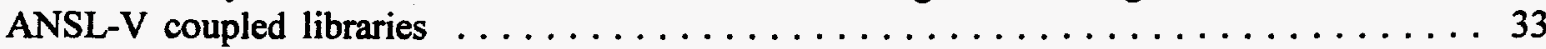

B-2 Type of nuclear data available for all 138 nuclides in the $39 \mathrm{n} / 44 \mathrm{~g}$

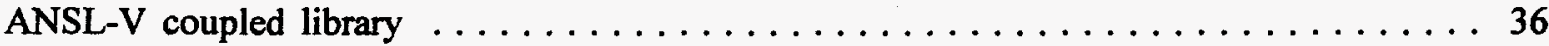

B-3 Temperature-independent $1-\mathrm{D}$ neutron processes for each nuclide $\ldots \ldots \ldots \ldots \ldots \ldots 42$

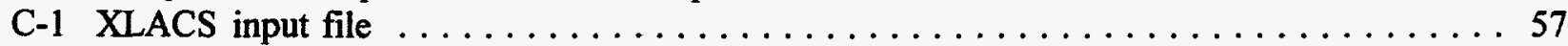

C-2 SMUG input file $\ldots \ldots \ldots \ldots \ldots \ldots \ldots \ldots \ldots \ldots \ldots \ldots \ldots \ldots$

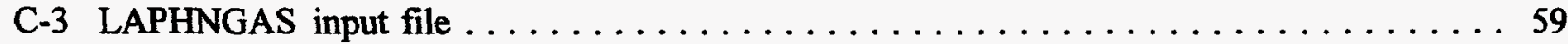

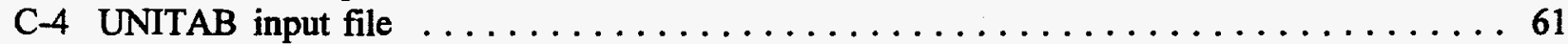

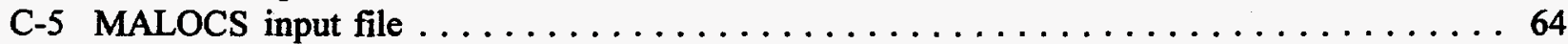

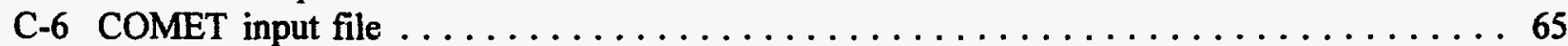

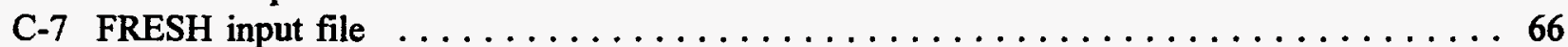

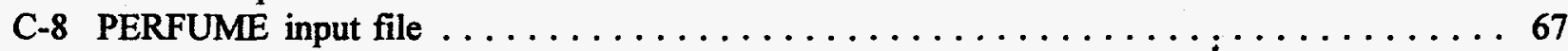


. 


\section{ACRONYMS}

1-D

2-D

ANS

BCD

IBM

JCL

MAT

NRC

ORNL

RSIC

one-dimensional

two-dimensional

Advanced Neutron Source

binary coded decimal

International Business Machines

job control language

material number

U.S. Nuclear Regulatory Commission

Oak Ridge National Laboratory

Radiation Shielding Information Center 
, 


\begin{abstract}
The original ANSL-V cross-section libraries (ORNL-6618) were developed over a period of several years for the physics analysis of the ANS reactor, with little thought toward including the materials commonly needed for shielding applications. Materials commonly used for shielding applications include calcium, barium, sulfur, phosphorous, and bismuth. These materials, as well as ${ }^{6} \mathrm{Li},{ }^{7} \mathrm{Li}$, and the naturally occurring isotopes of hafnium, have been added to the ANSL-V libraries. The gamma-ray production and gamma-ray interaction cross sections were completely regenerated for the ANSL-V $99 \mathrm{n} / 44 \mathrm{~g}$ library which did not exist previously. The MALOCS module was used to collapse the $99 \mathrm{n} / 44 \mathrm{~g}$ coupled library to the $39 \mathrm{n} / 44 \mathrm{~g}$ broad-group library. COMET was used to renormalize the two-dimensional (2-D) neutron matrix sums to agree with the one-dimensional (1-D) averaged values. The FRESH module was used to adjust the thermal scattering matrices on the 99n/44g and 39n/44g ANSL-V libraries. PERFUME was used to correct the original XLACS Legendre polynomial fits to produce acceptable distributions. The final ANSL-V $99 \mathrm{n} / 44 \mathrm{~g}$ and $39 \mathrm{n} / 44 \mathrm{~g}$ cross-section libraries were both checked by running RADE. The AIM module was used to convert the master cross-section libraries from binary coded decimal to binary format (or vice versa).
\end{abstract}


. 


\section{INTRODUCTION}

The original ANSL-V cross-section libraries' were developed over a period of several years for the physics analysis of the Advanced Neutron Source (ANS) reactor, with little thought, initially, toward including the materials commonly needed for shielding applications. As a result, there were a number of materials that had to be added before the ANSL-V libraries could be used for shielding analyses. Materials commonly used for shielding applications include calcium, barium, phosphorous, sulfur, zinc, and bismuth, none of which were included in the initial ANSL-V libraries described in ref. 1. Unfortunately there is no evaluation for zinc in ENDF/B format, so it was not possible to include data for zinc. This is not a serious problem since (1) zinc is only present as a trace element in materials used in the ANS shielding analyses, and (2) activation sources due to zinc (in Al-6061, for example) may still be calculated using the standard activation libraries available with the ORIGEN-S code.

In the original work, there was a 99-group neutron library, including 125 material isotopes, a 39-group neutron library, including 125 material isotopes, and a $39 \mathrm{n} / 44 \mathrm{~g}$ (39 neutron groups/44 gamma groups) coupled library, including only 57 material isotopes. For shielding applications, a $99 \mathrm{n} / 44 \mathrm{~g}$ coupled library was considered to be a much better alternative. This $99 \mathrm{n} / 44 \mathrm{~g}$ coupled library could be produced with very little effort since the 99-group neutron library was already available. In the newly enhanced libraries, it was decided to include the gamma-ray interaction data for all materials (including those for which no gamma-ray production data were available) so as to make the coupled libraries as complete as possible. Some important materials in the ENDF/B-V library do not have gamma-ray production files in the evaluation. As a result, data from the LENDL-V evaluations were used for 12 materials.

When the LENDL-V evaluations are used, it is very important to use the evaluation for both neutron cross sections and the gamma-ray production cross sections. The use of hybrid (ENDF/B-V and LENDL) data sets would be a potentially very serious mistake. This was clearly demonstrated in the 1991 work on ${ }^{11} \mathrm{~B}$ (see ref. 2 and/or Appendix A). There, it was also shown that the old hybrid ENDF/B-V neutron/LENDL gamma-ray production data for hafnium gave excessive gamma heating in the ANS control rods. From that experience, it was concluded that such hybrid sets should never be used.

The remainder of this report documents the work done since the publication of the original ANSL-V report ${ }^{1}$ in Sept. 1990. Most of the additional work described here was performed between May and July of 1993. The present report concentrates on a description of the final libraries, including a detailed summary of the content of the libraries, and typical input files for the AMPX ${ }^{3}$ programs used to generate these libraries. The materials in the final $99 \mathrm{n} / 44 \mathrm{~g}$ and $39 \mathrm{n} / 44 \mathrm{~g} \mathrm{ANSL-V}$ libraries are given in Table B-1, which also gives a brief summary of the data available for all of the 138 materials. 


\section{ANSL-V LIBRARY SPECIFICATIONS}

We will not attempt to discuss all the ANSL-V specifications in this report. Only the most important specifications will be briefly reviewed, and the reader should consult ref. 1 for other details not covered here. The ANSL-V 99-group energy boundaries are given in Table 1. The photon 44-group energy boundaries are given in Table 2. The 39-group (neutron) energy boundaries are given in Table 3 . The reader should consult ref. 1 for a discussion of the neutron weighting functions (type A, B, C) used for the ANSL-V libraries. A new gamma-ray weighting function was used for this work. All the gamma-ray interaction data was regenerated using this new gamma-ray weighting function. The new gamma-ray weighting function (1/E plus high- and low-energy rolloffs) is shown in Table 4 . The reader should note that the function is only defined for four different energies. Thus it is very important to use $\log -\log$ interpolation with this weighting function.

A summary of the AMPX modules used for the ANSL-V generation is given in Table 5. The reader should consult the AMPX-77 report ${ }^{3}$ for additional details and for the input descriptions. Sample input files for each of the programs used here are given in Appendix C. Materials taken from the LENDL-V library are shown in Table 6. The table also has a brief discussion of the LENDL-V library and includes a list of ten materials not available in either the ENDF/B-V or ENDF/B-VI libraries. Six of these materials have half-lives less than 120 days.

\section{LENDL-V Data Library:}

LENDL-V contains evaluated neutron cross-section and photon production data for 94 materials. All reactions are complete, covering all relevant reactions for incident energies from $0.0001 \mathrm{eV}$ to 20 $\mathrm{MeV}$. Resonance parameters are not used in the LENDL-V library (in general, this is a serious limitation of the library; for this reason, ENDF/B evaluations were used for the ANSL-V library whenever possible). The LENDL-V data were used whenever photon production data were needed and were not available in the ENDF/B evaluation. The LENDL-V library was converted to the ENDF/B-V format by R. J. Howerton, Lawrence Livermore National Laboratory, starting from the ENDL-84 library in 1984. The LENDL-V library is available from the Oak Ridge Radiation Shielding Information Center (RSIC) as data library DLC-120. LENDL-V includes ten materials not available in either the ENDF/B-V or ENDF/B-VI libraries:

\begin{tabular}{llllll} 
MATERIAL & MAT & HALF-LIFE & MATERIAL & MAT & HALF-LIFE \\
\hline 33-As-74 & 830 & $17.78 \mathrm{~d}$ & $90-$ Th-233 & 7865 & $22.3 \mathrm{~m}$ \\
39-Y-88 & 8303 & $106.6 \mathrm{~d}$ & $92-\mathrm{U}-239$ & 7872 & $23.5 \mathrm{~m}$ \\
50-Sn-nat & 7850 & Stable & $92-\mathrm{U}-240$ & 7873 & $14.1 \mathrm{~h}$ \\
78-Pt-nat & 7860 & Stable & $93-\mathrm{Np}-235$ & 8307 & $1.085 \mathrm{y}$ \\
90-Th-231 & 7863 & $1.063 \mathrm{~d}$ & $93-\mathrm{Np}-236$ & $\mathbf{8 3 0 8}$ & $155000 \mathrm{y}$ \\
\hline
\end{tabular}


Table 1. Neutron group energy boundaries for the 99-group ANSL-V library (eV)

\begin{tabular}{|c|c|c|c|c|c|}
\hline 1 & $2.0000 \mathrm{E}+07$ & 34 & $1.7411 \mathrm{E}+05$ & 67 & $7.8600 \mathrm{E}+00$ \\
\hline 2 & $1.5941 \mathrm{E}+07$ & 35 & $1.3195 \mathrm{E}+05$ & 68 & $6.1780 \mathrm{E}+00$ \\
\hline 3 & $1.2706 \mathrm{E}+07$ & 36 & $1.0000 \mathrm{E}+05$ & 69 & $4.8559 E+00$ \\
\hline 4 & $1.0127 \mathrm{E}+07$ & 37 & $7.0160 \mathrm{E}+04$ & 70 & $3.8168 \mathrm{E}+00$ \\
\hline 5 & $8.0722 E+06$ & 38 & $4.9224 \mathrm{E}+04$ & 71 & $3.0000 \mathrm{E}+00$ \\
\hline 6 & $6.4340 \mathrm{E}+06$ & 39 & $3.4536 \mathrm{E}+04$ & 72 & $2.6996 \mathrm{E}+00$ \\
\hline 7 & $5.5234 \mathrm{E}+06$ & 40 & $2.4230 \mathrm{E}+04$ & 73 & $2.4292 \mathrm{E}+00$ \\
\hline 8 & $4.7417 \mathrm{E}+06$ & 41 & $1.7000 \mathrm{E}+04$ & 74 & $2.1859 \mathrm{E}+00$ \\
\hline 9 & $4.0707 \mathrm{E}+06$ & 42 & $1.2017 \mathrm{E}+04$ & 75 & $1.9670 \mathrm{E}+00$ \\
\hline 10 & $3.4946 \mathrm{E}+06$ & 43 & $8.4941 E+03$ & 76 & $1.7700 \mathrm{E}+00$ \\
\hline 11 & $3.0000 \mathrm{E}+06$ & 44 & $6.0042 E+03$ & 77 & $1.3000 \mathrm{E}+00$ \\
\hline 12 & $2.7235 \mathrm{E}+06$ & 45 & $4.2441 E+03$ & 78 & $1.0000 \mathrm{E}+00$ \\
\hline 13 & $2.4725 E+06$ & 46 & $3.0000 \mathrm{E}+03$ & 79 & $7.6500 \mathrm{E}-01$ \\
\hline 14 & $2.2447 \mathrm{E}+06$ & 47 & $2.1368 E+03$ & 80 & $6.2500 \mathrm{E}-01$ \\
\hline 15 & $2.0378 E+06$ & 48 & $1.5220 \mathrm{E}+03$ & 81 & 4.7900E-01 \\
\hline 16 & $1.8500 \mathrm{E}+06$ & 49 & $1.0841 \mathrm{E}+03$ & 82 & $3.9700 \mathrm{E}-01$ \\
\hline 17 & $1.7497 \mathrm{E}+06$ & 50 & $7.7217 \mathrm{E}+02$ & 83 & $3.3000 \mathrm{E}-01$ \\
\hline 18 & $1.6548 \mathrm{E}+06$ & 51 & $5.5000 \mathrm{E}+02$ & 84 & $2.7000 \mathrm{E}-01$ \\
\hline 19 & $1.5651 \mathrm{E}+06$ & 52 & $3.9110 \mathrm{E}+02$ & 85 & $2.1500 \mathrm{E}-01$ \\
\hline 20 & $1.4803 E+06$ & 53 & $2.7811 \mathrm{E}+02$ & 86 & $1.6200 \mathrm{E}-01$ \\
\hline 21 & $1.4000 \mathrm{E}+06$ & 54 & $1.9776 \mathrm{E}+02$ & 87 & $1.0400 \mathrm{E}-01$ \\
\hline 22 & $1.2816 \mathrm{E}+06$ & 55 & $1.4063 E+02$ & 88 & $5.0000 \mathrm{E}-02$ \\
\hline 23 & $1.1732 E+06$ & 56 & $1.0000 \mathrm{E}+02$ & 89 & $3.0000 \mathrm{E}-02$ \\
\hline 24 & $1.0740 E+06$ & 57 & $7.8600 \mathrm{E}+01$ & 90 & $1.0000 \mathrm{E}-02$ \\
\hline 25 & $9.8315 \mathrm{E}+05$ & 58 & $6.1780 \mathrm{E}+01$ & 91 & 4.4500E-03 \\
\hline 26 & $9.0000 \mathrm{E}+05$ & 59 & $4.8559 \mathrm{E}+01$ & 92 & $3.2500 \mathrm{E}-03$ \\
\hline 27 & $7.6525 \mathrm{E}+05$ & 60 & $3.8168 \mathrm{E}+01$ & 93 & $2.6000 \mathrm{E}-03$ \\
\hline 28 & $6.5068 \mathrm{E}+05$ & 61 & $3.0000 \mathrm{E}+01$ & 94 & $2.1500 \mathrm{E}-03$ \\
\hline 29 & $5.5326 \mathrm{E}+05$ & 62 & $2.4082 \mathrm{E}+01$ & 95 & $1.8000 \mathrm{E}-03$ \\
\hline 30 & $4.7043 E+05$ & 63 & $1.9332 \mathrm{E}+01$ & 96 & 1.4500 E-03 \\
\hline 31 & $4.0000 \mathrm{E}+05$ & 64 & $1.5518 \mathrm{E}+01$ & 97 & $1.1500 \mathrm{E}-03$ \\
\hline 32 & $3.0314 \mathrm{E}+05$ & 65 & $1.2457 \mathrm{E}+01$ & 98 & 8.5000E-04 \\
\hline 33 & $2.2974 \mathrm{E}+05$ & 66 & $1.0000 \mathrm{E}+01$ & 99 & $5.5000 \mathrm{E}-04$ \\
\hline
\end{tabular}


Table 2. Photon group energy boundaries for ANSL-V library (eV)

\begin{tabular}{llll}
\hline 1 & $2.0000 \mathrm{E}+07$ & 23 & $1.5000 \mathrm{E}+01$ \\
2 & $1.4000 \mathrm{E}+07$ & 24 & $1.4400 \mathrm{E}+06$ \\
3 & $1.2000 \mathrm{E}+07$ & 25 & $1.3300 \mathrm{E}+06$ \\
4 & $1.0000 \mathrm{E}+07$ & 26 & $1.2000 \mathrm{E}+06$ \\
5 & $8.0000 \mathrm{E}+06$ & 27 & $1.0000 \mathrm{E}+06$ \\
6 & $7.5000 \mathrm{E}+06$ & 28 & $8.0000 \mathrm{E}+05$ \\
7 & $7.0000 \mathrm{E}+06$ & 29 & $7.0000 \mathrm{E}+05$ \\
8 & $6.5000 \mathrm{E}+06$ & 30 & $6.0000 \mathrm{E}+05$ \\
9 & $6.0000 \mathrm{E}+06$ & 31 & $5.1200 \mathrm{E}+05$ \\
10 & $5.5000 \mathrm{E}+06$ & 32 & $5.1000 \mathrm{E}+05$ \\
11 & $5.0000 \mathrm{E}+06$ & 33 & $4.5000 \mathrm{E}+05$ \\
12 & $4.5000 \mathrm{E}+06$ & 34 & $4.0000 \mathrm{E}+05$ \\
13 & $4.0000 \mathrm{E}+06$ & 35 & $3.0000 \mathrm{E}+05$ \\
14 & $3.5000 \mathrm{E}+06$ & 36 & $2.0000 \mathrm{E}+05$ \\
15 & $3.0000 \mathrm{E}+06$ & 37 & $1.5000 \mathrm{E}+05$ \\
16 & $2.5000 \mathrm{E}+06$ & 38 & $1.0000 \mathrm{E}+05$ \\
17 & $2.3500 \mathrm{E}+06$ & 39 & $7.5000 \mathrm{E}+04$ \\
18 & $2.1500 \mathrm{E}+06$ & 40 & $7.0000 \mathrm{E}+04$ \\
19 & $2.0000 \mathrm{E}+06$ & 41 & $6.0000 \mathrm{E}+04$ \\
20 & $1.8000 \mathrm{E}+06$ & 42 & $4.5000 \mathrm{E}+04$ \\
21 & $1.6600 \mathrm{E}+06$ & 43 & $3.0000 \mathrm{E}+04$ \\
22 & $1.5700 \mathrm{E}+06$ & 44 & $2.0000 \mathrm{E}+04$ \\
& & & $1.0000 \mathrm{E}+04$ \\
\hline
\end{tabular}


Table 3. Broad-group neutron energy boundaries for 39-group library (eV)

\begin{tabular}{llll}
\hline 1 & $2.0000 \mathrm{E}+07$ & 21 & $4.7900 \mathrm{E}-01$ \\
2 & $6.4340 \mathrm{E}+06$ & 22 & $3.9700 \mathrm{E}-01$ \\
3 & $3.0000 \mathrm{E}+06$ & 23 & $3.3000 \mathrm{E}-01$ \\
4 & $1.8500 \mathrm{E}+06$ & 24 & $2.7000 \mathrm{E}-01$ \\
5 & $1.4000 \mathrm{E}+06$ & 25 & $2.1500 \mathrm{E}-01$ \\
6 & $9.0000 \mathrm{E}+05$ & 26 & $1.6200 \mathrm{E}-01$ \\
7 & $4.0000 \mathrm{E}+05$ & 27 & $1.0400 \mathrm{E}-01$ \\
8 & $1.0000 \mathrm{E}+05$ & 28 & $5.0000 \mathrm{E}-02$ \\
9 & $1.7000 \mathrm{E}+04$ & 29 & $3.0000 \mathrm{E}-02$ \\
10 & $3.0000 \mathrm{E}+03$ & 30 & $1.0000 \mathrm{E}-02$ \\
11 & $5.5000 \mathrm{E}+02$ & 31 & $4.4500 \mathrm{E}-03$ \\
12 & $1.0000 \mathrm{E}+02$ & 32 & $3.2500 \mathrm{E}-03$ \\
13 & $3.0000 \mathrm{E}+01$ & 33 & $2.6000 \mathrm{E}-03$ \\
14 & $1.0000 \mathrm{E}+01$ & 34 & $2.1500 \mathrm{E}-03$ \\
15 & $3.0000 \mathrm{E}+00$ & 35 & $1.8000 \mathrm{E}-03$ \\
16 & $1.7700 \mathrm{E}+00$ & 36 & $1.4500 \mathrm{E}-03$ \\
17 & $1.3000 \mathrm{E}+00$ & 37 & $1.1500 \mathrm{E}-03$ \\
18 & $1.0000 \mathrm{E}+00$ & 38 & $8.5000 \mathrm{E}-04$ \\
19 & $7.6500 \mathrm{E}-01$ & 39 & $5.5000 \mathrm{E}-04$ \\
20 & $6.2500 \mathrm{E}-01$ & & $1.0000 \mathrm{E}-05$ \\
\hline
\end{tabular}

Table 4. Gamma-ray weighting function

\begin{tabular}{lcc}
\hline & Energy (eV) & Weight \\
1 & $1.0000 \mathrm{E}+03$ & $1.0000 \mathrm{E}-04$ \\
2 & $1.0000 \mathrm{E}+05$ & $1.0000 \mathrm{E}+00$ \\
3 & $1.0000 \mathrm{E}+07$ & $1.0000 \mathrm{E}-02$ \\
4 & $3.0000 \mathrm{E}+07$ & $1.0000 \mathrm{E}-04$ \\
\hline
\end{tabular}

Note: use $\log -\log$ interpolation 
Table 5. Summary of AMPX modules ${ }^{3}$ used for ANSL-V generation

\begin{tabular}{|c|c|}
\hline Module & Function $^{\mathrm{a}}$ \\
\hline XLACS & $\begin{array}{l}\text { Module to generate multigroup neutron-only cross-section libraries. XLACS } \\
\text { produces a multigroup library in the AMPX master library format by averaging } \\
\text { pointwise neutron cross-section data taken from the ENDF/B data files. For } \\
\text { most nuclides the pointwise cross sections are constructed from resonance } \\
\text { parameter data given in the ENDF/B evaluation. }\end{array}$ \\
\hline SMUG & $\begin{array}{l}\text { Module to generate multigroup gamma-ray cross-section libraries. SMUG } \\
\text { calculates multigroup photon cross sections, with transfer coefficients } \\
\text { represented by a Legendre approximation of an arbitrary order. The scattering } \\
\text { moments are computed from the Klein-Nishina equation. The photoelectric and } \\
\text { pair-production cross sections are obtained from the ENDF/B evaluations. }\end{array}$ \\
\hline LAPHNGAS & $\begin{array}{l}\text { Module to generate multigroup neutron/gamma production terms. LAPHNGAS } \\
\text { retrieves photon production data from the ENDF/B data file and calculates } \\
\text { either multigroup gamma-ray production cross sections (SGRPXS) and/or } \\
\text { multigroup secondary gamma-ray yields (multiplicities) that are written to an } \\
\text { AMPX master interface. }\end{array}$ \\
\hline UNITAB & $\begin{array}{l}\text { Module to combine the XLACS, LAPHNGAS, and SMUG files into a coupled } \\
\text { neutron/gamma AMPX master interface. }\end{array}$ \\
\hline MALOCS & $\begin{array}{l}\text { Module to collapse AMPX master cross-section libraries. MALOCS can be } \\
\text { used to collapse neutron, gamma-ray, or coupled neutron-gamma libraries. For } \\
\text { this project, MALOCS was used to collapse the } 99 / 44 \text { neutron-gamma coupled } \\
\text { library to a } 39 / 44 \text { coupled library. Note that only the neutron groups were } \\
\text { collapsed; the gamma-ray groups were not collapsed. }\end{array}$ \\
\hline COMET & $\begin{array}{l}\text { Module to force consistency between groupwise average cross sections and the } \\
\text { transfer matrices in the AMPX master interface. Operations are provided to } \\
\text { ensure that transfer matrices are normalized to the proper 1-D values, or vice } \\
\text { versa. Although coupled neutron-gamma libraries can be read in, COMET only } \\
\text { operates on the neutron data on a master library. }\end{array}$ \\
\hline FRESH & $\begin{array}{l}\text { Module that allows one to post-process the thermal-scattering matrices for } \\
\text { many resonance nuclides produced by XLACS in order to normalize them to } \\
\text { user-specified values. For the } 99 / 44 \text { ANSL-V cross section library, some } \\
\text { thermal matrices were not adjusted (option } 0 \text { ) and the thermal matrices for } \\
\text { some nuclides were renormalized to averaged values produced by the resonance } \\
\text { calculation in XLACS; see Sect. } 3.2 .3 \text { of ref. } 1 \text { and/or the FRESH input file } \\
\text { given elsewhere in this documentation. }\end{array}$ \\
\hline
\end{tabular}


Table 5 (continued)

\begin{tabular}{|c|c|}
\hline Module & Function $^{\mathrm{a}}$ \\
\hline PERFUME & $\begin{array}{l}\text { Module to correct the group-to-group Legendre transfer coefficients for minor } \\
\text { roundoff problems that otherwise may prevent the Monte Carlo codes (KENO } \\
\text { and MORSE) from finding moment-preserving scattering angles in the range } \\
\text { from }-1 \text { to }+1 \text { (which would have precluded the use of the ANSL-V libraries in } \\
\text { these codes, had these corrections not been made). It is important to note that } \\
\text { the order in which COMET, FRESH, and PERFUME are executed is very } \\
\text { important. The preferred order is COMET-FRESH- PERFUME; in any case, } \\
\text { PERFUME should be executed last. }\end{array}$ \\
\hline RADE & $\begin{array}{l}\text { Module to check AMPX master or working libraries. RADE will also check an } \\
\text { ANISN binary-formatted library. The AMPX file can be a neutron, gamma, or } \\
\text { a coupled neutron-gamma library. RADE performs a number of very important } \\
\text { checks; generally it is worthwhile to do a RADE run even for intermediate } \\
\text { libraries to make sure that errors are not introduced. }\end{array}$ \\
\hline AJAX & $\begin{array}{l}\text { Module to combine data from AMPX interfaces. Options are provided to allow } \\
\text { merging from any number of files in a manner as to allow the user to determine } \\
\text { the final nuclide ordering. Any form of master interface (neutron, gamma, or } \\
\text { neutron-gamma) can be accessed. }\end{array}$ \\
\hline AIM & $\begin{array}{l}\text { Module to read a binary-formatted master library and to write a card-image } \\
\text { (BCD) format or vice versa. Because all machines can read card-image files, } \\
\text { the BCD format serves to transmit data between different computers. }\end{array}$ \\
\hline
\end{tabular}

asee ref. 3 for additional details.

Table 6. Materials taken from LENDL library

\begin{tabular}{lcc}
\hline \multicolumn{1}{c}{ Nuclide } & AMPX ID & MAT Number \\
\hline${ }^{11} \mathrm{~B}$ & 5011 & 7811 \\
$\mathrm{Zr}$ & 40000 & 7841 \\
${ }^{107} \mathrm{Ag}$ & 47107 & 7845 \\
${ }^{109} \mathrm{Ag}$ & 47109 & 7846 \\
$\mathrm{Cd}$ & 48000 & 7847 \\
$\mathrm{Sn}$ & 50000 & 7850 \\
$\mathrm{Eu}$ & 63000 & 7852 \\
$\mathrm{Hf}$ & 72000 & 8305 \\
${ }^{233} \mathrm{U}$ & 92233 & 7866 \\
${ }^{234} \mathrm{U}$ & 92234 & 7867 \\
${ }^{236} \mathrm{U}$ & 92236 & 7869 \\
${ }^{238} \mathrm{Pu}$ & 94238 & 7875 \\
\hline
\end{tabular}




\section{METHODOLOGY USED TO GENERATE CROSS-SECTION LIBRARIES}

The AMPX modules used to generate the various libraries are (1) XLACS for the neutron- only library, (2) SMUG for the gamma-ray interaction library, and (3) LAPHNGAS for the gamma-ray production library. Details concerning these AMPX modules, including the input descriptions, are given in ref. 3 . In the text below we will give only a brief summary of what was done, while typical input files for each of the modules may be found in Appendix $C$. These files clearly document the options used in the generation of the various libraries.

\subsection{NEUTRON CROSS-SECTION LIBRARIES (XLACS)}

Most of the materials included in the ANSL-V neutron cross-section libraries were generated prior to 1990 and were extensively documented in the first release of the library (cf. ref. 1, September 1990). Since that time, a number of additions or revisions have been made to the 99-group neutron cross-section library:

23 May 1991:

Replacement of the data for carbon bound in graphite with new data based on a more correct representation of the S(alpha,beta) scattering kernel. The previous data had been found to be incorrect. These revised data were therefore deemed necessary for work being done on graphite-moderated reactors and on the ANS hot source.

5 June 1991: Revision of the cross-section data for ten different nuclides in the existing ANSL-V coupled neutron/gamma library. They were ${ }^{11} \mathrm{~B}, \mathrm{Zr},{ }^{107} \mathrm{Ag},{ }^{109} \mathrm{Ag}$, $\mathrm{Cd}$, natural $\mathrm{Hf},{ }^{233} \mathrm{U},{ }^{234} \mathrm{U},{ }^{236} \mathrm{U}$, and ${ }^{238} \mathrm{Pu}$. In the initial ANSL-V library, the data for each of these nuclides were based on a hybrid combination of ENDF/B-V neutron data and LENDL $(n, g)$ production data. (This was necessitated by the fact that not all the necessary data were available in the ENDF/B-V data libraries.) As noted in Appendix A, however, this led to certain inconsistencies, including the generation of excessively high gamma heating rates in the ANS hafnium control rods. Moreover, it was concluded that such hybrid datasets should never be used. The new datasets for these ten nuclides are based entirely on self-consistent LENDL datasets.

22 June 1991:

Addition of data for ${ }^{6} \mathrm{Li}$ and ${ }^{7} \mathrm{Li}$. These isotopes were not in the original ANSL-V library, but were needed for reactor physics studies then being performed by J. P. Renier.

25 Aug 1991:

Addition of data for 11 new isotopes that were not in the original ANSL-V library. These included ${ }^{31} \mathrm{P},{ }^{32} \mathrm{~S}$, natural sulfur, natural calcium, ${ }^{209} \mathrm{Bi},{ }^{134} \mathrm{Ba}$, ${ }^{135} \mathrm{Ba},{ }^{136} \mathrm{Ba},{ }^{137} \mathrm{Ba},{ }^{138} \mathrm{Ba}$, and ${ }^{140} \mathrm{Ba}$. These were deemed necessary for many of the shielding calculations that were to be undertaken the following year. (Without such data, for example, it would have been impossible to model regular concrete, barytes concrete, and several other materials outside the reactor itself.) Also addition of data for six specific hafnium isotopes that were not in the original ANSL-V library. These included ${ }^{174} \mathrm{Hf},{ }^{176} \mathrm{Hf},{ }^{177} \mathrm{Hf}$, ${ }^{178} \mathrm{Hf},{ }^{179} \mathrm{Hf}$, and ${ }^{180} \mathrm{Hf}$. These were added so that his ongoing reactor physics studies could explicitly model the actual depletion in the hafnium control rods. 
1 April 1993: Revision of the existing cross-section data for 8 isotopes: ${ }^{235} \mathrm{U},{ }^{238} \mathrm{U}$, ${ }^{181} \mathrm{Ta}$, ${ }^{182} \mathrm{Ta},{ }^{151} \mathrm{Eu},{ }^{152} \mathrm{Eu},{ }^{153} \mathrm{Eu}$, and ${ }^{154} \mathrm{Eu}$. (Data for ${ }^{155} \mathrm{Eu}$ were left unchanged.)

3 June 1993: $\quad$ Replacement of the existing multigroup data for natural Eu (based on ENDFB/V) with revised multigroup data based on the LENDL-V library.

Whereas the original 99-group neutron-only library had data for 125 isotopes, and whereas data for 19 new isotopes have been added as noted above, the new ANSL-V 99n/44g and $39 \mathrm{n} / 44 \mathrm{~g}$ libraries only have data for 138 isotopes. The difference is that 6 of the earlier datasets have been

deleted in the new libraries. These include the Type B weighted data for ${ }^{107} \mathrm{Ag},{ }^{109} \mathrm{Ag}$, natural europium, and natural hafnium (although the Type $C$ weighted data have been retained in all four cases). The two quasi-realistic "lumped" datasets corresponding to "moderately absorbing fission products" and "weakly absorbing fission products" (which previously existed in the original 99-group neutron-only ANSL-V library) have also been deleted. In addition, the user should also note that many of the AMPX nuclide ID numbers for the various isotopes have now been changed so as to conform more closely to the actual ZA ID numbers in common usage in most of the SCALE and AMPX cross-section libraries. For that reason, the previous users are urged to consult the new AMPX nuclide numbers listed in Table B-1 of the present report.

As noted above, data for several nuclides in the original ANSL-V library were revised in 1991 and 1993. Several of these involved replacing the earlier data (based on ENDFB/V) with data based on the LENDL-V evaluations. One of these LENDL-V materials was natural europium (Eu-nat).

The XLACS input file for Eu-nat is given in Appendix C (Table C-1). Since the ANSL-V runs were done on the IBM mainframe, Table C-1 includes the IBM JCL as well as the input data. Note that a RADE run was also done as part of this same sequence.

All of the remarks above apply to the neutron data in the ANSL-V 99-group neutron-only library and the ANSL-V 99n/44g coupled library. Lastly, it should be noted that all of the data in the ANSL-V $39 \mathrm{n} / 44 \mathrm{~g}$ coupled library were subsequently regenerated completely by collapsing the data in the $99 \mathrm{n} / 44 \mathrm{~g}$ library to the $39 \mathrm{n} / 44 \mathrm{~g}$ energy group structure in order to ensure consistency between the two libraries.

\subsection{GAMMA-RAY INTERACTION CROSS SECTIONS (SMUG)}

The gamma-ray interaction (photon) cross sections in the ANSL-V libraries were completely regenerated. The SMUG module was used for this purpose. The 44-group ANSL-V gamma-ray energy structure is listed in Table 2. The materials in the original ANSL-V library are listed in Table 5.1 of ref. 1. Only 34 materials (elements) were included in the original work. For this revision, it was decided to include all elements from $Z=1$ to 99 . This choice was made because the SMUG runs required very little computer time and it was considered desirable to have a complete set of gamma-ray interaction cross sections for all elements.

A brief summary of the SMUG module is given in Table 5. A typical input file for SMUG is given in Table C-2. The SMUG input weighting function is shown in Table 4 and is included as the $7^{* *}$ array in the SMUG input in Table C-2. The input case shown in Table C-2 was for 24 elements, from $Z=76$ to 99 , inclusive. The SMUG output file was written on unit 60 for the case shown in Table C-2. The AJAX module (see brief summary given in Table 5) was used to combine the SMUG files into a single AMPX master interface containing the gamma-ray interaction data for all 99 elements. 


\subsection{GAMMA-RAY PRODUCTION CROSS SECTIONS (LAPHNGAS)}

The gamma-ray production cross sections in the ANSL-V 99n/44g library were completely regenerated between May 18 and June 4,1993. This was necessary since the $99 \mathrm{n} / 44 \mathrm{~g}$ library did not exist previously. The LAPHNGAS module is summarized briefly in Table 5 , but the reader should consult ref. 3 for additional details. A typical input file for LAPHNGAS is given in Table C-3. This case included four materials, ${ }^{250} \mathrm{Cf},{ }^{251} \mathrm{Cf},{ }^{252} \mathrm{Cf}$, and $\mathrm{Sn}$. The first three materials were read from unit 62 (ENDF/B-V) and the Sn data were read from unit 63 (LENDL-V). Note the input unit for each material can be on a different input unit (input as the third entry in the $14 \$ \$$ array). The total number of materials which were processed by LAPHNGAS was 69 . Allowing for cases where the same basic data appear in more than one AMPX data set (i.e., ${ }^{1} \mathrm{H},{ }^{2} \mathrm{H},{ }^{12} \mathrm{C}, \mathrm{Al}$, and $\mathrm{Si}$ ), the total number of materials with gamma-ray production cross sections is 76 . There are 62 materials which do not have gamma-ray production data. Those that do and do not can be determined by checking the number of "neutron-to-gamma processes" for each nuclide in Table B-1 of Appendix B.

\subsection{ANSL-V COUPLED 99N/44G NEUTRON-GAMMA LIBRARY (UNITAB)}

The neutron-only, gamma-only, and gamma-ray production libraries were combined using the UNITAB module. The output from UNITAB is a coupled neutron/gamma AMPX master interface. The AJAX module can be used to combine data from two or more neutron/gamma master interfaces. The materials included in the ANSL-V 99n/44g neutron-gamma library are given in Table B-1 which also gives a brief summary of the data available for all 138 materials. Table B-1 gives the AMPX ID number, the alphanumeric nuclide name, the date created, the type of weighting function used for the neutron cross-section data, the number of neutron-to-gamma processes, and the ENDF/B MAT (material number) corresponding to the fast neutron data. The ENDF/B thermal scattering data may come from a different evaluation which is completely separate from the fast data.

\subsection{ANSL-V COUPLED 39N/44G NEUTRON-GAMMA LIBRARY (MALOCS)}

The MALOCS module (see brief summary in Table 5) was used to collapse the $99 \mathrm{n} / 44 \mathrm{~g}$ coupled library to the $39 \mathrm{n} / 44 \mathrm{~g}$ broad-group library. Note that only the neutron groups are collapsed, while the gamma-ray groups are not collapsed. The 39-group (neutron) energy boundaries are given in Table 3. The MALOCS input file is given in Table C-5. The value of IWN (5th entry in the 1\$\$ array was set to 1 ; this flag specifies that the original fine-group neutron weighting function $(M T=1099)$ from the fine-group master data set should be used to collapse the data to the broadgroup energy structure. The neutron broad-group numbers by fine group are given in the $4 \$ \$$ array. Other MALOCS input is discussed in ref. 3. The contents of the $39 \mathrm{n} / 44 \mathrm{~g}$ AMPX master interface are given in Table B-1. The information in Table B-1 applies to both the $99 \mathrm{n} / 44 \mathrm{~g}$ and the $39 \mathrm{n} / 44 \mathrm{~g}$ libraries. Additional information concerning the 39n/44g ANSL-V library is given in Table B-2. Most of the information in Table B-2 also applies to the $99 \mathrm{n} / 44 \mathrm{~g}$ library, but some of the numbers will be different. The data that do not apply to the $99 \mathrm{n} / 44 \mathrm{~g}$ library are the maximum lengths of the two-dimensional (2-D) length and the number of Bondarenko groups. The other data are the same for both libraries. The temperature-independent 1-D processes for each material are shown in Table B-3. A description of the various types of nuclear reactions associated with each of the MT process IDs listed in Table B-3 may be found in Sect. 4 of the AMPX-77 manual. ${ }^{3}$ The number of such processes will vary greatly from one material to another. This variation is a function of the data 
given in the ENDF/B format evaluation. Table B-3 is very useful for anyone who is interested in the content of the ENDF/B evaluations and/or the content of the AMPX master interface files. In some cases, reactions of interest for an application of interest to the user may be missing from the ENDF/B evaluation. This can be determined quite easily from an examination of information given in Table B-3. 


\section{FUNCTIONS OF THE OTHER AMPX MODULES}

The generation of the ANSL-V cross-section libraries was discussed in Sect. 3. The purpose of this section is to discuss the other AMPX modules which were subsequently used on the AMPX master interface files to produce the final ANSL-V cross-section libraries. These modules were executed for both the $99 \mathrm{n} / 44 \mathrm{~g}$ and $39 \mathrm{n} / 44 \mathrm{~g}$ libraries.

\subsection{TREATMENT OF DELAYED FISSION GAMMAS}

In early 1993, results of studies by J. V. Pace (using the original ANSL-V library for analyses of the HFIR reactor) suggested that not all of the fission gammas from ${ }^{235} U$ and ${ }^{238} U$ were being accounted for properly. (Note that there are two types of fission gammas: prompt fission gammas which typically include only those gammas released in the first 50 to 100 nanoseconds after fission, and delayed fission-product decay gammas. While some of the latter are released over a period of many years, the bulk of the more energetic ones are released in the first 1 to 10 seconds after fission, if not in the first few hundredths of a second after fission. As such, the effect of these delayed fission gammas really should be included in steady-state shielding analyses.) In this case, it was found that the yield data for the prompt fission gammas were being properly folded with the appropriate fission cross sections, but the delayed fission gamma yields were not, even though these data were in the ANSL-V library. As per Sect. 4.6 of ref. 1, the failure of the AMPXNITAWL code to include these data in working libraries subsequently created from the AMPX master library was due to the fact that, unlike the prompt fission gamma yields which are folded with reaction type MT=18 (the fission cross section), the delayed fission product gamma yields were to be folded with reaction type $M T=181$ (a fictitious, nonexistent cross section). Subsequent processing of the ${ }^{235} U$ and ${ }^{238} \mathrm{U}$ data through the NITAWL code therefore gave a message saying "the neutron cross section cannot be found to convert the yield data for $M T=181$," which meant that the delayed fission gammas would not be included in the $(\mathrm{n}, \mathrm{g})$ production terms. [See discussion of the MT=181 data in Sect. 4.6 of ref. 1.] In reality, these secondary gamma source terms should be included, and these particular yield data should be folded with the fission cross section (MT=18) to obtain the $(n, g)$ production terms. To remedy this deficiency, the following small block of programming

\footnotetext{
DO $135 \mathrm{JAB}=1, \mathrm{~N} 2 \mathrm{DY}$

IF (MTX(JAB).EQ.181) MTX(JAB) $=18$

135 CONTINUE
}

was inserted between the end of do-loop 130 and the beginning of do-loop 150 in subroutine KOPY in a special (ANS) version of the AJAX module in the AMPX code system. This special ANS version of the AJAX program was then used to copy the entire master library from one dataset to another, while making this one small change for the ${ }^{235} U$ and ${ }^{238} U$ data. (This allows both the prompt and the delayed fission gammas to be folded with the fission cross section, and allows both to be included in the secondary gamma production cross sections in all subsequent working libraries created by NITAWL.) Since May 1993, this enhancement has been a permanent feature of both the $99 \mathrm{n} / 44 \mathrm{~g}$ and the $39 \mathrm{n} / 44 \mathrm{~g}$ AMPX master libraries. 


\subsection{RENORMALIZATION OF 2-D ARRAYS (COMET)}

COMET was used to renormalize the 2-D neutron-scattering matrices to agree with the 1-D averaged values. A brief summary of the COMET code is given in Table 5. Additional details regarding the function of the code are given in Sect. 3.2.5 of the original ANSL-V document, ${ }^{1}$ while details regarding the input data are described in ref. 3. The COMET input file used for the $99 \mathrm{n} / 44 \mathrm{~g}$ library is given in Table C-6. For all materials in the $99 \mathrm{n} / 44 \mathrm{~g}$ library, the 2-D matrices for MT $=2$, $4,16,17,22,23,24,25,28$, and 37 were renormalized to the corresponding 1-D averaged values.

\subsection{ADJUST THERMAL SCATTERING MATRICES (FRESH)}

The FRESH module was used to adjust the thermal scattering matrices in the $99 \mathrm{n} / 44 \mathrm{~g}$ and $39 \mathrm{n} / 44 \mathrm{~g}$ ANSL-V libraries. The function of the FRESH module is discussed briefly in Table 5 and more fully (in terms of the nuclear physics) in Sect. 3.2.3 of the original ANSL-V document. ${ }^{1}$ The general input description for the FRESH code is given in ref. 3, while the particular input file for the $99 \mathrm{n} / 44 \mathrm{~g}$ library is given in Table C-7. The $6 \$ \$$ array contains the nuclide ID and the option to be used for that nuclide. An entry of option 0 in the $6 \$ \$$ array means that the thermal scattering matrix for that nuclide was not changed. An entry of option 1 in the $6 \$ \$$ array means that the thermal scattering matrix is renormalized to agree with the group-averaged resonance value.

\subsection{CORRECT LEGENDRE POLYNOMIAL FITS (PERFUME)}

PERFUME was not used in the development of the original ANSL-V library described in ref. 1. Nevertheless, this module performs an important function, as described briefly in Table 5 . PERFUME examines scattering matrices to locate those that yield nonphysical fits to the angular scattering distributions and makes slight adjustments to produce acceptable distributions. This procedure involves an examination of the moments of the scattering cross sections and is described in Appendix F9.D.2 of ref. 4. The PERFUME input data are described in ref. 3; the input file for the $99 \mathrm{n} / 44 \mathrm{~g}$ library is given in Table B-8. The PERFUME input file is very short, consisting of only the title card and the $0 \$ \$$ and $1 \$ \$$ arrays. The entry in the $1 \$ \$$ array is only used for edit purposes. As noted in Table 5, PERFUME should be executed after COMET and FRESH since those modules may impact what was already done by PERFUME. Moreover, because of the inevitable small roundoff errors that occur whenever cross-section libraries are converted from binary to card image form on one computer and back to binary on another computer using the AIM module described below, the PERFUME module should be run again.

February 1995 Update Regarding the PERFUME Module:

In February 1995, work on a completely unrelated project for the U.S. Nuclear Regulatory Commission (NRC) revealed that all previous versions of the PERFUME module contained a long-standing but previously undiscovered problem that could potentially affect some of the $(\mathrm{n}, \mathrm{g})$ production data for some nuclides. In particular, the problem was found to occur only when one had more neutron groups than gamma groups. Moreover, it affected only the $(n, g)$ production data, and then only those $(\mathrm{n}, \mathrm{g})$ production terms that are anisotropic in nature [i.e., the most common, isotropic $(\mathrm{n}, \mathrm{g})$ production terms were not affected; only the anisotropic production terms resulting from high-energy $\left(n, n^{\prime}, g\right)$ reactions were affected]. Nevertheless, this raised some concern since the ANSL-V cross sections had also been processed using this module. Thus once the error in the PERFUME module had been repaired, both the 99n/44g and the 39n/44g ANSL-V cross-section libraries were regenerated (from pre-PERFUMED versions) and checked. As noted above, the ANSL-V 39n/44g library was not affected-the new library agreed byte-per-byte with the version 
previously generated in July 1993. The ANSL-V 99n/44g library did, however, differ slightly from the earlier (July 1993) version. Fortunately, the $39 \mathrm{n} / 44 \mathrm{~g}$ library was the only one ever used in a production mode on the ANS shielding task. Thus all results reported to date were totally unaffected. Also, since the $99 \mathrm{n} / 44 \mathrm{~g}$ library has only been used in a very limited number of benchmark calculations that did not involve the affected nuclides, those results were also unaffected. The new versions of the ANSL-V libraries, however, are the ones that will be made available through RSIC for future use.

\subsection{ANSL-V CROSS-SECTION LIBRARY CHECKING (RADE)}

The final ANSL-V $99 \mathrm{n} / 44 \mathrm{~g}$ and $39 \mathrm{n} / 44 \mathrm{~g}$ cross-section libraries were both checked by running the RADE module. RADE performs a number of very important consistency checks. The function of the RADE module is described briefly in Table 5. Other details are discussed in Sect. 3.2.2 of ref. 1, and in ref. 3. Cross-section checks performed by RADE are summarized in Table 7. RADE will also compute an estimate of the capture binding energy for each neutron group in a coupled neutron-gamma set. This can be a very useful tool for locating errors in coupled neutron-gamma libraries. RADE also generates an output file with much of the same information given in Table B-2. The reader should consult ref. 3 for the RADE input description.

Table 7. Cross-section checks performed by RADE on AMPX master interface files"

\begin{tabular}{ll}
\hline 1 & $\sigma_{\mathrm{t}}=\sigma_{\mathrm{a}}+\sigma_{\mathrm{s}}$ \\
2 & $\sigma_{\mathrm{in}}=\Sigma \sigma_{\mathrm{in}}($ partial $)$ \\
3 & $\sigma_{\mathrm{a}}=\sigma_{\mathrm{c}}+\sigma_{\mathrm{f}}$ \\
4 & $\sigma_{\mathrm{c}}=\sigma_{\mathrm{ng}}+\sigma_{\mathrm{na}}+\sigma_{\mathrm{np}}+\sigma_{\mathrm{nd}}+\ldots$ \\
5 & $\sigma_{\mathrm{et}}(\mathrm{g})=\underset{\mathrm{g}^{\prime}}{\Sigma} \sigma_{\mathrm{el}, \mathrm{o}}\left(\mathrm{g} \rightarrow \mathrm{g}^{\prime}\right)$ (for all processes with scattering matrix) \\
6 & $\sigma_{\mathrm{o}}\left(\mathrm{g} \rightarrow \mathrm{g}^{\prime}\right)>0$ \\
7 & $\sigma_{\mathrm{t}}, \sigma_{\mathrm{a}}, \sigma_{\mathrm{f}}, \sigma_{\mathrm{na}}, \sigma_{\mathrm{np}}, \ldots>0$ \\
8 & $-1 \leq\left\{\mu\left(\mathrm{g} \rightarrow \mathrm{g}^{\prime}\right)=\sigma_{\ell}\left(\mathrm{g} \rightarrow \mathrm{g}^{\prime}\right) /(2 \ell+1) \sigma_{\mathrm{o}}\left(\mathrm{g} \rightarrow \mathrm{g}^{\prime}\right)\right\} \leq 1$, for all odd $\ell .^{\mathrm{b}}$
\end{tabular}

"Deviations between the right- and left-hand sides of the above relationships are printed if greater than a user-supplied tolerance.

bor even $\ell$, the left-hand side of this inequality is given by the table:

\begin{tabular}{ll}
$\ell$ & $\mu\left(g \rightarrow g^{\prime}\right)$ \\
\hline 2 & -0.5 \\
4 & -0.433 \\
6 & -0.419 \\
8 & -0.414
\end{tabular}




\subsection{MODULE TO CONVERT MASTER CROSS-SECTION LIBRARIES FROM BCD TO BINARY FORMAT (OR VICE VERSA): AIM}

AIM is the name of the AMPX module used to read a binary-formatted master library and write a card-image (BCD) file or vice versa. Because all machines can read card-image files, the $\mathrm{BCD}$ format serves to transmit AMPX libraries between different computers.

\subsection{A CAUTIONARY NOTE REGARDING PHOTONEUTRONS}

On page 24 of the section on Radiation Shielding in Vol. III of the 1962 Reactor Handbook, ${ }^{5}$ it was noted that "With a shield which attenuates neutrons rapidly but is practically transparent to gamma rays, photoneutrons can provide most of the observed dose in the outer regions of the shield." More recent calculations by J. A. Bucholz ${ }^{6}$ confirmed that this was the case for the ANS reactor where photoneutron production is compounded by the fact that low energy $(n, g)$ reactions in the aluminum reflector vessel yield high-energy gammas which are also capable of producing photoneutrons in the D2O reflector. Moreover, Bucholz found that fast neutron fluxes deep in the reflector close to the vessel may be as much as 3300 times higher than one would estimate if one did not account for photoneutrons. Likewise, Gallmeier and Bucholz ${ }^{7}$ have found that the neutron dose rate at the top of the subpile room (below the ANS core) may be as much as 5 or 6 orders of magnitude greater than one would estimate if one did not account for photoneutrons. Lastly, other studies by Bucholz have shown that the neutron dose rate directly above the heavy-water-filled spent fuel transfer canal may be rather large and 7 to 8 orders of magnitude greater than one would predict if one does not account for photoneutrons produced in the heavy water by high-energy gammas coming from a typical spent fuel element in the canal.

Unfortunately, neither the $99 \mathrm{n} / 44 \mathrm{~g}$ or the $39 \mathrm{n} / 44 \mathrm{~g}$ ANSL-V master cross-section libraries include the $(g, n)$ photoneutron production cross sections for deuterium. This deficiency stems not from an ignorance of the data or any oversight, but from an intrinsic limitation in the basic structure of the AMPX master cross-section interface files. Because photoneutron production data have not traditionally been included in the basic ENDF/B-II, -III, -IV, or -V cross-section files, none of the cross-section processing codes in the AMPX code system are capable of processing such data. As a result, the basic structure of the AMPX cross-section interface files simply do not provide positions and/or pointers to accommodate such data. The present ANSL-V libraries are no exception, and users are cautioned that straightforward blind use of these libraries (in the presence of heavy water) will not account for this potentially important physical phenomenon.

Fortunately, data in the ANSL-V AMPX master libraries are never used directly in shielding analysis codes, but are always processed through a series of other codes prior to use. During this processing, the necessary photoneutron production data may be incorporated in the final DORT-ready cross-section library. Briefly, some of the common application-oriented processing steps are as follows: (1) After the shielding material mixtures have been identified, the data from the AMPX master library will have to be resonance-self-shielded using the BONAMI or NITAWL modules from the AMPX code system. The latter module will also convert the resonance-shielded microscopic data to an AMPX working format. (2) The ICE module is then used to mix the microscopic data with the appropriate atomic number densities for the nuclides in the various materials, thereby creating a macroscopic cross-section library in an ANISN "nuclide-oriented" format. (3) This library will then be processed using the GIP code (or a newer derivative called JIPSY) to convert the ANISN "nuclide-oriented" library to an ANISN "group-independent" library which may be used with either the 1-D ANISN shielding code or the 2-D DORT shielding code. (4) At this point, the SPARK program (described in Sect 4.3 and Appendix B of ref. 6 may be used to read the original DORT-ready macroscopic cross-section library prepared by GIP or JIPSY (without 
photoneutrons), automatically expand the group-to-group scattering matrix to include the (g,n) photoneutron production terms as additional scattering data, and output the final DORT-ready macroscopic cross-section library with photoneutron data.

The total photoneutron production cross section as a function of gamma energy, the assumptions and algorithms used to obtain the corresponding gamma-group-to-neutron-group scattering matrix, and the SPARK program itself, are all described in Sect. 4.3 and Appendix B of ref. 6 . The point here is that whenever one has a problem involving heavy water or pure deuterium, the ANSL-V cross-section libraries must first be supplemented in this fashion to account for photoneutrons. 



\section{AVAILABILITY}

The three ANSL-V cross-section libraries described here in Supplement 1 (the 99n/44g coupled library, the $39 \mathrm{n} / 44 \mathrm{~g}$ coupled library, and the 44-group gamma-only library) will all be made available through RSIC at ORNL. 


\section{REFERENCES}

1. W. E. Ford et al., ANSL-V: ENDF/B-V Based Multigroup Cross-Section Libraries for Advanced Neutron Source (ANS) Reactor Studies, ORNL-6618, Martin Marietta Energy Systems, Inc., Oak Ridge Natl. Lab., September 1990.

2. Personal communication, R. Q. Wright to R. T. Primm III, dated June 12, 1991.

3. N. M. Greene, W. E. Ford III, L. M. Petrie, and J. W. Arwood, AMPX-77: A Modular Code System for Generating Coupled Multigroup Neutron-Gamma Cross-Section Libraries from $E N D F / B-I V$ and/or ENDF/B-V, ORNL/CSD/TM-283, Martin Marietta Energy Systems, Inc., Oak Ridge Natl. Lab., October 1992.

4. J. T. West, T. J. Hoffman, and M. B. Emmett, "MORSE-SGC for the SCALE System," Sect. F9 of SCALE: A Modular Code System for Performing Standardized Computer Analyses for Licensing Evaluation, NUREG/CR-0200, Rev. 4 (ORNL/NUREG/CSD-2/R4), Vols. I, II, and III (April 1995). Available from Radiation Shielding Information Center as CCC-545.

5. E. P. Blizzard, ed., Vol. III, Part B on Radiation Shielding in the "Reactor Handbook," Interscience Publishers, a Division of John Wiley and Sons, 1962.

6. J. A. Bucholz, Initial Global 2-D Shielding Analysis for the ANS Core and Reflector, ORNL/TM-12672, Lockheed Martin Energy Systems, Inc., Oak Ridge Natl. Lab., 1995.

7. F. Gallmeier et al., Analyses of the In-Vessel Control Rod Guide Tube and Subpile Room Shielding Design for the ANS Reactor, ORNL/TM-12996, Lockheed Martin Energy Systems, Inc., Oak Ridge Natl. Lab., to be published in 1995. 
APPENDIX A

UPDATE TO ANSL-V COUPLED NEUTRON-GAMMA LIBRARY (JUNE 1991) 

June 12, 1991

R. T. Primm, III, 6025, MS-6363 (4-0566)

Update to ANSL-V Coupled Neutron-Gamma Library

The requested update to the ANSL-V Coupled Library has now been completed. The procedure outlined in your memorandum of March 7,1991 was followed. The purpose of this memo is to document the new libraries and also to briefly document the problem which is encountered in using the old ENDF/B-V, LENDL hybrid data sets.

XLACS cases were executed for the 10 nuclides shown in Table 1. As we discussed previously, weight function $\mathrm{C}$ was used for these cases. The XLACS runs were done using the 99 group structure. Table 1 gives the LENDL MAT numbers, as well as the AMPX IDs for the 99 group cases. MALOCS was then used to collapse the 99 group cross sections to 39 groups. The UNITAB module was then used to produce the final 39 neutron group, 44 gamma-ray group coupled library. The IBM data set names are given in Table 2. The input for the UNITAB run is shown in Table 3. Note that the Hf AMPX ID is 72000 in the Coupled Library rather than 720001 as in the 99- and 39-group neutron only libraries.

As has been previously noted in Ref. 1, the old hybrid ENDF/B-V neutron/LENDL gamma-ray production data for Hf gave excessive gamma heating in the ANS control rods; the reason for this is now clearly understood. Table 4 shows the output from the RADE module for the B-11 n-gamma (MT 102) reaction for both the HYBRID set and the ALL LENDL set. This table gives the total energy and the n-gamma (capture) cross sections as computed by RADE for the two data sets. The problem is that the calculation of the total energy uses the n-gamma cross sections. In the hybrid set there are actually two different n-gamma cross sections; the LENDL set is used for gamma-ray production and the ENDF/B-V data (HYBRID set in Table 4) is used for the neutron cross sections. The RADE calculation uses the gamma-ray production set in the numerator and the neutron set in the denominator. Thus the total energy will be in error by a factor equal to the ratio of the two cross sections, e.g. a factor of 3348 for group 5 and a factor of 35 for group 10, as shown in Table 4. A similar problem would also occur in the case of $\mathrm{Hf}$ and, in general, for all of the hybrid sets since the n-gamma cross sections can be quite different in the different evaluations, especially at high energies where the cross sections are usually small and sometimes poorly known. As a result of this problem, it can be generally expected that the hybrid sets will not give the correct total energy and for this reason hybrid sets should never be used. 
Another reservation concerning the LENDL B-11 evaluation should be stated, however. In my opinion, the ENDF/B-V evaluation for the n-gamma cross section is likely to be more nearly correct. This conclusion is supported by the fact that in the ENDF/BVI evaluation for B-11 the n-gamma cross section is unchanged from ENDF/B-V. As a consequence if the new all LENDL set is used for calculations in which the B-11 absorption rate is important and is needed to high accuracy extreme care should be exercised. This same comment also applies to the other LENDL evaluations.

R. Q. Wright

RQW:jh

cc: R. G. Alsmiller

N. M. Greene

D. T. Ingersoll

R. A. Lillie

C. V. Parks

R. M. Westfall

B. A. Worley

\section{REFERENCE}

1. R. A. Lillie, "Cause of Calculated Excessive Heating in ANS Control Rods," Internal Correspondence, Sept. 24, 1990. 
Table A-1. 99 Group XLACS Cases from LENDL Library

Nuclide

B-11

$\mathrm{Zr}$

$\mathrm{Cd}$

Hf

Ag-107

Ag-109

U-233

U-234

U-236

Pu-238
AMPX ID

5011

40000

48000

720001

47107

47109

92233

92234

92236

94238
MAT Number

7811

7841

7847

8305

7845

7846

7866

7867

7869

7875

Table A-2. IBM Data Set Names

99 Group Neutron

39 Group Neutron 44 Grp. Interaction 39/44 Grp. Production 39/44 Grp. Coupled
X.RQW39085.LENDL.GRP99N

X.RQW39085.LENDL.GRP39N

A.JZW28697.SNUG

A.JZW28697.IAPHNGAS

X.RQW39085.LENDL.N39G44 
Table A-3. UNITAB Input Data

\begin{tabular}{|c|c|c|c|c|}
\hline Nuclide & ID & File & ID & Type of Data \\
\hline Ag-107 & 47107 & 62 & 47107 & Neutron \\
\hline $\mathrm{Ag}$ & 47107 & 61 & 47 & Gamma Interaction \\
\hline Ag-107 & 47107 & 60 & 7845 & Production \\
\hline Ag-109 & 47109 & 62 & 47109 & Neutron \\
\hline $\mathrm{Ag}$ & 47109 & 61 & 47 & Gamma Interaction \\
\hline $\mathrm{Ag}-109$ & 47109 & 60 & 7846 & Production \\
\hline B-11 & 5011 & 62 & 5011 & Neutron \\
\hline B & 5011 & 61 & 5 & Gamma Interaction \\
\hline B-11 & 5011 & 60 & 7811 & Production \\
\hline $\mathrm{Cd}$ & 48000 & 62 & 48000 & Neutron \\
\hline $\mathrm{Cd}$ & 48000 & 61 & 48 & Gamma Interaction \\
\hline $\mathrm{Cd}$ & 48000 & 60 & 7847 & Production \\
\hline Hf & 72000 & 62 & 720001 & Neutron \\
\hline Hf & 72000 & 61 & 72 & Gamma Interaction \\
\hline Hf & 72000 & 60 & 8305 & Production \\
\hline U-233 & 92233 & 62 & 92233 & Neutron \\
\hline $\mathrm{U}$ & 92233 & 61 & 92 & Gamma Interaction \\
\hline U-233 & 92233 & 60 & 7866 & Production \\
\hline U-234 & 92234 & 62 & 92234 & Neutron \\
\hline $\mathbf{U}$ & 92234 & 61 & 92 & Gamma Interaction \\
\hline U-234 & 92234 & 60 & 7867 & Production \\
\hline U-236 & 92236 & 62 & 92236 & Neutron \\
\hline $\mathrm{U}$ & 92236 & 61 & 92 & Gamma Interaction \\
\hline U-236 & 92236 & 60 & 7869 & Production \\
\hline $\mathrm{Zr}$ & 40000 & 62 & 40000 & Neutron \\
\hline $\mathrm{Zr}$ & 40000 & 61 & 40 & Gamma Interaction \\
\hline $\mathrm{Zr}$ & 40000 & 60 & 7841 & Production \\
\hline $\mathrm{Pu}-238$ & 94238 & 62 & 94238 & Neutron \\
\hline $\mathbf{P u}$ & 94238 & 61 & 94 & Gamma Interaction \\
\hline $\mathrm{Pu}-238$ & 94238 & 60 & 7875 & Production \\
\hline
\end{tabular}


Table A-4. Gamma Ray Production Process 102 for B-11, Total Energy and Cross Section

ALL LENDL

$\begin{array}{lllll}\text { Grp. } & \text { Total Energy } & \text { Cross Section } & \text { Total Energy } & \text { Cross Section } \\ & & & & \\ 1 & 1.9912 \mathrm{e}+09 & 4.4459 \mathrm{e}-07 & 1.0642 \mathrm{e}+07 & 8.3188 \mathrm{e}-05 \\ 2 & 3.8318 \mathrm{e}+09 & 9.7979 \mathrm{e}-07 & 6.8470 \mathrm{e}+06 & 5.4831 \mathrm{e}-04 \\ 3 & 2.3217 \mathrm{e}+10 & 1.8093 \mathrm{e}-06 & 5.5301 \mathrm{e}+06 & 7.5959 \mathrm{e}-03 \\ 4 & 1.7318 \mathrm{e}+10 & 2.4472 \mathrm{e}-06 & 4.9152 \mathrm{e}+06 & 8.6225 \mathrm{e}-03 \\ 5 & 1.4856 \mathrm{e}+10 & 3.1718 \mathrm{e}-06 & 4.4379 \mathrm{e}+06 & 1.0618 \mathrm{e}-02 \\ 6 & 1.3033 \mathrm{e}+10 & 3.8360 \mathrm{e}-06 & 3.9499 \mathrm{e}+06 & 1.2658 \mathrm{e}-02 \\ 7 & 1.6673 \mathrm{e}+10 & 2.6545 \mathrm{e}-06 & 3.6823 \mathrm{e}+06 & 1.2019 \mathrm{e}-02 \\ 8 & 9.7851 \mathrm{e}+05 & 4.2809 \mathrm{e}-05 & 3.4336 \mathrm{e}+06 & 1.2200 \mathrm{e}-03 \\ 9 & 1.7116 \mathrm{e}+08 & 1.6162 \mathrm{e}-05 & 3.4359 \mathrm{e}+06 & 8.0508 \mathrm{e}-04 \\ 10 & 1.2617 \mathrm{e}+08 & 2.2887 \mathrm{e}-05 & 3.6096 \mathrm{e}+06 & 8.0000 \mathrm{e}-04\end{array}$

Note: Only groups 1 to 10 are shown in this table; smaller differences in the total energy are also seen for groups 11 to 39 . 

APPENDIX B

\section{SUMMARY OF ANSL-V LIBRARY DATA}



Table B-1. Brief summary of data for all 138 nuclides in the 99n/44g and 39n/44g ANSL-V coupled libraries.

\begin{tabular}{|c|c|c|c|c|c|c|c|}
\hline $\begin{array}{l}\text { hhanumeric nuclide } n \\
\text { ce created .......... } \\
\text { ighting type ....... } \\
\text { it-to-gamma processe } \\
\text { if mat of fast neut }\end{array}$ & $\begin{array}{c}1001 \\
\text { H-1-WATER } \\
05-05-87 \\
\text { type A } \\
1 \\
1301\end{array}$ & $\begin{array}{c}1002 \\
H-2-D 20 \\
05-06-87 \\
\text { type A } \\
1 \\
1302\end{array}$ & $\begin{array}{c}1003 \\
H-3 \\
05-29-87 \\
\text { type A } \\
0 \\
1169\end{array}$ & $\begin{array}{c}1401 \\
H-1-\text { PARA } \\
09-28-87 \\
\text { type A } \\
1 \\
1301\end{array}$ & $\begin{array}{r}1402 \\
H-2-\text { PARA } \\
\text { 09-30-87 } \\
\text { type A } \\
1 \\
1302\end{array}$ & $\begin{array}{r}1501 \\
\text { H-1-0RTHO } \\
09-30-87 \\
\text { type A } \\
1 \\
1301\end{array}$ & $\begin{array}{c}1801 \\
H-1-\text { FGAS } \\
05-29-87 \\
\text { type A } \\
1 \\
1301\end{array}$ \\
\hline $\begin{array}{l}\text { nuciide id number } \ldots \ldots \\
\text { meric nuciide name } \ldots \ldots \\
\text { eated } \ldots \ldots \ldots \ldots \ldots \ldots \\
\text { ng type } \ldots \ldots \ldots \ldots \\
\text {-gamma processes } \ldots \ldots \ldots \\
t \text { of fast neut data } \ldots \ldots\end{array}$ & $\begin{array}{r}2003 \\
\mathrm{HE}-3 \\
05-19-87 \\
\text { type A } \\
0 \\
1146\end{array}$ & $\begin{array}{r}2004 \\
H E-4 \\
05-19-87 \\
\text { type A } \\
0 \\
1270\end{array}$ & $\begin{array}{r}3006 \\
\text { LI }-6 \\
06-22-90 \\
\text { type C } \\
2 \\
1303\end{array}$ & $\begin{array}{r}3007 \\
\text { LI }-7 \\
06-25-90 \\
\text { type C } \\
2 \\
1397\end{array}$ & $\begin{array}{r}4009 \\
B E-9 \\
08-07-87 \\
\text { type A } \\
2 \\
1304\end{array}$ & $\begin{array}{r}5010 \\
\text { B-10 } \\
05-19-87 \\
\text { type A } \\
4 \\
1305\end{array}$ & $\begin{array}{r}5011 \\
B-11 \\
06-05-91 \\
\text { type C } \\
8 \\
7811\end{array}$ \\
\hline $\begin{array}{l}\text { Ipx za nuclide id number } \\
\text { phanumeric nuclide name } \\
\text { te created .............. } \\
\text { ighting type .......... } \\
\text { ut-to-gamma processes } \\
\text { df mat of fast neut data }\end{array}$ & $\begin{array}{r}6012 \\
C-12 \\
12-04-89 \\
\text { type A } \\
2 \\
1306\end{array}$ & $\begin{array}{r}6312 \\
\text { GRAPHITE } \\
\text { 05-23-91 } \\
\text { type A } \\
2 \\
1306\end{array}$ & $\begin{array}{r}7014 \\
N-14 \\
05-29-87 \\
\text { type A } \\
6 \\
1275\end{array}$ & $\begin{array}{r}7015 \\
N-15 \\
10-24-89 \\
\text { type A } \\
6 \\
1307\end{array}$ & $\begin{array}{r}8016 \\
0-16 \\
05-06-87 \\
\text { type A } \\
5 \\
1276\end{array}$ & $\begin{array}{r}9019 \\
F-19 \\
1-12-90 \\
M-1 E-F \\
4 \\
1309\end{array}$ & $\begin{array}{r}11023 \\
N A-23 \\
6-05-87 \\
\text { type B } \\
3 \\
1311\end{array}$ \\
\hline $\begin{array}{l}\text { px za nuclide id number } \ldots \ldots \\
\text { phanumeric nuclide name } \ldots \ldots \\
\text { te created } \ldots \ldots \ldots \ldots \ldots \ldots \\
\text { ighting type } \ldots \ldots \ldots \ldots \ldots \\
\text { ut-to-gamma processes } \ldots \ldots \ldots \\
\text { df mat of fast neut data } \ldots \ldots\end{array}$ & $\begin{array}{r}12000 \\
M G \\
05-19-87 \\
\text { type B } \\
2 \\
1312\end{array}$ & $\begin{array}{r}13027 \\
\text { AL }-27 \\
05-06-87 \\
\text { type B } \\
4 \\
1313\end{array}$ & $\begin{array}{r}13327 \\
A L-27 \\
05-06-87 \\
\text { type C } \\
4 \\
1313\end{array}$ & $\begin{array}{r}14000 \\
S I \\
05-19-87 \\
\text { type } B \\
6 \\
1314\end{array}$ & $\begin{array}{r}14300 \\
5 I \\
05-19-87 \\
\text { type C } \\
6 \\
1314\end{array}$ & $\begin{array}{r}15031 \\
P-31 \\
8-25-91 \\
\text { type } B \\
2 \\
1315\end{array}$ & $\begin{array}{r}16000 \\
\text { S-NAT } \\
\text { B-25-91 } \\
\text { type B } \\
2 \\
1347\end{array}$ \\
\hline $\begin{array}{l}\text { ampx za nuclide id number } \ldots \ldots \\
\text { alphanumeric nuclide name } \ldots \ldots \\
\text { date created } \ldots \ldots \ldots \ldots \ldots \ldots \\
\text { weighting type } \ldots \ldots \ldots \ldots \ldots \\
\text { neut-to-gamma processes } \ldots \ldots \ldots \\
\text { endf mat of fast neut data } \ldots \ldots\end{array}$ & $\begin{array}{r}16032 \\
5-32 \\
\text { 0B-25-91 } \\
\text { type B } \\
2 \\
1316\end{array}$ & $\begin{array}{r}19000 \\
K \\
05-29-87 \\
\text { type B } \\
21 \\
1150\end{array}$ & $\begin{array}{r}20000 \\
\text { CA-NAT } \\
08-25-91 \\
\text { type B } \\
6 \\
1320\end{array}$ & $\begin{array}{r}22000 \\
T 1 \\
06-05-87 \\
\text { type } B \\
2 \\
1322\end{array}$ & $\begin{array}{r}23000 \\
V \\
06-05-87 \\
\text { type } 8 \\
2 \\
1323\end{array}$ & $\begin{array}{r}24000 \\
\text { CR } \\
6-15-87 \\
\text { type B } \\
3 \\
1324\end{array}$ & $\begin{array}{r}25055 \\
M N-55 \\
08-11-87 \\
\text { type B } \\
2 \\
1325\end{array}$ \\
\hline 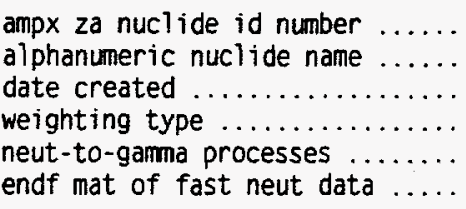 & $\begin{array}{r}26000 \\
F E \\
06-05-87 \\
\text { type B } \\
13 \\
1326\end{array}$ & $\begin{array}{r}27059 \\
\text { C0-59 } \\
06-15-87 \\
\text { type B } \\
2 \\
1327\end{array}$ & $\begin{array}{r}28000 \\
N I \\
05-29-87 \\
\text { type B } \\
2 \\
1328\end{array}$ & $\begin{array}{r}29000 \\
C U \\
12-04-89 \\
\text { type B } \\
2 \\
1329\end{array}$ & $\begin{array}{r}36082 \\
\text { KR-82 } \\
10-11-89 \\
\text { type C } \\
0 \\
1332\end{array}$ & $\begin{array}{r}36083 \\
\text { KR-83 } \\
10-11-89 \\
\text { type C } \\
0 \\
1333\end{array}$ & $\begin{array}{r}40000 \\
\text { 2IRC } \\
06-05-91 \\
\text { type C } \\
2 \\
7841\end{array}$ \\
\hline $\begin{array}{l}\text { px za nuclide id number } \ldots . . \\
\text { phanumeric nuclide name } \ldots . \\
\text { te created } \ldots \ldots \ldots \ldots \ldots \ldots \\
\text { ighting type } \ldots \ldots \ldots \ldots \\
\text { ut-to-gamma processes } \ldots \ldots \\
\text { df mat of fast neut data.... }\end{array}$ & $\begin{array}{r}40090 \\
Z R-90 \\
06-05-87 \\
\text { type C } \\
0 \\
1385\end{array}$ & $\begin{array}{r}40091 \\
Z R-91 \\
06-15-87 \\
\text { type } C \\
0 \\
1386\end{array}$ & $\begin{array}{r}40092 \\
2 R-92 \\
06-15-87 \\
\text { type } C \\
0 \\
1387\end{array}$ & $\begin{array}{r}40093 \\
2 R-93 \\
05-29-87 \\
\text { type } C \\
0 \\
9232\end{array}$ & $\begin{array}{r}40094 \\
2 R-94 \\
06-15-87 \\
\text { type } C \\
0 \\
1388\end{array}$ & $\begin{array}{r}40096 \\
2 R-96 \\
06-04-87 \\
\text { type C } \\
0 \\
1389\end{array}$ & $\begin{array}{r}42000 \\
M D \\
2-04-89 \\
\text { type } B \\
2 \\
1321\end{array}$ \\
\hline $\begin{array}{l}x \text { za nuclide id number } \ldots . \\
\text { hanumeric nuclide name } \ldots . \\
\text { e created } \ldots \ldots \ldots \ldots \ldots \\
\text { ghting type } \ldots \ldots \ldots \ldots \\
\text { t-to-gamma processes } \ldots \ldots \\
\text { f mat of fast neut data } \ldots\end{array}$ & $\begin{array}{r}42097 \\
\text { M0-97 } \\
10-11-89 \\
\text { type C } \\
0 \\
9284\end{array}$ & $\begin{array}{r}43099 \\
\text { TC-99 } \\
10-11-89 \\
\text { type C } \\
0 \\
1308\end{array}$ & $\begin{array}{r}44101 \\
R U-101 \\
10-11-89 \\
\text { type C } \\
0 \\
9330\end{array}$ & $\begin{array}{r}44103 \\
R U-103 \\
10-11-89 \\
\text { type C } \\
0 \\
9332\end{array}$ & $\begin{array}{r}45103 \\
\text { RH-103 } \\
10-11-89 \\
\text { type C } \\
0 \\
1310\end{array}$ & $\begin{array}{r}45105 \\
R H-105 \\
10-11-89 \\
\text { type C } \\
0 \\
9355\end{array}$ & $\begin{array}{r}47107 \\
\text { AG-107 } \\
06-05-91 \\
\text { type C } \\
2 \\
7845\end{array}$ \\
\hline $\begin{array}{l}\text { ampx za nuclide id number } \\
\text { alphanumeric nuclide name } \\
\text { date created ............... } \\
\text { weighting type ........... } \\
\text { neut-to-gamma processes } \\
\text { endf mat of fast neut data }\end{array}$ & $\begin{array}{r}47109 \\
\text { AG-109 } \\
06-05-91 \\
\text { type C } \\
2 \\
7846\end{array}$ & $\begin{array}{r}48000 \\
C D C \\
6-05-91 \\
\text { type C } \\
2 \\
7847\end{array}$ & $\begin{array}{r}48113 \\
C D-113 \\
18-07-87 \\
\text { type } C \\
0 \\
1318\end{array}$ & $\begin{array}{r}50000 \\
\text { SN } \\
01-02-90 \\
\text { type C } \\
2 \\
8850\end{array}$ & $\begin{array}{r}53135 \\
1-135 \\
0-11-89 \\
\text { type C } \\
0 \\
9618\end{array}$ & $\begin{array}{r}54131 \\
X E-131 \\
10-11-89 \\
\text { type C } \\
0 \\
1351\end{array}$ & $\begin{array}{r}54133 \\
X E-133 \\
10-12-89 \\
\text { type C } \\
0 \\
9643\end{array}$ \\
\hline
\end{tabular}


Table B-1 (continued)

\begin{tabular}{|c|c|c|c|c|c|c|c|}
\hline 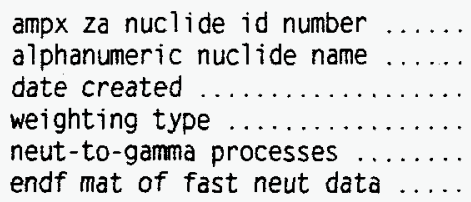 & $\begin{array}{r}54135 \\
X E-135 \\
10-12-89 \\
\text { type C } \\
0 \\
1294\end{array}$ & $\begin{array}{r}\text { CS }-133 \\
0-12-89 \\
\text { type C } \\
0 \\
1355\end{array}$ & $\begin{array}{r}55134 \\
\text { CS-134 } \\
0-12-89 \\
\text { type C } \\
0 \\
4663\end{array}$ & $\begin{array}{r}55135 \\
\text { CS-135 } \\
0-12-89 \\
\text { type C } \\
0 \\
9665\end{array}$ & $\begin{array}{r}56134 \\
\text { BA-134 } \\
8-25-91 \\
\text { type B } \\
0 \\
9684\end{array}$ & $\begin{array}{r}56135 \\
\text { BA-135 } \\
8-25-91 \\
\text { type B } \\
0 \\
9685\end{array}$ & $\begin{array}{r}56136 \\
\text { BA-136 } \\
\text { B-25-91 } \\
\text { type B } \\
0 \\
9687\end{array}$ \\
\hline 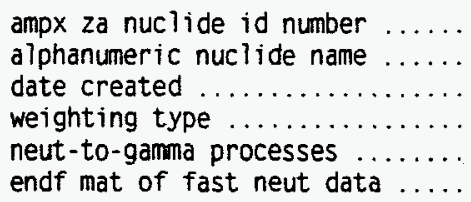 & $\begin{array}{r}56137 \\
\text { BA-137 } \\
08-25-91 \\
\text { type B } \\
0 \\
9689\end{array}$ & $\begin{array}{r}56138 \\
\text { BA-138 } \\
08-25-91 \\
\text { type B } \\
2 \\
1353\end{array}$ & $\begin{array}{r}56140 \\
\text { BA-140 } \\
8-25-91 \\
\text { type B } \\
0 \\
9693\end{array}$ & $\begin{array}{r}58141 \\
C E-141 \\
08-11-87 \\
\text { type C } \\
0 \\
9725\end{array}$ & $\begin{array}{r}59143 \\
\text { PR-143 } \\
8-11-87 \\
\text { type C } \\
0 \\
9745\end{array}$ & $\begin{array}{r}60143 \\
\text { ND-143 } \\
0-19-89 \\
\text { type C } \\
0 \\
9764\end{array}$ & $\begin{array}{r}60145 \\
N 0-145 \\
0-19-89 \\
\text { type C } \\
0 \\
9766\end{array}$ \\
\hline $\begin{array}{l}\text { ampx za nuclide id number } \ldots \ldots \\
\text { alphanumeric nuclide name } \ldots \ldots \\
\text { date created } \ldots \ldots \ldots \ldots \ldots \ldots \\
\text { weighting type } \ldots \ldots \ldots \ldots \\
\text { neut-to-gamma processes } \ldots \ldots \ldots \\
\text { endf mat of fast neut data } \ldots \ldots\end{array}$ & $\begin{array}{r}60147 \\
N D-147 \\
10-19-89 \\
\text { type C } \\
0 \\
4768\end{array}$ & $\begin{array}{r}61147 \\
\text { PM-147 } \\
06-05-87 \\
\text { type C } \\
0 \\
9783\end{array}$ & $\begin{array}{r}61148 \\
\text { PM-148 } \\
10-19-89 \\
\text { type C } \\
0 \\
9784\end{array}$ & $\begin{array}{r}61149 \\
\text { PM-149 } \\
10-19-89 \\
\text { type C } \\
0 \\
9786\end{array}$ & $\begin{array}{r}61601 \\
\text { PM-148M } \\
0-19-89 \\
\text { type C } \\
0 \\
9785\end{array}$ & $\begin{array}{r}62149 \\
\text { SM-149 } \\
8-31-87 \\
\text { type C } \\
0 \\
1319\end{array}$ & $\begin{array}{r}62150 \\
S M-150 \\
0-23-89 \\
\text { type C } \\
0 \\
9809\end{array}$ \\
\hline 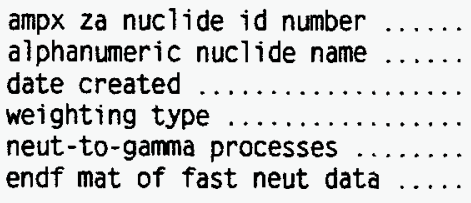 & $\begin{array}{r}62151 \\
\text { SM-151 } \\
10-23-89 \\
\text { type C } \\
0 \\
9810\end{array}$ & $\begin{array}{r}62152 \\
\text { SM-152 } \\
10-23-89 \\
\text { type C } \\
0 \\
9811\end{array}$ & $\begin{array}{r}62153 \\
\text { SM-153 } \\
08-11-87 \\
\text { type C } \\
0 \\
9812\end{array}$ & $\begin{array}{r}63000 \\
\text { EU-NAT } \\
\text { 06-03-93 } \\
\text { type C } \\
2 \\
7852\end{array}$ & $\begin{array}{r}63151 \\
\text { EU-151 } \\
4-01-93 \\
\text { type C } \\
11 \\
1357\end{array}$ & $\begin{array}{r}63152 \\
\text { EU-152 } \\
4-01-93 \\
\text { type C } \\
0 \\
4292\end{array}$ & $\begin{array}{r}63153 \\
\text { EU-153 } \\
4-01-93 \\
\text { type C } \\
13 \\
1359\end{array}$ \\
\hline $\begin{array}{l}\text { lide id number } \\
\text { c nuclide name } \\
\text { d } \ldots \ldots \ldots \ldots \ldots \\
\text { ype } \ldots \ldots \ldots \ldots\end{array}$ & $\begin{array}{r}63154 \\
\text { EU-154 } \\
04-01-93 \\
\text { type C } \\
0 \\
4293\end{array}$ & $\begin{array}{r}63155 \\
\text { EU-155 } \\
10-23-89 \\
\text { type } C \\
0 \\
4832\end{array}$ & $\begin{array}{r}72000 \\
\text { HF-NAT } \\
5-24-91 \\
\text { type C } \\
2 \\
8305\end{array}$ & $\begin{array}{r}72174 \\
\text { HF-174 } \\
08-25-91 \\
\text { poldnt } \\
0 \\
1374\end{array}$ & $\begin{array}{r}72176 \\
H F-176 \\
08-25-91 \\
\text { poldnt } \\
0 \\
1376\end{array}$ & $\begin{array}{r}72177 \\
H F-177 \\
8-25-91 \\
\text { poldnt } \\
0 \\
1377\end{array}$ & $\begin{array}{r}\text { HF-178 } \\
8-25-91 \\
\text { poldnt } \\
0 \\
1378\end{array}$ \\
\hline $\begin{array}{l}\text { lide id number } \\
\text { ic nuclide name } \\
\text { nu............ }\end{array}$ & $\begin{array}{r}72179 \\
H F-179 \\
08-25-91 \\
\text { poldnt } \\
0 \\
1383\end{array}$ & $\begin{array}{r}72180 \\
H F-180 \\
0 B-25-91 \\
\text { poldnt } \\
0 \\
1384\end{array}$ & $\begin{array}{r}73181 \\
\text { TA-181 } \\
4-01-93 \\
\text { type B } \\
2 \\
1285\end{array}$ & $\begin{array}{r}73182 \\
\text { TA-182 } \\
04-01-93 \\
\text { type B } \\
0 \\
1127\end{array}$ & $\begin{array}{r}82000 \\
P B \\
2-04-89 \\
\text { type B } \\
2 \\
1382\end{array}$ & $\begin{array}{r}83209 \\
\text { BI-209 } \\
8-25-91 \\
\text { type B } \\
2 \\
1375\end{array}$ & $\begin{array}{r}90232 \\
\text { TH-232 } \\
12-11-89 \\
\text { type C } \\
3 \\
1390\end{array}$ \\
\hline $\begin{array}{l}\text { ampx za nuclide id number } \ldots \ldots \\
\text { alphanumeric nuclide name } \ldots \ldots \\
\text { date created } \ldots \ldots \ldots \ldots \ldots \ldots \\
\text { weighting type } \ldots \ldots \ldots \ldots \ldots \\
\text { neut-to-gamma processes } \ldots \ldots \ldots \\
\text { endf mat of fast neut data } \ldots \ldots\end{array}$ & $\begin{array}{r}92233 \\
U-233 \\
06-05-91 \\
\text { type } C \\
3 \\
7866\end{array}$ & $\begin{array}{r}92234 \\
U-234 \\
06-05-91 \\
\text { type C } \\
3 \\
7867\end{array}$ & $\begin{array}{r}92235 \\
U-235 \\
4-01-93 \\
\text { type C } \\
4 \\
1395\end{array}$ & $\begin{array}{r}92236 \\
U-236 \\
06-05-91 \\
\text { type C } \\
3 \\
7869\end{array}$ & $\begin{array}{r}92237 \\
U-237 \\
12-04-89 \\
\text { type C } \\
3 \\
8237\end{array}$ & $\begin{array}{r}92238 \\
U-238 \\
4-01-93 \\
\text { type C } \\
3 \\
1398\end{array}$ & $\begin{array}{r}93237 \\
N P-237 \\
12-11-89 \\
\text { type C } \\
0 \\
1337\end{array}$ \\
\hline 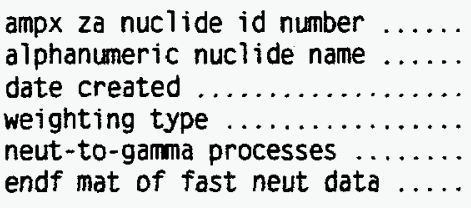 & $\begin{array}{r}93238 \\
N P-238 \\
12-12-89 \\
\text { type C } \\
0 \\
8338\end{array}$ & $\begin{array}{r}93239 \\
N P-239 \\
2-12-89 \\
\text { type C } \\
0 \\
2932\end{array}$ & $\begin{array}{r}94238 \\
\text { PU-238 } \\
16-05-91 \\
\text { type C } \\
3 \\
7875\end{array}$ & $\begin{array}{r}94239 \\
\text { PU-239 } \\
12-12-89 \\
\text { type C } \\
4 \\
1399\end{array}$ & $\begin{array}{r}94240 \\
P U-240 \\
12-11-89 \\
\text { type C } \\
4 \\
1380\end{array}$ & $\begin{array}{r}94241 \\
\text { PU-241 } \\
12-12-89 \\
\text { type C } \\
3 \\
2945\end{array}$ & $\begin{array}{r}94242 \\
\text { PU-242 } \\
2-11-89 \\
\text { type C } \\
3 \\
1342\end{array}$ \\
\hline $\begin{array}{l}\text { ampx za nuclide id number } \ldots \ldots \\
\text { alphanumeric nuclide name } \ldots \ldots \ldots \\
\text { date created } \ldots \ldots \ldots \ldots \ldots \ldots \\
\text { weighting type } \ldots \ldots \ldots \ldots \ldots \\
\text { neut-to-gamma processes } \ldots \ldots \ldots \\
\text { endf mat of fast neut data } \ldots \ldots\end{array}$ & $\begin{array}{r}94243 \\
\text { PU-243 } \\
12-11-89 \\
\text { type C } \\
3 \\
8443\end{array}$ & $\begin{array}{r}95241 \\
\text { AM-241 } \\
2-11-89 \\
\text { type C } \\
3 \\
1361\end{array}$ & $\begin{array}{r}95242 \\
\text { AM-242 } \\
2-11-89 \\
\text { type C } \\
0 \\
8542\end{array}$ & $\begin{array}{r}95243 \\
\text { AM-243 } \\
12-11-89 \\
\text { type } C \\
3 \\
1363\end{array}$ & $\begin{array}{r}95601 \\
\text { AM-242M } \\
12-07-89 \\
\text { type C } \\
3 \\
1369\end{array}$ & $\begin{array}{r}96242 \\
\mathrm{CM}-242 \\
12-05-89 \\
\text { type C } \\
3 \\
8642\end{array}$ & $\begin{array}{r}96243 \\
C M-243 \\
12-07-89 \\
\text { type C } \\
3 \\
1343\end{array}$ \\
\hline
\end{tabular}


Table B-1 (continued)

\begin{tabular}{|c|c|c|c|c|c|c|c|}
\hline $\begin{array}{l}\text { ampx za nuclide id number } \ldots \ldots \\
\text { alphanumeric nuclide name } \ldots \ldots \\
\text { date created } \ldots \ldots \ldots \ldots \ldots \ldots \\
\text { weighting type } \ldots \ldots \ldots \ldots \\
\text { neut-to-gamma processes } \ldots \ldots \ldots \\
\text { endf mat of fast neut data } \ldots \ldots\end{array}$ & $\begin{array}{r}96244 \\
\text { CM-244 } \\
12-05-89 \\
\text { type C } \\
3 \\
1344\end{array}$ & $\begin{array}{r}96245 \\
\text { CM-245 } \\
12-05-89 \\
\text { type C } \\
3 \\
1345\end{array}$ & $\begin{array}{r}96246 \\
\text { CM-246 } \\
12-05-89 \\
\text { type C } \\
3 \\
1346\end{array}$ & $\begin{array}{r}96247 \\
\text { CM-247 } \\
12-05-89 \\
\text { type C } \\
3 \\
8647\end{array}$ & $\begin{array}{r}96248 \\
\text { CM-248 } \\
12-07-89 \\
\text { type C } \\
3 \\
8648\end{array}$ & $\begin{array}{r}97249 \\
\text { BK-249 } \\
12-07-89 \\
\text { type C } \\
0 \\
8749\end{array}$ & $\begin{array}{r}98249 \\
\text { CF-249 } \\
12-07-89 \\
\text { type C } \\
0 \\
8849\end{array}$ \\
\hline 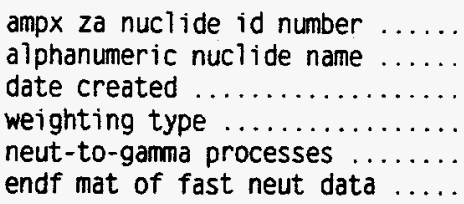 & $\begin{array}{r}98250 \\
C F-250 \\
12-07-89 \\
\text { type C } \\
3 \\
8850\end{array}$ & $\begin{array}{r}98251 \\
C F-251 \\
12-07-89 \\
\text { type C } \\
3 \\
8851\end{array}$ & $\begin{array}{r}98252 \\
\text { CF- } 252 \\
12-07-89 \\
\text { type C } \\
3 \\
8852\end{array}$ & $\begin{array}{r}98253 \\
\text { CF-253 } \\
12-07-89 \\
\text { type C } \\
0 \\
8853\end{array}$ & $\begin{array}{r}99253 \\
E S-253 \\
12-07-89 \\
\text { type C } \\
0 \\
8953\end{array}$ & & \\
\hline
\end{tabular}


Table B-2. Type of nuclear data available for all 138 nuclides in the 39n/44g ANSL-V coupled library




Table B-2 (continued)

\begin{tabular}{|c|c|c|c|c|c|c|c|c|c|c|c|c|}
\hline 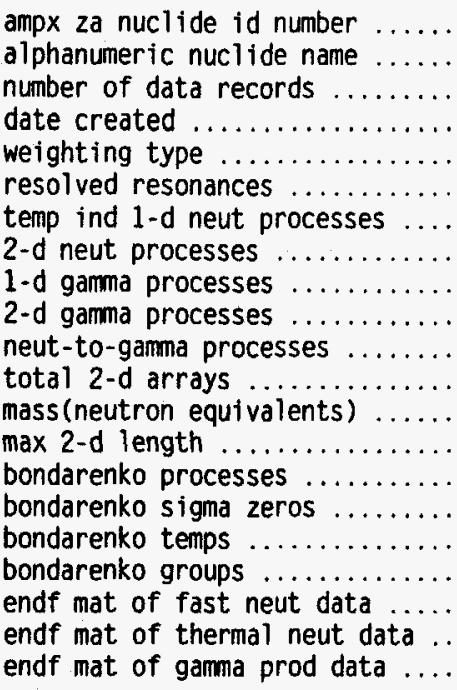 & $\begin{array}{c}14000 \\
\text { SI } \\
174 \\
05-19-87 \\
\text { type B } \\
0 \\
77 \\
28 \\
9 \\
2 \\
6 \\
159 \\
27.844 \\
898 \\
0 \\
0 \\
0 \\
0 \\
1314 \\
0 \\
1314\end{array}$ & $\begin{array}{c}14300 \\
\text { SI } \\
174 \\
05-19-87 \\
\text { type C } \\
0 \\
77 \\
28 \\
9 \\
2 \\
6 \\
159 \\
27.844 \\
898 \\
0 \\
0 \\
0 \\
0 \\
1314 \\
0 \\
1314\end{array}$ & $\begin{array}{c}15031 \\
P-31 \\
37 \\
08-25-91 \\
\text { type } 8 \\
0 \\
21 \\
5 \\
9 \\
2 \\
2 \\
22 \\
30.708 \\
1608 \\
0 \\
0 \\
0 \\
0 \\
1315 \\
0 \\
1315\end{array}$ & $\begin{array}{c}16000 \\
\text { S-NAT } \\
279 \\
08-25-91 \\
\text { type B } \\
19 \\
69 \\
46 \\
9 \\
2 \\
2 \\
263 \\
31.788 \\
1045 \\
0 \\
0 \\
0 \\
0 \\
1347 \\
0 \\
1347\end{array}$ & $\begin{array}{c}16032 \\
5-32 \\
37 \\
08-25-91 \\
\text { type B } \\
0 \\
22 \\
5 \\
9 \\
2 \\
2 \\
22 \\
31.697 \\
707 \\
0 \\
0 \\
0 \\
0 \\
1316 \\
0 \\
1316\end{array}$ & $\begin{array}{c}19000 \\
K \\
159 \\
05-29-87 \\
\text { type B } \\
0 \\
39 \\
23 \\
9 \\
2 \\
21 \\
144 \\
38.766 \\
962 \\
0 \\
0 \\
0 \\
0 \\
1150 \\
0 \\
1150\end{array}$ & $\begin{array}{c}20000 \\
\text { CA-NAT } \\
156 \\
\text { 08-25-91 } \\
\text { type B } \\
0 \\
48 \\
25 \\
9 \\
2 \\
6 \\
141 \\
39.736 \\
848 \\
0 \\
0 \\
0 \\
0 \\
1320 \\
0 \\
1320\end{array}$ & $\begin{array}{c}22000 \\
T I \\
111 \\
06-05-87 \\
\text { type B } \\
0 \\
42 \\
19 \\
9 \\
2 \\
2 \\
96 \\
468 \\
468 \\
117 \\
0 \\
0 \\
0 \\
0 \\
1322 \\
0 \\
1322\end{array}$ & $\begin{array}{c}23000 \\
V \\
80 \\
06-05-87 \\
\text { type B } \\
0 \\
33 \\
13 \\
9 \\
2 \\
2 \\
65 \\
50.504 \\
1204 \\
0 \\
0 \\
0 \\
0 \\
1323 \\
0 \\
1323\end{array}$ & $\begin{array}{c}24000 \\
\text { CR } \\
281 \\
06-15-87 \\
\text { type B } \\
86 \\
72 \\
47 \\
9 \\
2 \\
3 \\
265 \\
51.549 \\
1445 \\
0 \\
0 \\
0 \\
0 \\
1324 \\
0 \\
1324\end{array}$ & $\begin{array}{c}25055 \\
\text { MN-55 } \\
112 \\
08-11-87 \\
\text { type B } \\
45 \\
37 \\
19 \\
9 \\
2 \\
2 \\
96 \\
54.466 \\
1080 \\
0 \\
0 \\
0 \\
0 \\
1325 \\
0 \\
1325\end{array}$ & $\begin{array}{c}26000 \\
F E \\
290 \\
06-05-87 \\
\text { type } 8 \\
62 \\
66 \\
46 \\
9 \\
2 \\
13 \\
274 \\
55.365 \\
1342 \\
0 \\
0 \\
0 \\
0 \\
1326 \\
0 \\
1326\end{array}$ \\
\hline 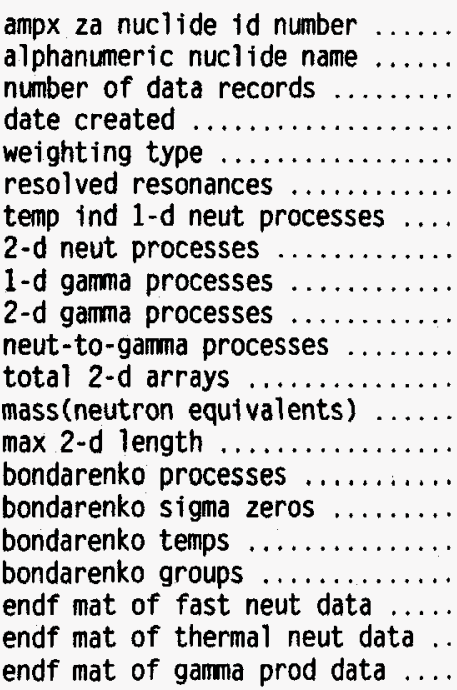 & $\begin{array}{c}27059 \\
\text { C0-59 } \\
105 \\
06-15-87 \\
\text { type B } \\
74 \\
36 \\
17 \\
9 \\
2 \\
2 \\
89 \\
58.427 \\
1297 \\
0 \\
0 \\
0 \\
0 \\
1327 \\
0 \\
1327\end{array}$ & $\begin{array}{c}28000 \\
\text { NI } \\
195 \\
05-29-87 \\
\text { type B } \\
134 \\
53 \\
32 \\
9 \\
2 \\
2 \\
179 \\
58.183 \\
1434 \\
0 \\
0 \\
0 \\
0 \\
1328 \\
0 \\
1328\end{array}$ & $\begin{array}{c}29000 \\
\text { CU } \\
106 \\
12-04-89 \\
\text { type B } \\
49 \\
37 \\
18 \\
9 \\
2 \\
2 \\
90 \\
63.546 \\
1496 \\
0 \\
0 \\
0 \\
0 \\
1329 \\
0 \\
1329\end{array}$ & $\begin{array}{c}36082 \\
\text { KR-82 } \\
88 \\
10-11-89 \\
\text { type C } \\
3 \\
33 \\
13 \\
9 \\
2 \\
0 \\
73 \\
81.210 \\
707 \\
0 \\
0 \\
0 \\
0 \\
1332 \\
0 \\
0\end{array}$ & $\begin{array}{c}36083 \\
\text { KR-83 } \\
71 \\
10-11-89 \\
\text { type C } \\
4 \\
31 \\
11 \\
9 \\
2 \\
0 \\
56 \\
82.202 \\
707 \\
0 \\
0 \\
0 \\
0 \\
1333 \\
0 \\
0\end{array}$ & $\begin{array}{c}40000 \\
\text { ZIRC } \\
85 \\
06-05-91 \\
\text { type C } \\
0 \\
28 \\
13 \\
9 \\
2 \\
2 \\
70 \\
90.440 \\
1646 \\
0 \\
0 \\
0 \\
0 \\
7841 \\
0 \\
7841\end{array}$ & $\begin{array}{c}40090 \\
\text { ZR-90 } \\
64 \\
06-05-87 \\
\text { type C } \\
36 \\
25 \\
9 \\
9 \\
2 \\
0 \\
49 \\
89.132 \\
707 \\
0 \\
0 \\
0 \\
0 \\
1385 \\
0 \\
0\end{array}$ & $\begin{array}{c}40091 \\
\text { ZR-91 } \\
100 \\
06-15-87 \\
\text { type C } \\
37 \\
31 \\
15 \\
9 \\
2 \\
0 \\
85 \\
90.122 \\
707 \\
0 \\
0 \\
0 \\
0 \\
1386 \\
0 \\
0\end{array}$ & $\begin{array}{c}40092 \\
\text { ZR-92 } \\
70 \\
06-15-87 \\
\text { type C } \\
17 \\
26 \\
10 \\
9 \\
2 \\
0 \\
55 \\
91.112 \\
707 \\
0 \\
0 \\
0 \\
0 \\
1387 \\
0 \\
0\end{array}$ & $\begin{array}{c}40093 \\
\text { ZR-93 } \\
92 \\
05-29-87 \\
\text { type C } \\
0 \\
27 \\
13 \\
9 \\
2 \\
0 \\
78 \\
92.108 \\
707 \\
0 \\
0 \\
0 \\
0 \\
9232 \\
0 \\
0\end{array}$ & $\begin{array}{c}40094 \\
\text { ZR-94 } \\
82 \\
06-15-87 \\
\text { type C } \\
24 \\
28 \\
12 \\
9 \\
2 \\
0 \\
67 \\
93.096 \\
707 \\
0 \\
0 \\
0 \\
0 \\
1388 \\
0 \\
0\end{array}$ & $\begin{array}{c}40096 \\
\text { ZR-96 } \\
58 \\
\text { 06-04-87 } \\
\text { type C } \\
10 \\
23 \\
8 \\
9 \\
2 \\
0 \\
43 \\
95.081 \\
707 \\
0 \\
0 \\
0 \\
0 \\
1389 \\
0 \\
0\end{array}$ \\
\hline
\end{tabular}


Table B-2 (continued)

\begin{tabular}{|c|c|c|c|c|c|c|c|c|c|c|c|c|}
\hline 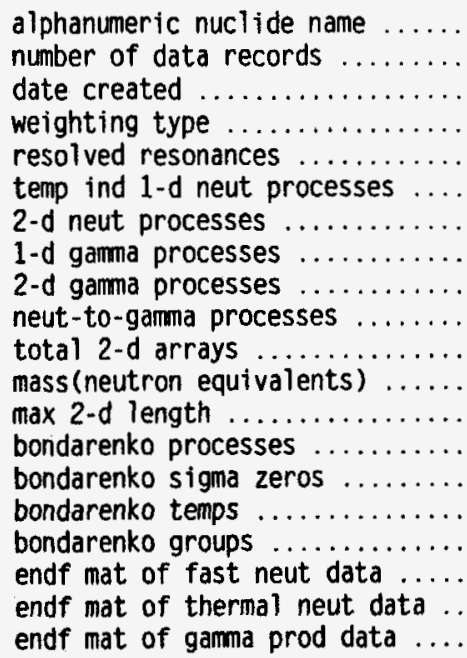 & $\begin{array}{c}\text { M0 } \\
52 \\
12-04-89 \\
\text { type B } \\
33 \\
19 \\
5 \\
9 \\
2 \\
2 \\
22 \\
95.116 \\
1318 \\
6 \\
5 \\
5 \\
3 \\
1321 \\
0 \\
1321\end{array}$ & $\begin{array}{c}\text { Mo-97 } \\
147 \\
10-11-89 \\
\text { type C } \\
32 \\
36 \\
22 \\
9 \\
2 \\
0 \\
132 \\
96.074 \\
707 \\
0 \\
0 \\
0 \\
0 \\
9284 \\
0 \\
0\end{array}$ & $\begin{array}{c}\text { TC-99 } \\
110 \\
10-11-89 \\
\text { type C } \\
44 \\
29 \\
15 \\
9 \\
2 \\
0 \\
85 \\
98.150 \\
707 \\
4 \\
4 \\
5 \\
4 \\
1308 \\
0 \\
0\end{array}$ & $\begin{array}{c}\text { RU-101 } \\
147 \\
10-11-89 \\
\text { type C } \\
9 \\
36 \\
22 \\
9 \\
2 \\
0 \\
132 \\
100.039 \\
707 \\
0 \\
0 \\
0 \\
0 \\
9330 \\
0 \\
0\end{array}$ & $\begin{array}{c}\text { RU-103 } \\
116 \\
10-11-89 \\
\text { type C } \\
0 \\
31 \\
17 \\
9 \\
2 \\
0 \\
102 \\
102.022 \\
707 \\
0 \\
0 \\
0 \\
0 \\
9332 \\
0 \\
0\end{array}$ & $\begin{array}{c}\text { RH-103 } \\
118 \\
10-11-89 \\
\text { type C } \\
61 \\
32 \\
18 \\
9 \\
2 \\
0 \\
103 \\
102.021 \\
707 \\
0 \\
0 \\
0 \\
0 \\
1310 \\
0 \\
0\end{array}$ & $\begin{array}{c}\text { RH-105 } \\
50 \\
10-11-89 \\
\text { type C } \\
0 \\
20 \\
6 \\
9 \\
2 \\
0 \\
36 \\
104.005 \\
707 \\
0 \\
0 \\
0 \\
0 \\
9355 \\
0 \\
0\end{array}$ & $\begin{array}{c}\text { AG-107 } \\
73 \\
06-05-91 \\
\text { type C } \\
0 \\
29 \\
11 \\
9 \\
2 \\
2 \\
58 \\
105.992 \\
1570 \\
0 \\
0 \\
0 \\
0 \\
7845 \\
0 \\
7845\end{array}$ & $\begin{array}{c}\text { AG-109 } \\
67 \\
06-05-91 \\
\text { type C } \\
0 \\
26 \\
10 \\
9 \\
2 \\
2 \\
52 \\
107.964 \\
1532 \\
0 \\
0 \\
0 \\
0 \\
7846 \\
0 \\
7846\end{array}$ & $\begin{array}{c}\text { CDC } \\
37 \\
06-05-91 \\
\text { type C } \\
0 \\
19 \\
5 \\
9 \\
2 \\
2 \\
22 \\
111.434 \\
1304 \\
0 \\
0 \\
0 \\
0 \\
7847 \\
0 \\
7847\end{array}$ & $\begin{array}{c}\text { CD-113 } \\
52 \\
08-07-87 \\
\text { type C } \\
14 \\
23 \\
7 \\
9 \\
2 \\
0 \\
37 \\
111.930 \\
707 \\
0 \\
0 \\
0 \\
0 \\
1318 \\
0 \\
0\end{array}$ & $\begin{array}{r}\text { SN } \\
37 \\
01-02-90 \\
\text { type C } \\
0 \\
20 \\
5 \\
9 \\
2 \\
2 \\
22 \\
117.670 \\
1646 \\
0 \\
0 \\
0 \\
0 \\
8850 \\
0 \\
7850\end{array}$ \\
\hline 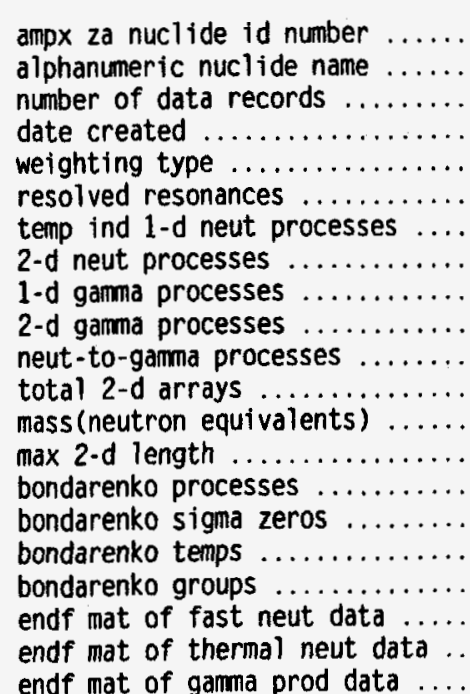 & $\begin{array}{c}53135 \\
1-135 \\
32 \\
10-11-89 \\
\text { type } c \\
0 \\
17 \\
3 \\
9 \\
2 \\
0 \\
18 \\
133.751 \\
707 \\
0 \\
0 \\
0 \\
0 \\
9618 \\
0 \\
0\end{array}$ & $\begin{array}{c}54131 \\
X E-131 \\
71 \\
10-11-89 \\
\text { type C } \\
41 \\
29 \\
11 \\
9 \\
2 \\
0 \\
56 \\
129.781 \\
707 \\
0 \\
0 \\
0 \\
0 \\
1351 \\
0 \\
0\end{array}$ & $\begin{array}{c}54133 \\
X E-133 \\
38 \\
10-12-89 \\
\text { type C } \\
0 \\
18 \\
4 \\
9 \\
2 \\
0 \\
24 \\
131.764 \\
707 \\
0 \\
0 \\
0 \\
0 \\
9643 \\
0 \\
0\end{array}$ & $\begin{array}{c}54135 \\
X E-135 \\
38 \\
10-12-89 \\
\text { type C } \\
0 \\
18 \\
4 \\
9 \\
2 \\
0 \\
24 \\
133.748 \\
707 \\
0 \\
0 \\
0 \\
0 \\
1294 \\
0 \\
0\end{array}$ & $\begin{array}{c}55133 \\
\text { CS-133 } \\
64 \\
10-12-89 \\
\text { type C } \\
125 \\
25 \\
9 \\
9 \\
2 \\
0 \\
49 \\
131.764 \\
707 \\
0 \\
0 \\
0 \\
0 \\
1355 \\
0 \\
0\end{array}$ & $\begin{array}{c}55134 \\
\text { CS-134 } \\
63 \\
10-12-89 \\
\text { type C } \\
8 \\
22 \\
8 \\
9 \\
2 \\
0 \\
48 \\
132.757 \\
707 \\
0 \\
0 \\
0 \\
0 \\
4663 \\
0 \\
0\end{array}$ & $\begin{array}{c}55135 \\
\text { CS-135 } \\
50 \\
10-12-89 \\
\text { type C } \\
0 \\
20 \\
6 \\
9 \\
2 \\
0 \\
36 \\
133.747 \\
707 \\
0 \\
0 \\
0 \\
0 \\
9665 \\
0 \\
0\end{array}$ & $\begin{array}{c}56134 \\
\text { BA-134 } \\
75 \\
08-25-91 \\
\text { type B } \\
8 \\
24 \\
10 \\
9 \\
2 \\
0 \\
60 \\
132.754 \\
707 \\
0 \\
0 \\
0 \\
0 \\
9684 \\
0 \\
0\end{array}$ & $\begin{array}{c}56135 \\
\text { BA-135 } \\
87 \\
08-25-91 \\
\text { type B } \\
15 \\
26 \\
12 \\
9 \\
2 \\
0 \\
72 \\
133.747 \\
707 \\
0 \\
0 \\
0 \\
0 \\
9685 \\
0 \\
0\end{array}$ & $\begin{array}{c}56136 \\
\text { BA-136 } \\
93 \\
08-25-91 \\
\text { type B } \\
4 \\
27 \\
13 \\
9 \\
2 \\
0 \\
78 \\
134.737 \\
707 \\
0 \\
0 \\
0 \\
0 \\
9687 \\
0 \\
0\end{array}$ & $\begin{array}{c}56137 \\
\text { BA-137 } \\
81 \\
08-25-91 \\
\text { type B } \\
7 \\
25 \\
11 \\
9 \\
2 \\
0 \\
66 \\
135.729 \\
707 \\
0 \\
0 \\
0 \\
0 \\
9689 \\
0 \\
0\end{array}$ & $\begin{array}{c}56138 \\
\text { BA-138 } \\
37 \\
08-25-91 \\
\text { type B } \\
0 \\
21 \\
5 \\
9 \\
2 \\
2 \\
22 \\
136.715 \\
1380 \\
0 \\
0 \\
0 \\
0 \\
1353 \\
0 \\
1353\end{array}$ \\
\hline
\end{tabular}


Table B-2 (continued)

\begin{tabular}{|c|c|c|c|c|c|c|c|c|c|c|c|c|}
\hline $\begin{array}{l}\text { ampx za nuclide id number } \\
\text { alphanumeric nuclide name }\end{array}$ & $\begin{array}{r}56140 \\
B A-140\end{array}$ & $\begin{array}{r}58141 \\
C E-141\end{array}$ & $\begin{array}{r}59143 \\
P R-143\end{array}$ & $\begin{array}{r}60143 \\
\text { ND-143 }\end{array}$ & $\begin{array}{r}60145 \\
N D-145\end{array}$ & $\begin{array}{r}60147 \\
N D-147\end{array}$ & $\begin{array}{r}61147 \\
P M-147\end{array}$ & $\begin{array}{r}61148 \\
\mathrm{PM}-148\end{array}$ & $\begin{array}{r}61149 \\
P M-149\end{array}$ & $\begin{array}{r}61601 \\
P M-148 M\end{array}$ & $\begin{array}{r}62149 \\
S M-149\end{array}$ & $\begin{array}{r}62150 \\
S M-150\end{array}$ \\
\hline number of data records ... & 32 & 56 & 68 & 85 & 121 & 51 & 67 & 32 & 68 & 33 & 95 & 129 \\
\hline date created $\ldots \ldots \ldots \ldots$ & $08-25-91$ & $08-11-87$ & $08-11-87$ & $10-19-89$ & $10-19-89$ & $10-19-89$ & $06-05-87$ & $10-19-89$ & $10-19-89$ & $10-19-89$ & $08-31-87$ & $10-23-89$ \\
\hline $\begin{array}{l}\text { weighting type } \ldots \ldots \ldots \ldots \ldots \ldots \\
\text { resolved resonances } \ldots \ldots \ldots \ldots \ldots\end{array}$ & $\begin{array}{r}\text { type } B \\
0\end{array}$ & $\begin{array}{r}\text { type } \mathrm{C} \\
0\end{array}$ & $\begin{array}{r}\text { type } C \\
0\end{array}$ & $\begin{array}{r}\text { type C } \\
19\end{array}$ & $\begin{array}{r}\text { type C } \\
81\end{array}$ & type ${ }_{9}$ & type ${ }_{15}$ & type C & type $\mathrm{C}$ & type $\mathrm{C}$ & type $C$ & type C \\
\hline temp ind $1-d$ neut processes ..... & 17 & 21 & 23 & 34 & $\begin{array}{l}81 \\
40\end{array}$ & $\begin{array}{r}9 \\
20\end{array}$ & $\begin{array}{l}15 \\
31\end{array}$ & $\begin{array}{r}0 \\
17\end{array}$ & $\begin{array}{r}0 \\
23\end{array}$ & $\begin{array}{r}3 \\
17\end{array}$ & $\begin{array}{l}31 \\
31\end{array}$ & $\begin{array}{l}13 \\
33\end{array}$ \\
\hline 2-d neut processes $\ldots \ldots \ldots \ldots$. & 3 & 7 & 9 & 15 & 21 & 6 & 12 & 3 & 9 & 3 & 15 & 19 \\
\hline 1-d gamma processes $\ldots \ldots$. & 9 & 9 & 9 & 9 & 9 & 9 & 9 & 9 & 9 & 9 & 9 & 9 \\
\hline 2-d gamma processes ..... & 2 & 2 & 2 & 2 & 2 & 2 & 2 & 2 & 2 & 2 & 2 & 2 \\
\hline neut-to-gamma processes .. & 0 & 0 & 0 & 0 & 0 & 0 & 0 & 0 & 0 & 0 & 0 & 0 \\
\hline total $2-d$ arrays $\ldots . \ldots \ldots$ & 18 & 42 & 54 & 70 & 106 & 36 & 52 & 18 & 54 & 18 & 80 & 114 \\
\hline mass (neutron equivalents) & 138.709 & 139.698 & 141.683 & 141.682 & 143.668 & 145.654 & 145.653 & 146.647 & 147.639 & 146.647 & 147.638 & 148.629 \\
\hline $\max 2-d$ length $\ldots \ldots \ldots$ & 707 & 707 & 707 & 707 & 707 & 707 & 707 & 707 & 707 & 707 & 707 & 707 \\
\hline bondarenko processes .. & 0 & 0 & 0 & 0 & 0 & 0 & 0 & 0 & 0 & 0 & 0 & 0 \\
\hline bondarenko sigma zeros & 0 & 0 & 0 & 0 & 0 & 0 & 0 & 0 & 0 & 0 & 0 & 0 \\
\hline bondarenko temps ....... & 0 & 0 & 0 & 0 & 0 & 0 & 0 & 0 & 0 & 0 & 0 & 0 \\
\hline bondarenko groups & 0 & 0 & 0 & 0 & 0 & 0 & 0 & 0 & 0 & 0 & 0 & 0 \\
\hline endf mat of fast neut data .... & 9693 & 9725 & 9745 & 9764 & 9766 & 4768 & 9783 & 9784 & 9786 & 9785 & 1319 & 9809 \\
\hline endf mat of thermal neut data .. & 0 & 0 & 0 & 0 & 0 & 0 & 0 & 0 & 0 & 0 & 0 & 0 \\
\hline endf mat of gamma prod data $\ldots$. & 0 & 0 & 0 & 0 & 0 & 0 & 0 & 0 & 0 & 0 & 0 & 0 \\
\hline ampx za nuclide id number & 62151 & 62152 & 62153 & 63000 & 63151 & 63152 & 63153 & 63154 & 63155 & 72000 & 72174 & 72176 \\
\hline alphanumeric nuclide name & SM-151 & SM-152 & SM-153 & EU-NAT & EU-151 & EU-152 & EU-153 & EU-154 & EU-155 & HF-NAT & $H F-174$ & HF-176 \\
\hline $\begin{array}{l}\text { number of data records } . . . \\
\text { date created }\end{array}$ & $\begin{array}{c}103 \\
10-23-89\end{array}$ & $\begin{array}{c}121 \\
10-23-89\end{array}$ & $\begin{array}{c}104 \\
08-11-87\end{array}$ & & $\begin{array}{c}117 \\
04-01-93\end{array}$ & $\begin{array}{c}81 \\
04-01-93\end{array}$ & $\begin{array}{c}131 \\
04-01-93\end{array}$ & $\begin{array}{c}81 \\
04-01-93\end{array}$ & $\begin{array}{c}91 \\
10-23-80\end{array}$ & $\begin{array}{c}61 \\
05-91\end{array}$ & $\begin{array}{c}52 \\
08-25-91\end{array}$ & $\begin{array}{c}52 \\
08-25-91\end{array}$ \\
\hline weighting type $\ldots \ldots \ldots \ldots \ldots \ldots$ & type C & type C & type C & type C & type $C$ & type C & type $C$ & type C & $\begin{array}{l}10-23-89 \\
\text { type C }\end{array}$ & $\begin{array}{l}\text { Us-24-9l } \\
\text { type } C\end{array}$ & $\begin{array}{l}08-25-91 \\
\text { poldnt }\end{array}$ & $\begin{array}{l}08-25-91 \\
\text { poldnt }\end{array}$ \\
\hline resolved resonances ....... & 9 & 59 & 0 & 0 & 93 & 85 & 73 & 61 & 9 & 0 & 12 & 24 \\
\hline temp ind $1-d$ neut processes & 37 & 40 & 29 & 19 & 35 & 31 & 38 & 31 & 35 & 23 & 22 & 22 \\
\hline $2-d$ neut processes. & 18 & 21 & 15 & 5 & 16 & 12 & 18 & 12 & 16 & 9 & 7 & 7 \\
\hline 1-d gamma processes $\ldots$. & 9 & 9 & 9 & 9 & 9 & 9 & 9 & 9 & 9 & 9 & 9 & g \\
\hline 2-d gamma processes ...... & 2 & 2 & 2 & 2 & 2 & 2 & 2 & 2 & 2 & 2 & 2 & 2 \\
\hline neut-to-gamma processes. & 0 & 0 & 0 & 2 & 11 & 0 & 13 & 0 & 0 & 2 & 0 & 0 \\
\hline total $2-d$ arrays $\ldots \ldots \ldots$ & 88 & 106 & 90 & 22 & 87 & 52 & 101 & 52 & 76 & 46 & 37 & 37 \\
\hline mass (neutron equivalents) & 149.623 & 150.615 & 151.608 & 150.655 & .000 & .000 & .000 & .000 & 153.592 & 176.957 & 172.446 & 174.430 \\
\hline $\max 2-d$ length $\ldots \ldots \ldots \ldots$ & 707 & 707 & 707 & 1494 & 1346 & 707 & 1346 & 707 & 707 & 1228 & 707 & 707 \\
\hline bondarenko processes .. & 0 & 0 & 0 & 0 & 6 & 6 & 6 & 6 & 0 & 0 & 0 & 0 \\
\hline bondarenko sigma zeros.. & 0 & 0 & 0 & 0 & 5 & 5 & 5 & 5 & 0 & 0 & 0 & 0 \\
\hline bondarenko temps ....... & 0 & 0 & 0 & 0 & 5 & 5 & 5 & 5 & 0 & 0 & 0 & 0 \\
\hline bondarenko groups .... & 0 & 0 & 0 & 0 & 4 & 4 & 4 & 4 & 0 & 0 & 0 & 0 \\
\hline endf mat of fast neut data & 9810 & 9811 & 9812 & 7852 & 1357 & 4292 & 1359 & 4293 & 4832 & 8305 & 1374 & 1376 \\
\hline endf mat of thermal neut data . & 0 & 0 & 0 & 0 & 0 & 0 & 0 & 0 & 0 & 0 & 0 & 0 \\
\hline endf mat of gamma prod data ... & 0 & 0 & 0 & 7852 & 1357 & 0 & 1359 & 0 & 0 & 8305 & 0 & 0 \\
\hline
\end{tabular}


Table B-2 (continued)

\begin{tabular}{|c|c|c|c|c|c|c|c|c|c|c|c|c|}
\hline 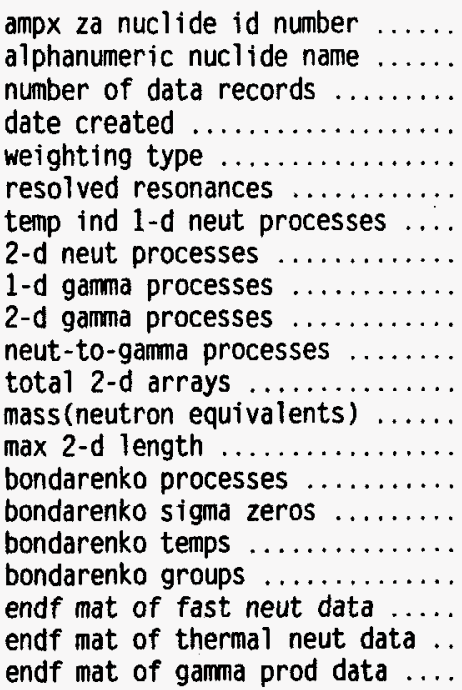 & $\begin{array}{c}72177 \\
\text { HF-177 } \\
94 \\
08-25-91 \\
\text { poldnt } \\
101 \\
29 \\
14 \\
9 \\
2 \\
0 \\
79 \\
175.423 \\
707 \\
0 \\
0 \\
0 \\
0 \\
1377 \\
0 \\
0\end{array}$ & $\begin{array}{c}72178 \\
H F-178 \\
52 \\
08-25-91 \\
\text { poldnt } \\
27 \\
22 \\
7 \\
9 \\
2 \\
0 \\
37 \\
176.415 \\
707 \\
0 \\
0 \\
0 \\
0 \\
1378 \\
0 \\
0\end{array}$ & $\begin{array}{c}72179 \\
\text { HF-179 } \\
58 \\
08-25-91 \\
\text { poldnt } \\
51 \\
23 \\
8 \\
9 \\
2 \\
0 \\
43 \\
177.409 \\
707 \\
0 \\
0 \\
0 \\
0 \\
1383 \\
0 \\
0\end{array}$ & $\begin{array}{c}72180 \\
H F-180 \\
52 \\
08-25-91 \\
\text { poldnt } \\
32 \\
22 \\
7 \\
9 \\
2 \\
0 \\
37 \\
178.401 \\
707 \\
0 \\
0 \\
0 \\
0 \\
1384 \\
0 \\
0\end{array}$ & $\begin{array}{c}73181 \\
\text { TA-181 } \\
112 \\
04-01-93 \\
\text { type B } \\
77 \\
30 \\
15 \\
9 \\
2 \\
2 \\
82 \\
000 \\
1235 \\
6 \\
4 \\
5 \\
3 \\
1285 \\
0 \\
1285\end{array}$ & $\begin{array}{c}73182 \\
\text { TA-182 } \\
97 \\
04-01-93 \\
\text { type B } \\
11 \\
28 \\
13 \\
9 \\
2 \\
0 \\
68 \\
000 \\
707 \\
6 \\
7 \\
5 \\
4 \\
1127 \\
0 \\
0\end{array}$ & $\begin{array}{c}82000 \\
P B \\
247 \\
12-04-89 \\
\text { type B } \\
0 \\
55 \\
40 \\
9 \\
2 \\
2 \\
232 \\
205.430 \\
707 \\
0 \\
0 \\
0 \\
0 \\
1382 \\
0 \\
1382\end{array}$ & $\begin{array}{c}83209 \\
\text { BI-209 } \\
74 \\
08-25-91 \\
\text { type B } \\
0 \\
28 \\
12 \\
9 \\
2 \\
2 \\
59 \\
207.185 \\
707 \\
0 \\
0 \\
0 \\
0 \\
1375 \\
0 \\
1375\end{array}$ & $\begin{array}{c}90232 \\
\text { TH-232 } \\
143 \\
12-11-89 \\
\text { type C } \\
243 \\
40 \\
20 \\
9 \\
2 \\
3 \\
113 \\
230.040 \\
1380 \\
6 \\
7 \\
5 \\
2 \\
1390 \\
0 \\
1390\end{array}$ & $\begin{array}{c}92233 \\
U-233 \\
38 \\
06-05-91 \\
\text { type C } \\
0 \\
25 \\
5 \\
9 \\
2 \\
3 \\
23 \\
231.038 \\
1570 \\
0 \\
0 \\
0 \\
0 \\
7866 \\
0 \\
7866\end{array}$ & $\begin{array}{c}92234 \\
U-234 \\
38 \\
\text { 06-05-91 } \\
\text { type C } \\
0 \\
25 \\
5 \\
9 \\
2 \\
3 \\
23 \\
232.029 \\
1380 \\
0 \\
0 \\
0 \\
0 \\
7867 \\
0 \\
7867\end{array}$ & $\begin{array}{c}92235 \\
U-235 \\
148 \\
04-01-93 \\
\text { type C } \\
131 \\
39 \\
21 \\
9 \\
2 \\
4 \\
120 \\
.000 \\
1482 \\
5 \\
7 \\
5 \\
5 \\
1395 \\
0 \\
1395\end{array}$ \\
\hline 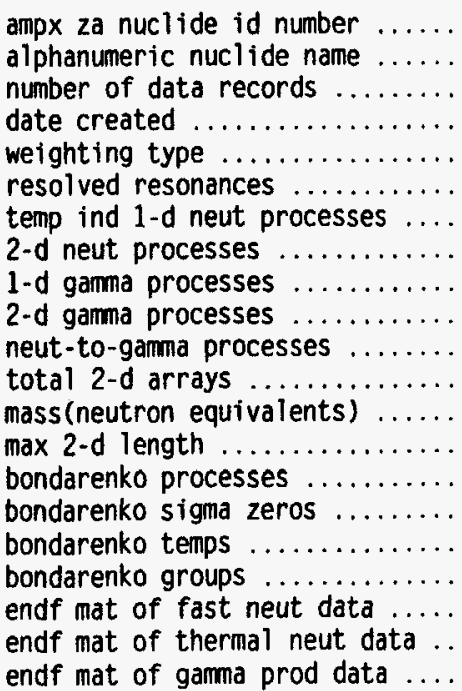 & $\begin{array}{c}92236 \\
\text { U-236 } \\
38 \\
06-05-91 \\
\text { type C } \\
0 \\
25 \\
5 \\
9 \\
2 \\
3 \\
23 \\
234.022 \\
1570 \\
0 \\
0 \\
0 \\
0 \\
7869 \\
0 \\
7869\end{array}$ & $\begin{array}{c}92237 \\
\text { U-237 } \\
53 \\
12-04-89 \\
\text { type C } \\
29 \\
23 \\
5 \\
9 \\
2 \\
3 \\
23 \\
235.012 \\
1570 \\
6 \\
7 \\
5 \\
3 \\
8237 \\
0 \\
8237\end{array}$ & $\begin{array}{c}92238 \\
U-238 \\
215 \\
04-01-93 \\
\text { type C } \\
165 \\
51 \\
32 \\
9 \\
2 \\
3 \\
185 \\
.000 \\
1570 \\
6 \\
7 \\
5 \\
3 \\
1398 \\
0 \\
1398\end{array}$ & $\begin{array}{c}93237 \\
\text { NP-237 } \\
113 \\
12-11-89 \\
\text { type C } \\
170 \\
34 \\
16 \\
9 \\
2 \\
0 \\
86 \\
235.012 \\
707 \\
5 \\
7 \\
5 \\
4 \\
1337 \\
0 \\
0\end{array}$ & $\begin{array}{c}93238 \\
\text { NP-238 } \\
32 \\
12-12-89 \\
\text { type C } \\
96 \\
21 \\
2 \\
9 \\
2 \\
0 \\
17 \\
236.006 \\
707 \\
0 \\
0 \\
0 \\
0 \\
8338 \\
0 \\
0\end{array}$ & $\begin{array}{c}93239 \\
\text { NP-239 } \\
82 \\
12-12-89 \\
\text { type C } \\
0 \\
31 \\
13 \\
9 \\
2 \\
0 \\
68 \\
236.999 \\
707 \\
0 \\
0 \\
0 \\
0 \\
2932 \\
0 \\
0\end{array}$ & $\begin{array}{c}94238 \\
\text { PU-238 } \\
29 \\
06-05-91 \\
\text { type C } \\
0 \\
25 \\
5 \\
0 \\
0 \\
3 \\
16 \\
236.005 \\
1570 \\
0 \\
0 \\
0 \\
0 \\
7875 \\
0 \\
7875\end{array}$ & $\begin{array}{c}94239 \\
\text { PU-239 } \\
162 \\
12-12-89 \\
\text { type C } \\
129 \\
44 \\
23 \\
9 \\
2 \\
4 \\
132 \\
236.999 \\
1482 \\
6 \\
7 \\
5 \\
4 \\
1399 \\
0 \\
1399\end{array}$ & $\begin{array}{c}94240 \\
\text { PU-240 } \\
126 \\
12-11-89 \\
\text { type C } \\
202 \\
37 \\
17 \\
9 \\
2 \\
4 \\
96 \\
237.992 \\
1482 \\
6 \\
7 \\
5 \\
2 \\
1380 \\
0 \\
1380\end{array}$ & $\begin{array}{c}94241 \\
\text { PU-241 } \\
119 \\
12-12-89 \\
\text { type C } \\
93 \\
33 \\
16 \\
9 \\
2 \\
3 \\
89 \\
238.986 \\
1297 \\
6 \\
7 \\
5 \\
4 \\
2945 \\
0 \\
1381\end{array}$ & $\begin{array}{c}94242 \\
\text { PU-242 } \\
167 \\
12-11-89 \\
\text { type C } \\
69 \\
42 \\
24 \\
9 \\
2 \\
3 \\
137 \\
239.979 \\
1400 \\
6 \\
7 \\
5 \\
2 \\
1342 \\
0 \\
1342\end{array}$ & $\begin{array}{c}94243 \\
\text { PU-243 } \\
51 \\
12-11-89 \\
\text { type C } \\
42 \\
24 \\
5 \\
9 \\
2 \\
3 \\
23 \\
240.974 \\
1570 \\
5 \\
4 \\
5 \\
3 \\
8443 \\
0 \\
8443\end{array}$ \\
\hline
\end{tabular}


Table B-2 (continued)

\begin{tabular}{|c|c|c|c|c|c|c|c|c|c|c|c|c|}
\hline 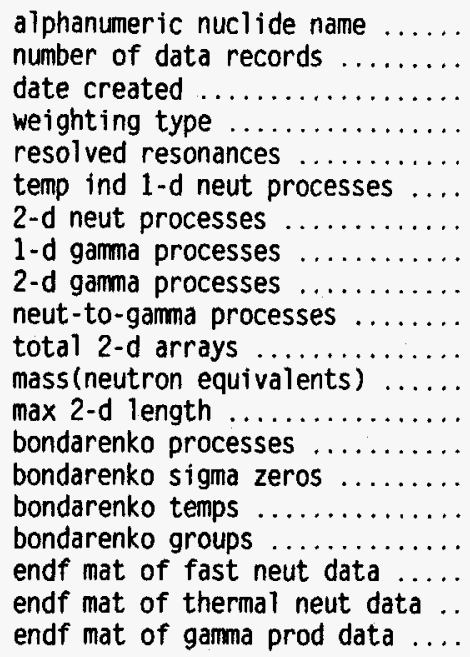 & $\begin{array}{c}\text { AM-241 } \\
161 \\
12-11-89 \\
\text { type C } \\
67 \\
41 \\
23 \\
9 \\
2 \\
3 \\
131 \\
238.986 \\
1400 \\
6 \\
7 \\
5 \\
4 \\
1361 \\
0 \\
1361\end{array}$ & $\begin{array}{c}\text { AM-242 } \\
44 \\
12-11-89 \\
\text { type C } \\
83 \\
19 \\
2 \\
9 \\
2 \\
0 \\
17 \\
239.980 \\
707 \\
5 \\
4 \\
5 \\
3 \\
8542 \\
0 \\
0\end{array}$ & $\begin{array}{c}\text { AM-243 } \\
155 \\
12-11-89 \\
\text { type C } \\
221 \\
41 \\
22 \\
9 \\
2 \\
3 \\
125 \\
240.973 \\
1176 \\
6 \\
5 \\
5 \\
3 \\
1363 \\
0 \\
1363\end{array}$ & $\begin{array}{c}\text { AM-242M } \\
129 \\
12-07-89 \\
\text { type C } \\
8 \\
37 \\
18 \\
9 \\
2 \\
3 \\
101 \\
239.980 \\
1608 \\
5 \\
3 \\
5 \\
6 \\
1369 \\
0 \\
1369\end{array}$ & $\begin{array}{c}\text { CM-242 } \\
71 \\
12-05-89 \\
\text { type C } \\
22 \\
26 \\
8 \\
9 \\
2 \\
3 \\
41 \\
239.979 \\
1400 \\
6 \\
7 \\
5 \\
3 \\
8642 \\
0 \\
8642\end{array}$ & $\begin{array}{c}\text { CM- } 243 \\
141 \\
12-07-89 \\
\text { type C } \\
17 \\
39 \\
20 \\
9 \\
2 \\
3 \\
113 \\
240.973 \\
1400 \\
5 \\
4 \\
5 \\
5 \\
1343 \\
0 \\
1343\end{array}$ & $\begin{array}{c}\text { CM-244 } \\
71 \\
\text { 12-05-89 } \\
\text { type C } \\
39 \\
26 \\
8 \\
9 \\
2 \\
3 \\
41 \\
241.966 \\
1400 \\
6 \\
7 \\
5 \\
3 \\
1344 \\
0 \\
1344\end{array}$ & $\begin{array}{c}\text { CM-245 } \\
39 \\
12-05-89 \\
\text { type C } \\
40 \\
28 \\
5 \\
9 \\
2 \\
3 \\
23 \\
242.960 \\
1570 \\
0 \\
0 \\
0 \\
0 \\
1345 \\
0 \\
1345\end{array}$ & $\begin{array}{c}\text { CM-246 } \\
119 \\
12-05-89 \\
\text { type C } \\
12 \\
35 \\
16 \\
9 \\
2 \\
3 \\
89 \\
243.953 \\
1570 \\
6 \\
7 \\
5 \\
3 \\
1346 \\
0 \\
1346\end{array}$ & $\begin{array}{c}\text { CM-247 } \\
53 \\
12-05-89 \\
\text { type C } \\
36 \\
24 \\
5 \\
9 \\
2 \\
3 \\
23 \\
244.950 \\
1570 \\
6 \\
7 \\
5 \\
4 \\
8647 \\
0 \\
8647\end{array}$ & $\begin{array}{c}C M-248 \\
95 \\
12-07-89 \\
\text { type C } \\
48 \\
31 \\
12 \\
9 \\
2 \\
3 \\
65 \\
245.941 \\
1570 \\
6 \\
7 \\
5 \\
2 \\
8648 \\
0 \\
8648\end{array}$ & $\begin{array}{c}\text { BK-249 } \\
49 \\
12-07-89 \\
\text { type C } \\
93 \\
24 \\
5 \\
9 \\
2 \\
0 \\
20 \\
246.935 \\
707 \\
6 \\
5 \\
5 \\
3 \\
8749 \\
0 \\
0\end{array}$ \\
\hline 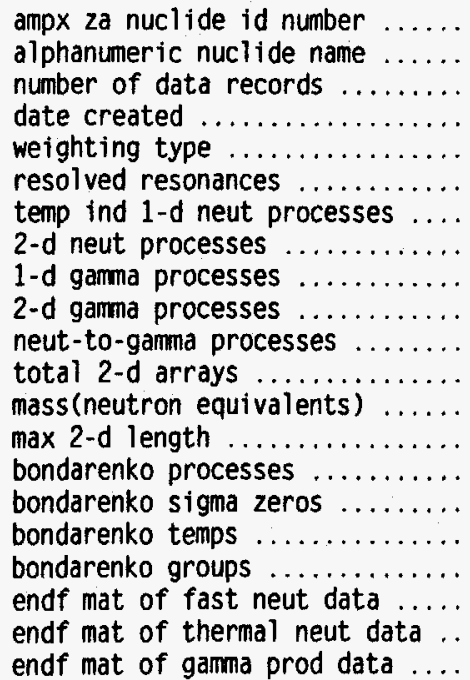 & $\begin{array}{c}98249 \\
\text { CF-249 } \\
49 \\
12-07-89 \\
\text { type C } \\
54 \\
24 \\
5 \\
9 \\
2 \\
0 \\
20 \\
246.935 \\
707 \\
6 \\
5 \\
5 \\
4 \\
8849 \\
0 \\
0\end{array}$ & $\begin{array}{c}98250 \\
\text { CF-250 } \\
53 \\
12-07-89 \\
\text { type C } \\
22 \\
24 \\
5 \\
9 \\
2 \\
3 \\
23 \\
247.928 \\
1380 \\
6 \\
7 \\
5 \\
3 \\
8850 \\
0 \\
8850\end{array}$ & $\begin{array}{c}98251 \\
\text { CF-251 } \\
53 \\
12-07-89 \\
\text { type C } \\
22 \\
24 \\
5 \\
9 \\
2 \\
3 \\
23 \\
248.923 \\
1570 \\
6 \\
7 \\
5 \\
3 \\
8851 \\
0 \\
8851\end{array}$ & $\begin{array}{c}98252 \\
\text { CF-252 } \\
53 \\
12-07-89 \\
\text { type C } \\
22 \\
24 \\
5 \\
9 \\
2 \\
3 \\
23 \\
249.916 \\
1570 \\
6 \\
7 \\
5 \\
3 \\
8852 \\
0 \\
8852\end{array}$ & $\begin{array}{c}98253 \\
\text { CF-253 } \\
46 \\
12-07-89 \\
\text { type C } \\
121 \\
19 \\
2 \\
9 \\
2 \\
0 \\
17 \\
250.910 \\
707 \\
6 \\
5 \\
5 \\
3 \\
8853 \\
0 \\
0\end{array}$ & $\begin{array}{c}99253 \\
\text { ES-253 } \\
42 \\
12-07-89 \\
\text { type C } \\
29 \\
15 \\
2 \\
9 \\
2 \\
0 \\
17 \\
250.910 \\
707 \\
4 \\
4 \\
5 \\
3 \\
8953 \\
0 \\
0\end{array}$ & $\begin{array}{l}\text { Other gen } \\
\text { max ord } \\
\text { unresolve } \\
\text { temp dep } \\
\text { neutron w } \\
\text { neutron w } \\
\text { gamma wgt } \\
\text { power/fis } \\
\text { energy/ca } \\
\text { id(41) n } \\
\text { gamma pro } \\
\text { id(43) no } \\
\text { gamma pro } \\
\text { endf mat }\end{array}$ & $\begin{array}{l}\text { leral notes } \\
\text { d resonanc } \\
1-d \text { neut } p \\
\text { gting opti } \\
\text { gt id .... } \\
\text { ing option } \\
\text { sion (watt- } \\
\text { pture(watt } \\
\text { lot used . } \\
\text { d wgt id } \\
\text { d used wgting o } \\
\text { of gamma d }\end{array}$ & $\begin{array}{l}\text { ter } \ldots . . . \\
\text { e points } \\
\text { rocesses } \\
\text { on } \ldots \ldots \ldots \\
\ldots \ldots \ldots \\
\ldots \ldots \ldots \ldots \\
\text { sec/fis) } \\
\text {-sec/cap) } \\
\ldots . . . . . .\end{array}$ & $\begin{array}{ll}0 & \text { for } \\
0 & \text { for } \\
0 & \text { for } \\
0 & \text { for } \\
0 & \text { for } \\
0 & \text { for } \\
0 & \text { for } \\
0 & \text { for } \\
0 & \text { for } \\
0 & \text { for } \\
0 & \text { for } \\
0 & \text { for }\end{array}$ & $\begin{array}{ll}\text { all } & 138 \\
\text { all } & 138 \\
\text { all } & 138 \\
\text { all } & 138 \\
\text { all } & 138 \\
\text { all } & 138 \\
\text { all } & 138 \\
\text { or all } & 138 \\
\text { all } & 138 \\
\text { all } & 138 \\
\text { all } & 138 \\
\text { all } & 138 \\
\end{array}$ & $\begin{array}{l}\text { luclides } \\
\text { luclides } \\
\text { luclides } \\
\text { luclides } \\
\text { luclides } \\
\text { uclides } \\
\text { luclides } \\
\text { nuclides } \\
\text { luclides } \\
\text { luclides } \\
\text { luclides } \\
\text { luclides }\end{array}$ \\
\hline
\end{tabular}


Table B-3. Temperature-independent 1-D neutron processes for each nuclide

AMPX Nuclide ID 1001 has 15 temperature-independent 1-D processes. These include MT numbers:

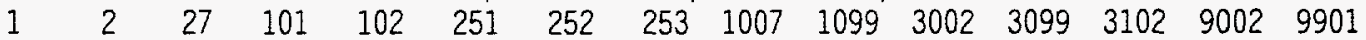

AMPX Nuclide ID 1002 has 16 temperature-independent 1-0 processes. These include MT numbers:

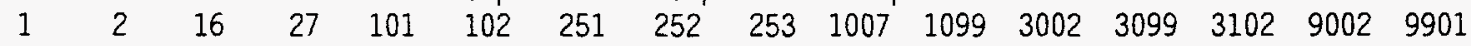

AMPX Nuclide ID 1003 has 14 temperature-independent 1-D processes. These include MT numbers:

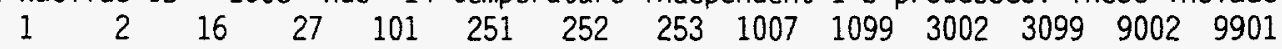

AMPX Nuclide ID 1401 has 15 temperature-independent 1-D processes. These include MT numbers:

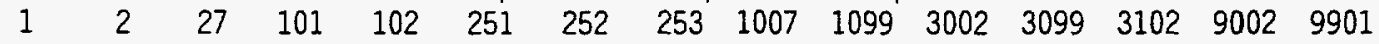

AMPX Nuclide ID 1402 has 16 temperature-independent 1-D processes. These include MT numbers:

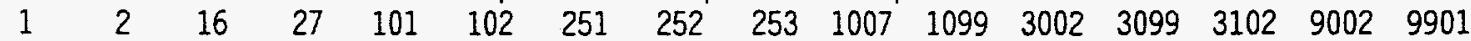

AMPX Nuclide ID 1501 has 15 temperature-independent 1-D processes. These include MT numbers:

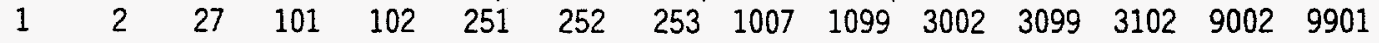

AMPX Nuclide ID 1801 has 15 temperature-independent 1-D processes. These include MT numbers:

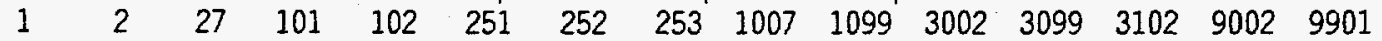

AMPX Nuclide ID 2003 has 15 temperature-independent 1-D processes. These include MT numbers:

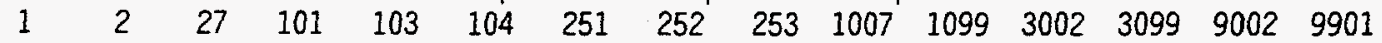

AMPX Nuclide ID 2004 has 13 temperature-independent 1-D processes. These include MT numbers:

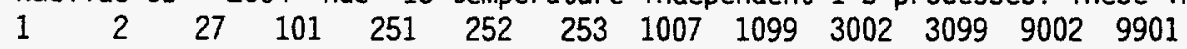

AMPX Nuclide ID 3006 has 50 temperature-independent 1-D processes. These include MT numbers:

\begin{tabular}{|c|c|c|c|c|c|c|c|c|c|c|c|c|c|c|c|}
\hline & 2 & 4 & 24 & 27 & 51 & 52 & 53 & 54 & $55^{\prime}$ & 56 & 57 & 58 & 59 & 60 & 61 \\
\hline $\begin{array}{r}78 \\
9002\end{array}$ & $\begin{array}{r}79 \\
9901\end{array}$ & 80 & 81 & 101 & 102 & 103 & 105 & 251 & 252 & 253 & 1007 & 1099 & 3002 & 3099 & 3102 \\
\hline
\end{tabular}

AMPX Nuclide ID 3007 has 52 temperature-independent 1-D processes. These include MT numbers:

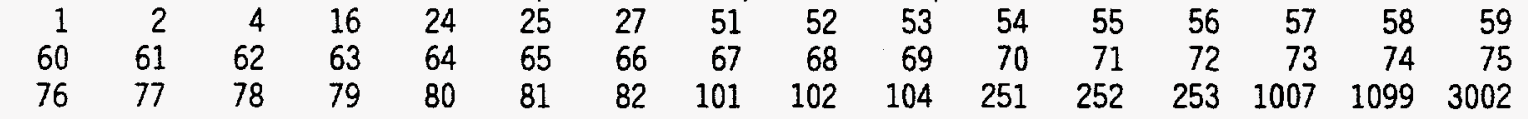

3099310290029901

AMPX NuClide ID 4009 has 29 temperature-independent 1-D processes. These include MT numbers:

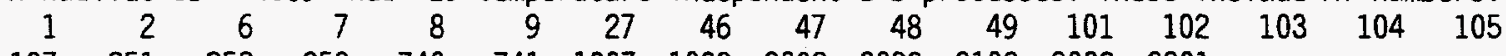

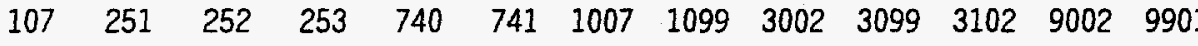

AMPX Nuclide ID 5010 has 61 temperature-independent 1-D processes. These include MT numbers:

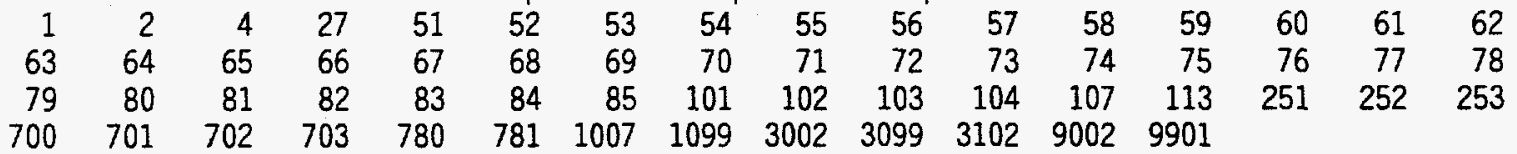

AMPX Nuclide ID 5011 has 24 temperature-independent 1-D processes. These include MT numbers:

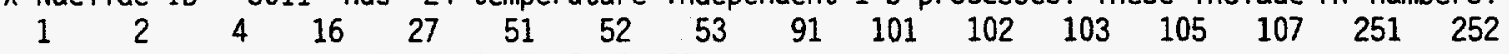

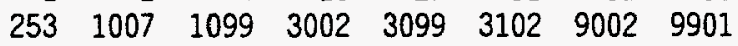


Table B-3 (continued)

$\begin{array}{rrrrrrrrrrrrrrrr}\text { AMPX Nuclide } & \text { ID } & 6012 & \text { has } & 42 & \text { temperature-independent } & 1-D & \text { processes. These include MT numbers: } \\ 1 & 2 & 3 & 4 & 27 & 51 & 52 & 53 & 54 & 55 & 56 & 57 & 58 & 59 & 60 & 61 \\ 62 & 63 & 64 & 65 & 66 & 67 & 68 & 91 & 101 & 102 & 103 & 104 & 107 & 203 & 204 & 207 \\ 251 & 252 & 253 & 1007 & 1099 & 3002 & 3099 & 3102 & 9002 & 9901 & & & & & & \end{array}$

AMPX Nuclide ID 6312 has 42 temperature-independent 1-D processes. These include MT numbers:

$\begin{array}{rrrrrrrrrrrrrrrr}1 & 2 & 3 & 4 & 27 & 51 & 52 & 53 & 54 & 55 & 56 & 57 & 58 & 59 & 60 & 61 \\ 62 & 63 & 64 & 65 & 66 & 67 & 68 & 91 & 101 & 102 & 103 & 104 & 107 & 203 & 204 & 207 \\ 251 & 252 & 253 & 1007 & 1099 & 3002 & 3099 & 3102 & 9002 & 9901 & & & & & & \end{array}$

AMPX Nuclide ID 7014 has 76 temperature-independent 1-D processes. These include MT numbers:

$\begin{array}{rrrrrrrrrrrrrrrr}1 & 2 & 4 & 16 & 27 & 51 & 52 & 53 & 54 & 55 & 56 & 57 & 58 & 59 & 60 & 61 \\ 62 & 63 & 64 & 65 & 66 & 67 & 68 & 69 & 70 & 71 & 72 & 73 & 74 & 75 & 76 & 77 \\ 78 & 79 & 80 & 81 & 82 & 101 & 102 & 103 & 104 & 105 & 107 & 108 & 251 & 252 & 253 & 700 \\ 701 & 702 & 703 & 704 & 720 & 721 & 722 & 723 & 740 & 741 & 780 & 781 & 782 & 783 & 784 & 785 \\ 786 & 787 & 788 & 789 & 790 & 1007 & 1099 & 3002 & 3099 & 3102 & 9002 & 9901 & & & & \end{array}$

AMPX Nuclide ID 7015 has 51 temperature-independent 1-D processes. These include MT numbers:

$$
\begin{array}{rrrrrrrrrrrrrrrr}
1 & 2 & 4 & 16 & 22 & 27 & 28 & 51 & 52 & 53 & 54 & 55 & 56 & 57 & 91 & 101 \\
102 & 103 & 104 & 105 & 107 & 251 & 252 & 253 & 700 & 701 & 718 & 719 & 720 & 721 & 722 & 738 \\
740 & 741 & 742 & 758 & 780 & 781 & 782 & 783 & 784 & 785 & 798 & 799 & 1007 & 1099 & 3002 & 3099 \\
3102 & 9002 & 9901 & & & & & & & & & & & & &
\end{array}
$$

AMPX Nuclide ID 8016 has 62 temperature-independent 1-D processes. These include MT numbers:

$$
\begin{array}{rrrrrrrrrrrrrrrr}
1 & 2 & 4 & 27 & 51 & 52 & 53 & 54 & 55 & 56 & 57 & 58 & 59 & 60 & 61 & 62 \\
63 & 64 & 65 & 66 & 67 & 68 & 69 & 70 & 71 & 72 & 73 & 74 & 75 & 76 & 77 & 78 \\
79 & 80 & 81 & 82 & 83 & 84 & 85 & 86 & 87 & 88 & 89 & 101 & 102 & 103 & 104 & 107 \\
251 & 252 & 253 & 780 & 781 & 782 & 783 & 1007 & 1099 & 3002 & 3099 & 3102 & 9002 & 9901 & &
\end{array}
$$

AMPX Nuclide ID 9019 has 46 temperature-independent 1-D processes. These include MT numbers:

$\begin{array}{rrrrrrrrrrrrrrrr}1 & 2 & 3 & 4 & 16 & 22 & 27 & 28 & 51 & 52 & 53 & 54 & 55 & 56 & 57 & 58 \\ 59 & 60 & 61 & 62 & 63 & 64 & 65 & 66 & 67 & 68 & 69 & 70 & 71 & 91 & 101 & 102 \\ 103 & 104 & 105 & 107 & 251 & 252 & 253 & 1007 & 1099 & 3002 & 3099 & 3102 & 9002 & 9901 & & \end{array}$

AMPX Nuclide ID 11023 has 39 temperature-independent 1-D processes. These include MT numbers: $\begin{array}{rrrrrrrrrrrrrrrr}1 & 2 & 3 & 4 & 16 & 27 & 51 & 52 & 53 & 54 & 55 & 56 & 57 & 58 & 59 & 60 \\ 61 & 62 & 63 & 64 & 65 & 66 & 67 & 68 & 91 & 101 & 102 & 103 & 107 & 251 & 252 & 253 \\ 1007 & 1099 & 3002 & 3099 & 3102 & 9002 & 9901 & & & & & & & & & \end{array}$

AMPX Nuclide ID 12000 has 63 temperature-independent 1-D processes. These include MT numbers:

$\begin{array}{rrrrrrrrrrrrrrrr}1 & 2 & 3 & 4 & 16 & 22 & 27 & 28 & 51 & 52 & 53 & 54 & 55 & 56 & 57 & 58 \\ 59 & 60 & 61 & 62 & 63 & 64 & 65 & 66 & 67 & 68 & 69 & 70 & 71 & 72 & 73 & 74 \\ 75 & 76 & 77 & 78 & 79 & 80 & 81 & 82 & 83 & 84 & 85 & 86 & 87 & 88 & 89 & 90 \\ 91 & 101 & 102 & 103 & 107 & 251 & 252 & 253 & 1007 & 1099 & 3002 & 3099 & 3102 & 9002 & 9901 & \end{array}$

AMPX Nuclide ID 13027 has 61 temperature-independent 1-D processes. These include MT numbers:

$\begin{array}{rrrrrrrrrrrrrrrr}1 & 2 & 4 & 16 & 27 & 51 & 52 & 53 & 54 & 55 & 56 & 57 & 58 & 59 & 60 & 61 \\ 62 & 63 & 64 & 65 & 66 & 67 & 68 & 69 & 70 & 71 & 72 & 73 & 74 & 75 & 76 & 77 \\ 78 & 79 & 80 & 81 & 82 & 83 & 84 & 85 & 86 & 87 & 88 & 89 & 90 & 101 & 102 & 103 \\ 104 & 105 & 107 & 251 & 252 & 253 & 1007 & 1099 & 3002 & 3099 & 3102 & 9002 & 9901 & & & \end{array}$


Table B-3 (continued)

$\begin{array}{rrrrrrrrrrrrrrrr}\text { AMPX Nuclide ID } & 13327 & \text { has } & 61 & \text { temperature-independent } & \text { 1-D processes. These include MT numbers: } \\ 1 & 2 & 4 & 16 & 27 & 51 & 52 & 53 & 54 & 55 & 56 & 57 & 58 & 59 & 60 & 61 \\ 62 & 63 & 64 & 65 & 66 & 67 & 68 & 69 & 70 & 71 & 72 & 73 & 74 & 75 & 76 & 77 \\ 78 & 79 & 80 & 81 & 82 & 83 & 84 & 85 & 86 & 87 & 88 & 89 & 90 & 101 & 102 & 103 \\ 104 & 105 & 107 & 251 & 252 & 253 & 1007 & 1099 & 3002 & 3099 & 3102 & 9002 & 9901 & & & \end{array}$

AMPX Nuclide ID 14000 has 77 temperature-independent 1-D processes. These include MT numbers:

$\begin{array}{rrrrrrrrrrrrrrrr}1 & 2 & 3 & 4 & 16 & 22 & 27 & 28 & 51 & 52 & 53 & 54 & 55 & 56 & 57 & 58 \\ 59 & 60 & 61 & 62 & 63 & 64 & 65 & 66 & 67 & 68 & 69 & 70 & 71 & 72 & 91 & 101 \\ 102 & 103 & 104 & 107 & 251 & 252 & 253 & 700 & 701 & 702 & 703 & 704 & 705 & 706 & 707 & 708 \\ 709 & 710 & 711 & 712 & 713 & 714 & 718 & 719 & 780 & 781 & 782 & 783 & 784 & 785 & 786 & 787 \\ 788 & 789 & 790 & 791 & 798 & 799 & 1007 & 1099 & 3002 & 3099 & 3102 & 9002 & 9901 & & & \end{array}$

AMPX Nuclide ID 14300 has 77 temperature-independent 1-D processes. These include MT numbers:

$\begin{array}{rrrrrrrrrrrrrrrr}1 & 2 & 3 & 4 & 16 & 22 & 27 & 28 & 51 & 52 & 53 & 54 & 55 & 56 & 57 & 58 \\ 59 & 60 & 61 & 62 & 63 & 64 & 65 & 66 & 67 & 68 & 69 & 70 & 71 & 72 & 91 & 101 \\ 102 & 103 & 104 & 107 & 251 & 252 & 253 & 700 & 701 & 702 & 703 & 704 & 705 & 706 & 707 & 708 \\ 709 & 710 & 711 & 712 & 713 & 714 & 718 & 719 & 780 & 781 & 782 & 783 & 784 & 785 & 786 & 787 \\ 788 & 789 & 790 & 791 & 798 & 799 & 1007 & 1099 & 3002 & 3099 & 3102 & 9002 & 9901 & & & \end{array}$

AMPX Nuclide ID 15031 has 21 temperature-independent 1-D processes. These include MT numbers: $\begin{array}{llllllllllllllll}1 & 2 & 4 & 16 & 27 & 28 & 91 & 101 & 102 & 103 & 107 & 251 & 252 & 253 & 1007 & 1099\end{array}$ $3002 \quad 30993102 \quad 90029901$

AMPX Nuclide ID 16000 has 69 temperature-independent I-D processes. These inciude MT numbers:

$\begin{array}{rrrrrrrrrrrrrrrr}1 & 2 & 4 & 16 & 22 & 27 & 28 & 51 & 52 & 53 & 54 & 55 & 56 & 57 & 58 & 59 \\ 60 & 61 & 62 & 63 & 64 & 65 & 66 & 67 & 68 & 69 & 70 & 71 & 72 & 73 & 74 & 75 \\ 76 & 77 & 78 & 79 & 80 & 81 & 82 & 83 & 84 & 85 & 86 & 87 & 88 & 89 & 90 & 91 \\ 101 & 102 & 103 & 104 & 105 & 107 & 111 & 203 & 204 & 205 & 207 & 251 & 252 & 253 & 1007 & 1099 \\ 3002 & 3099 & 3102 & 9002 & 9901 & & & & & & & & & & & \end{array}$

AMPX Nuclide ID 16032 has 22 temperature-independent 1-D processes. These include MT numbers: $\begin{array}{llllllllllllllll}1 & 2 & 4 & 16 & 27 & 28 & 91 & 101 & 102 & 103 & 105 & 107 & 251 & 252 & 253 & 1007\end{array}$ $\begin{array}{llllll}1099 & 3002 & 3099 & 3102 & 9002 & 9901\end{array}$

AMPX Nuclide ID 19000 has 39 temperature-independent 1-D processes. These include MT numbers: $\begin{array}{rrrrrrrrrrrrrrrr}1 & 2 & 4 & 16 & 22 & 27 & 28 & 51 & 52 & 53 & 54 & 55 & 56 & 57 & 58 & 59 \\ 60 & 61 & 62 & 63 & 64 & 65 & 66 & 67 & 91 & 101 & 102 & 103 & 107 & 251 & 252 & 253 \\ 1007 & 1099 & 3002 & 3099 & 3102 & 9002 & 9901 & & & & & & & & & \end{array}$

AMPX Nuclide ID 20000 has 48 temperature-independent 1-D processes. These include MT numbers:

$$
\begin{aligned}
& \begin{array}{rrrrrrrrrrrrrrrr}
1 & 2 & 3 & 4 & 16 & 22 & 27 & 28 & 51 & 52 & 53 & 54 & 55 & 56 & 57 & 58
\end{array}
\end{aligned}
$$

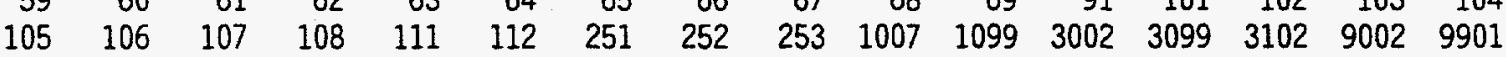

AMPX Nuclide ID 22000 has 42 temperature-independent 1-D processes. These include MT numbers:

$\begin{array}{rrrrrrrrrrrrrrrr}1 & 2 & 4 & 16 & 17 & 22 & 27 & 28 & 51 & 52 & 53 & 54 & 55 & 56 & 57 & 58 \\ 59 & 60 & 61 & 62 & 91 & 101 & 102 & 103 & 104 & 105 & 106 & 107 & 111 & 112 & 203 & 207 \\ 251 & 252 & 253 & 1007 & 1099 & 3002 & 3099 & 3102 & 9002 & 9901 & & & & & & \end{array}$


Table B-3 (continued)

AMPX Nuclide ID 23000 has 33 temperature-independent 1-D processes. These include MT numbers:

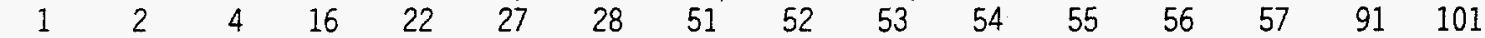

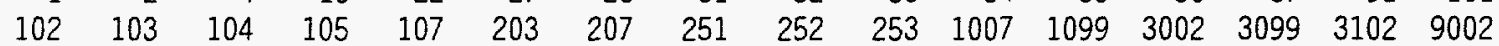
9901

AMPX Nuclide ID 24000 has 72 temperature-independent 1-D processes. These include MT numbers:

\begin{tabular}{|c|c|c|c|c|c|c|c|c|c|c|c|c|c|c|}
\hline 1 & 3 & 4 & 16 & 17 & 22 & 27 & 28 & 51 & 52 & 53 & 54 & 55 & 56 & 57 \\
\hline 59 & 60 & 61 & 62 & 63 & 64 & 65 & 66 & 67 & 68 & 69 & 70 & 71 & 72 & 73 \\
\hline 75 & 76 & 77 & 78 & 79 & 80 & 81 & 82 & 8 & 84 & 85 & 8 & 87 & 3 & \\
\hline 91 & 101 & 102 & 103 & 104 & 105 & 106 & 107 & 203 & 204 & 205 & 206 & 207 & 251 & 2 \\
\hline
\end{tabular}

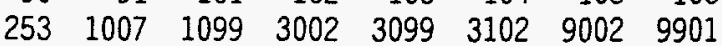

AMPX Nuclide ID 25055 has 37 temperature-independent 1-D processes. These include MT numbers:

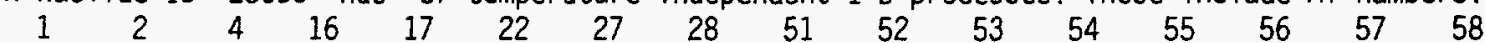

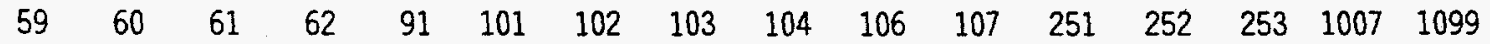

$300230993102 \quad 90029901$

AMPX Nuclide ID 26000 has 66 temperature-independent 1-D processes. These include MT numbers:

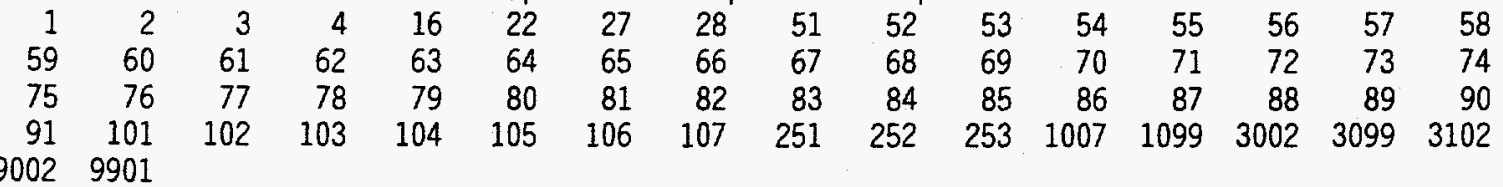

AMPX Nuclide ID 27059 has 36 temperature-independent 1-D processes. These include MT numbers:

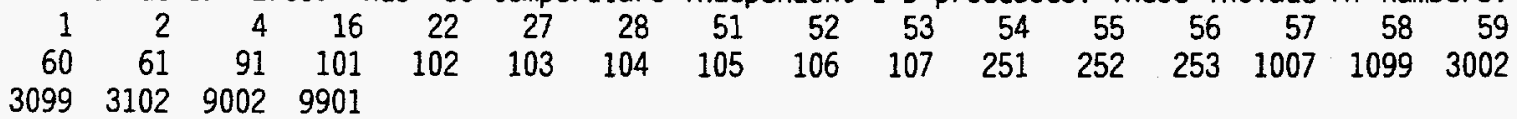

AMPX Nuclide ID 28000 has 53 temperature-independent 1-D processes. These include MT numbers:

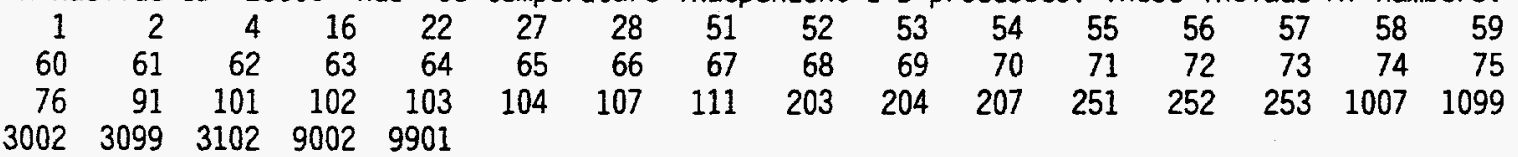

AMPX Nuclide ID 29000 has 37 temperature-independent 1-D processes. These include MT numbers:

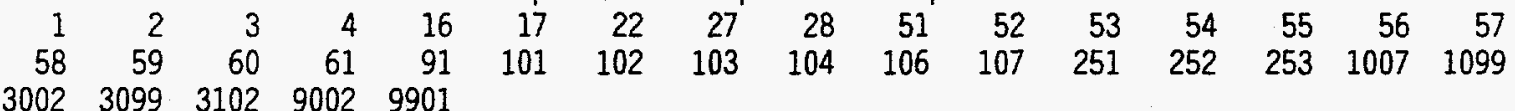

AMPX Nuclide ID 36082 has 33 temperature-independent 1-D processes. These include MT numbers:

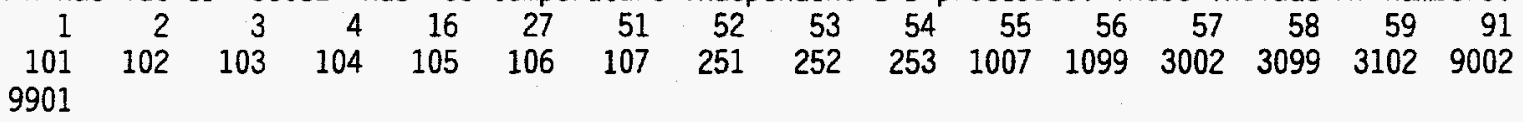

AMPX Nuclide ID 36083 has 31 temperature-independent 1-D processes. These include MT numbers:

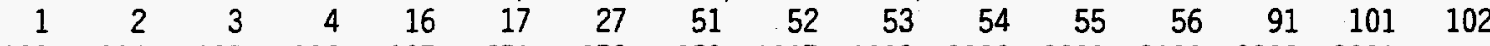

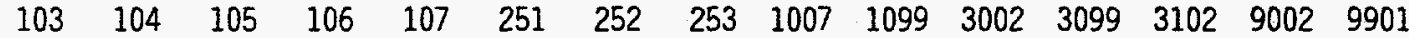

AMPX Nuclide ID 40000 has 28 temperature-independent 1-D processes. These include MT numbers:

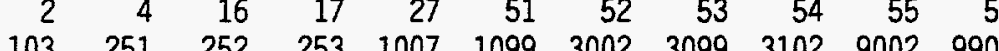


Table B-3 (continued)

AMPX Nuciide ID 40090 has 25 temperature-independent 1-D processes. These include MT numbers:

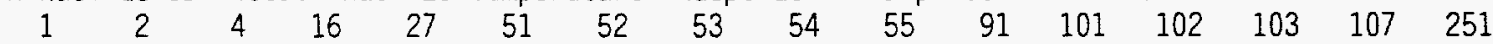
$\begin{array}{lllllllll}252 & 253 & 1007 & 1099 & 3002 & 3099 & 3102 & 9002 & 9901\end{array}$

AMPX Nuclide ID 40091 has 31 temperature-independent 1-D processes. These include MT numbers:

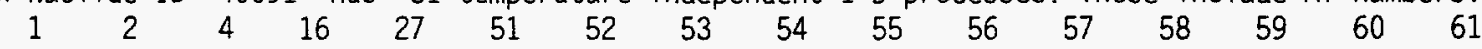

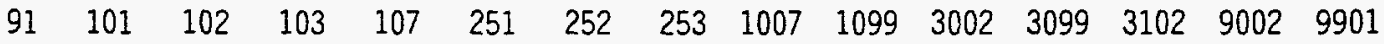

AMPX Nuclide ID 40092 has 26 temperature-independent 1-D processes. These include MT numbers:

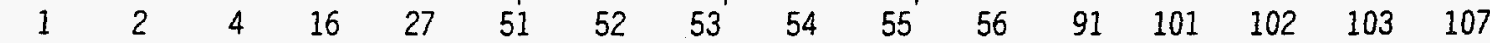
$\begin{array}{llllllllll}251 & 252 & 253 & 1007 & 1099 & 3002 & 3099 & 3102 & 9002 & 9901\end{array}$

AMPX Nuclide ID 40093 has 27 temperature-independent 1-D processes. These include MT numbers:

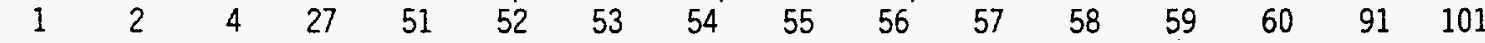
$\begin{array}{lllllllllll}102 & 251 & 252 & 253 & 1007 & 1099 & 3002 & 3099 & 3102 & 9002 & 9901\end{array}$

AMPX Nuclide ID 40094 has 28 temperature-independent 1-D processes. These include MT numbers:

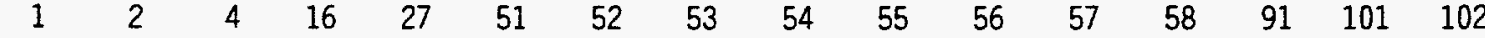

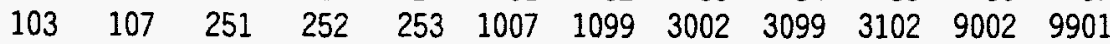

AMPX Nuclide ID 40096 has 23 temperature-independent 1-D processes. These include MT numbers:

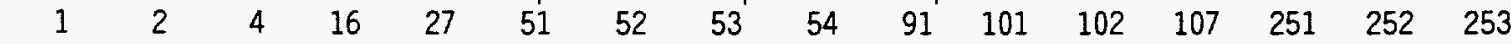

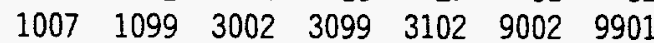

AMPX Nuclide ID 42000 has 19 temperature-independent 1-D processes. These include MT numbers:

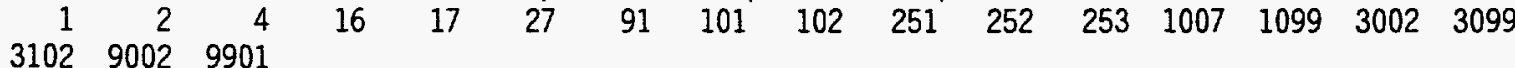

AMPX Nuclide ID 42097 has 36 temperature-independent 1-D processes. These include MT numbers:

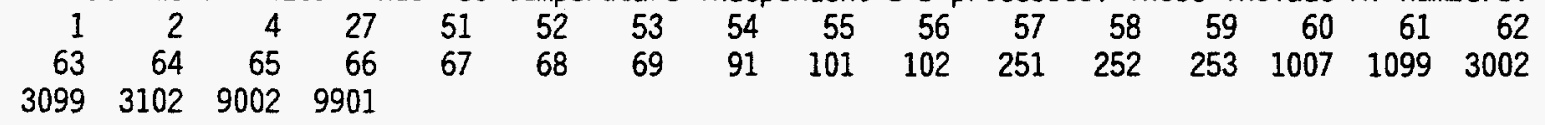

AMPX Nuclide ID 43099 has 29 temperature-independent 1-D processes. These include MT numbers:

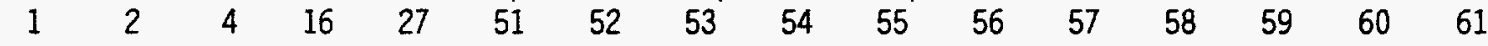

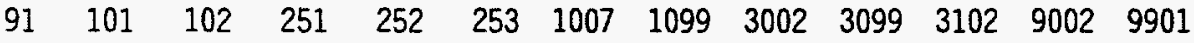

AMPX Nuclide ID 44101 has 36 temperature-independent 1-D processes. These include MT numbers:

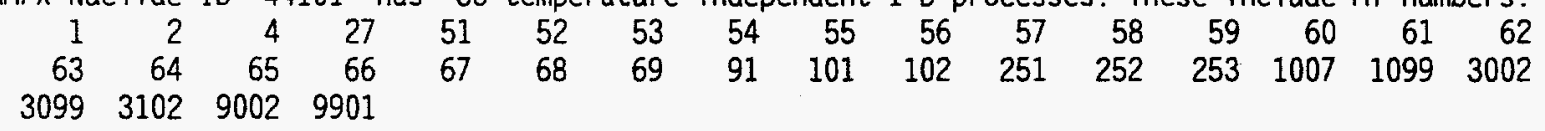

AMPX Nuclide ID 44103 has 31 temperature-independent 1-D processes. These include MT numbers:

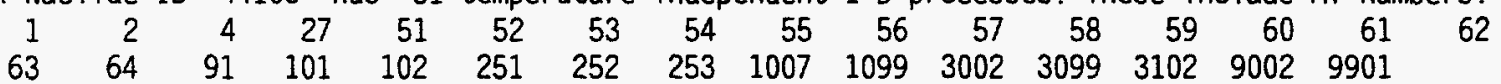

AMPX Nuclide ID 45103 has 32 temperature-independent 1-D processes. These include MT numbers:

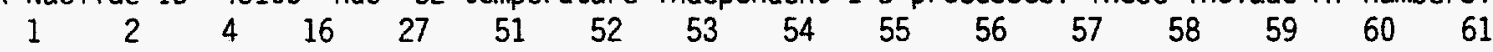

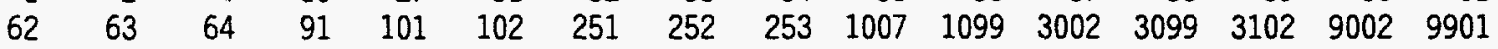


Table B-3 (continued)

AMPX Nuclide ID 45105 has 20 temperature-independent 1-D processes. These include MT numbers: $\begin{array}{llllllllllllllll}1 & 2 & 4 & 27 & 51 & 52 & 53 & 91 & 101 & 102 & 251 & 252 & 253 & 1007 & 1099 & 3002\end{array}$ $309931029002 \quad 9901$

AMPX Nuclide ID 47107 has 29 temperature-independent 1-D processes. These include MT numbers:

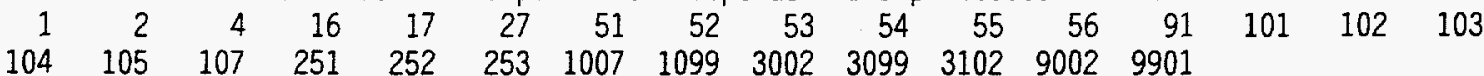

AMPX Nuclide ID 47109 has 26 temperature-independent 1-D processes. These include MT numbers: $\begin{array}{llllllllllllllll}1 & 2 & 4 & 16 & 17 & 27 & 51 & 52 & 53 & 54 & 55 & 91 & 101 & 102 & 103 & 107\end{array}$ $\begin{array}{llllllllll}251 & 252 & 253 & 1007 & 1099 & 3002 & 3099 & 3102 & 9002 & 9901\end{array}$

AMPX Nuclide ID 48000 has 19 temperature-independent 1-D processes. These include MT numbers: $\begin{array}{llllllllllllllll}1 & 2 & 4 & 16 & 17 & 27 & 91 & 101 & 102 & 251 & 252 & 253 & 1007 & 1099 & 3002 & 3099\end{array}$ 310290029901

AMPX Nuclide ID 48113 has 23 temperature-independent 1-D processes. These include MT numbers: $\begin{array}{llllllllllllllll}1 & 2 & 4 & 16 & 27 & 51 & 52 & 53 & 91 & 101 & 102 & 103 & 107 & 251 & 252 & 253\end{array}$ $1007 \quad 10993002 \quad 3099 \quad 3102 \quad 90029901$

AMPX Nuclide ID 50000 has 20 temperature-independent 1-D processes. These include MT numbers: $\begin{array}{llllllllllllllll}1 & 2 & 4 & 16 & 17 & 27 & 91 & 101 & 102 & 251 & 252 & 253 & 285 & 1007 & 1099 & 3002\end{array}$ $30993102 \quad 9002 \quad 9901$

AMPX Nuclide ID 53135 has 17 temperature-independent 1-D processes. These include MT numbers: 9901

AMPX Nuclide ID 54131 has 29 temperature-independent 1-D processes. These include MT numbers:

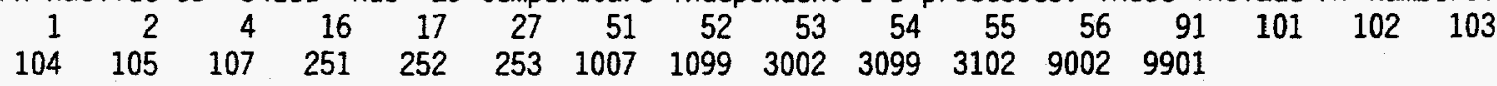

AMPX Nuclide ID 54133 has 18 temperature-independent 1-D processes. These include MT numbers: $\begin{array}{rrllllllllllllll}1 & 2 & 4 & 27 & 51 & 91 & 101 & 102 & 251 & 252 & 253 & 1007 & 1099 & 3002 & 3099 & 3102\end{array}$

AMPX Nuclide ID 54135 has 18 temperature-independent 1-D processes. These include MT numbers: $\begin{array}{llllllllllllllll}1 & 2 & 4 & 27 & 51 & 91 & 101 & 102 & 251 & 252 & 253 & 1007 & 1099 & 3002 & 3099 & 3102\end{array}$ 90029901

AMPX Nuclide ID 55133 has 25 temperature-independent 1-D processes. These include MT numbers:

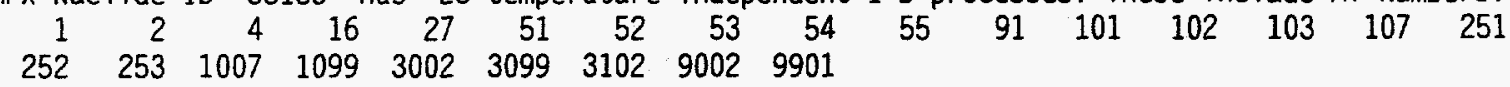

AMPX Nuclide ID 55134 has 22 temperature-independent 1-D processes. These include MT numbers: $\begin{array}{llllllllllllllll}1 & 2 & 4 & 27 & 51 & 52 & 53 & 54 & 55 & 91 & 101 & 102 & 251 & 252 & 253 & 1007\end{array}$ $10993002 \quad 3099 \quad 3102 \quad 90029901$

AMPX Nuclide ID 55135 has 20 temperature-independent 1-D processes. These include MT numbers: $\begin{array}{llllllllllllllll}1 & 2 & 4 & 27 & 51 & 52 & 53 & 91 & 101 & 102 & 251 & 252 & 253 & 1007 & 1099 & 3002\end{array}$ $\begin{array}{llll}3099 & 3102 \quad 9002 & 9901\end{array}$ 
Table B-3 (continued)

AMPX Nuclide ID 56134 has 24 temperature-independent 1-D processes. These include MT numbers: $\begin{array}{llllllllllllllll}1 & 2 & 4 & 27 & 51 & 52 & 53 & 54 & 55 & 56 & 57 & 91 & 101 & 102 & 251 & 252\end{array}$

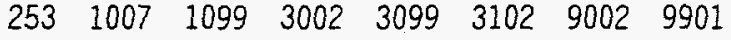

AMPX Nuclide ID 56135 has 26 temperature-independent 1-D processes. These include MT numbers: $\begin{array}{llllllllllllllll}1 & 2 & 4 & 27 & 51 & 52 & 53 & 54 & 55 & 56 & 57 & 58 & 59 & 91 & 101 & 102\end{array}$ $\begin{array}{llllllllll}251 & 252 & 253 & 1007 & 1099 & 3002 & 3099 & 3102 & 9002 & 9901\end{array}$

AMPX Nuclide ID 56136 has 27 temperature-independent 1-D processes. These include MT numbers: $\begin{array}{llllllllllllllll}1 & 2 & 4 & 27 & 51 & 52 & 53 & 54 & 55 & 56 & 57 & 58 & 59 & 60 & 91 & 101\end{array}$ $\begin{array}{lllllllllll}102 & 251 & 252 & 253 & 1007 & 1099 & 3002 & 3099 & 3102 & 9002 & 9901\end{array}$

AMPX Nuclide ID 56137 has 25 temperature-independent 1-D processes. These include MT numbers: $\begin{array}{llllllllllllllll}1 & 2 & 4 & 27 & 51 & 52 & 53 & 54 & 55 & 56 & 57 & 58 & 91 & 101 & 102 & 251\end{array}$ $\begin{array}{lllllllll}252 & 253 & 1007 & 1099 & 3002 & 3099 & 3102 & 9002 & 9901\end{array}$

AMPX Nuclide ID 56138 has 21 temperature-independent 1-D processes. These include MT numbers: $\begin{array}{llllllllllllllll}1 & 2 & 4 & 16 & 17 & 27 & 91 & 101 & 102 & 103 & 107 & 251 & 252 & 253 & 1007 & 1099\end{array}$ $\begin{array}{lllll}3002 & 3099 & 3102 & 9002 & 9901\end{array}$

AMPX Nuclide ID 56140 has 17 temperature-independent 1-D processes. These include MT numbers: 9901

AMPX Nuclide ID 58141 has 21 temperature-independent 1-D processes. These include MT numbers: $\begin{array}{llllllllllllllll}1 & 2 & 4 & 27 & 51 & 52 & 53 & 54 & 91 & 101 & 102 & 251 & 252 & 253 & 1007 & 1099\end{array}$ $\begin{array}{lllll}3002 & 3099 & 3102 & 9002 & 9901\end{array}$

AMPX Nuclide ID 59143 has 23 temperature-independent 1-D processes. These include MT numbers: $\begin{array}{llllllllllllllll}1 & 2 & 4 & 27 & 51 & 52 & 53 & 54 & 55 & 56 & 91 & 101 & 102 & 251 & 252 & 253\end{array}$ $\begin{array}{lllllll}1007 & 1099 & 3002 & 3099 & 3102 & 9002 & 9901\end{array}$

AMPX Nuclide ID 60143 has 34 temperature-independent 1-D processes. These include MT numbers: $\begin{array}{rrrrrrrrrrrrrrrr}1 & 2 & 4 & 16 & 17 & 22 & 27 & 28 & 51 & 52 & 53 & 54 & 55 & 56 & 57 & 58 \\ 91 & 101 & 102 & 103 & 104 & 105 & 106 & 107 & 251 & 252 & 253 & 1007 & 1099 & 3002 & 3099 & 3102 \\ 9002 & 9901 & & & & & & & & & & & & & & \end{array}$

AMPX Nuclide ID 60145 has 40 temperature-independent 1-D processes. These include MT numbers:

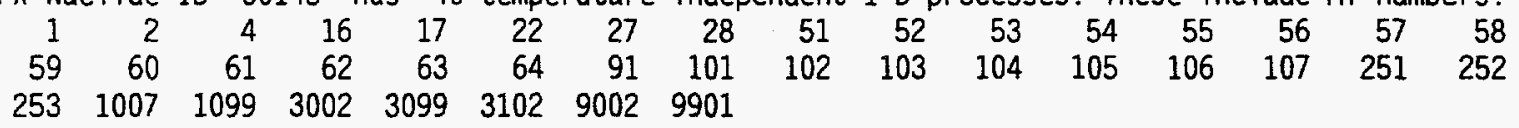

AMPX Nuclide ID 60147 has 20 temperature-independent 1-D processes. These include MT numbers: $\begin{array}{llllllllllllllll}1 & 2 & 4 & 27 & 51 & 52 & 53 & 91 & 101 & 102 & 251 & 252 & 253 & 1007 & 1099 & 3002\end{array}$ $30993102 \quad 90029901$

AMPX Nuclide ID 61147 has 31 temperature-independent 1-D processes. These include MT numbers: $\begin{array}{llllllllllllllll}1 & 2 & 4 & 16 & 17 & 22 & 27 & 28 & 51 & 52 & 53 & 54 & 55 & 91 & 101 & 102\end{array}$ $\begin{array}{lllllllllllllll}103 & 104 & 105 & 106 & 107 & 251 & 252 & 253 & 1007 & 1099 & 3002 & 3099 & 3102 & 9002 & 9901\end{array}$

AMPX Nuclide ID 61148 has 17 temperature-independent 1-D processes. These include MT numbers: 9901 
Table B-3 (continued)

AMPX Nuclide ID 61149 has 23 temperature-independent 1-0 processes. These include MT numbers:

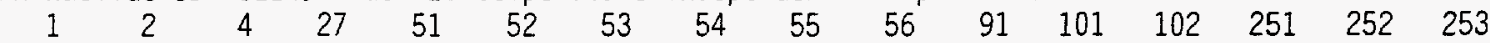
$1007 \quad 10993002 \quad 3099 \quad 3102 \quad 9002 \quad 9901$

AMPX Nuclide ID 61601 has 17 temperature-independent 1-D processes. These include MT numbers: 9901

AMPX Nuclide IO 62149 has 31 temperature-independent 1-D processes. These include MT numbers:

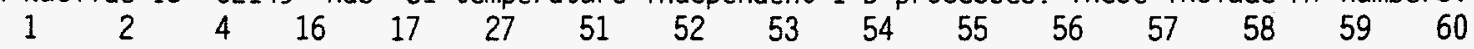

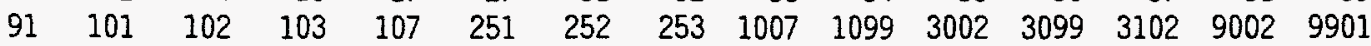

AMPX Nuclide ID 62150 has 33 temperature-independent 1-D processes. These include MT numbers:

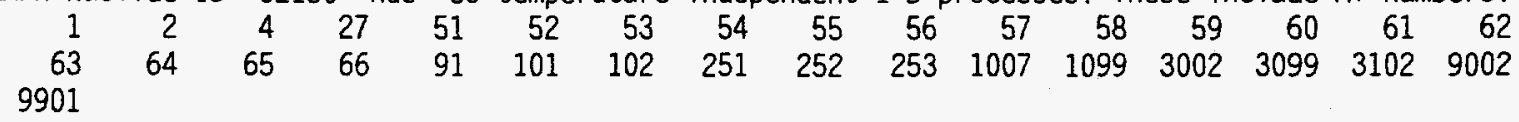

AMPX Nuclide ID 62151 has 37 temperature-independent 1-D processes. These include MT numbers:

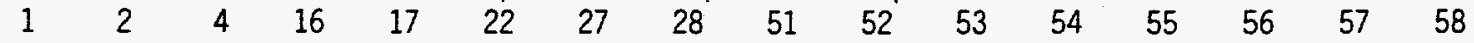

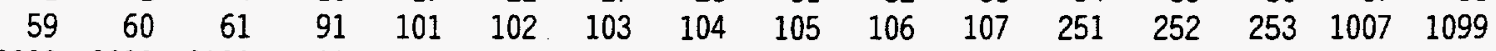

$$
\begin{aligned}
& 30023099 \quad 3102 \quad 9002 \quad 9901
\end{aligned}
$$

AMPX Nuclide ID 62152 has 40 temperature-independent 1-D processes. These include MT numbers:

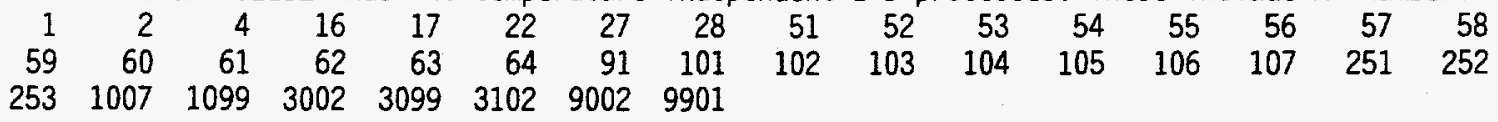

AMPX Nuclide ID 62153 has 29 temperature-independent 1-D processes. These include MT numbers:

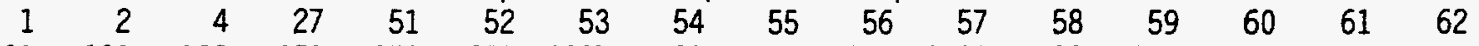

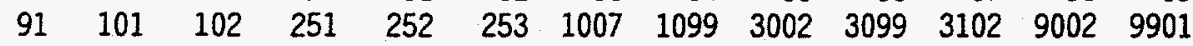

AMPX Nuclide ID 63000 has 19 temperature-independent 1-D processes. These include MT numbers:

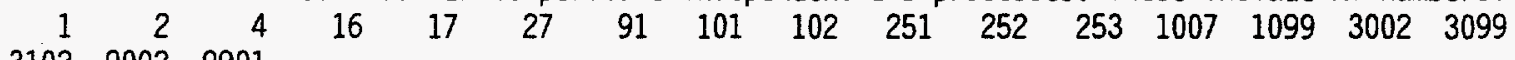
310290029901

AMPX Nuclide ID 63151 has 35 temperature-independent 1-D processes. These include MT numbers:

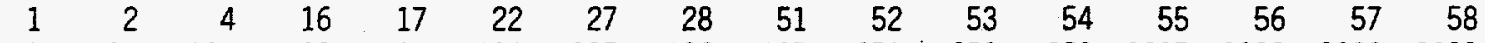

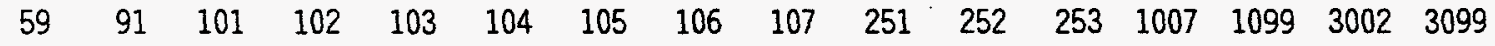

$$
\begin{aligned}
& 310290029901
\end{aligned}
$$

AMPX Nuclide ID 63152 has 31 temperature-independent 1-D processes. These include MT numbers:

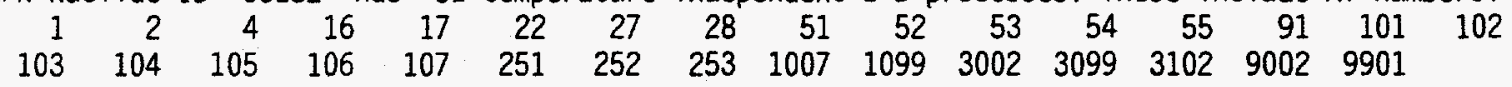

AMPX Nuclide ID 63153 has 38 temperature-independent 1-D processes. These include MT numbers:

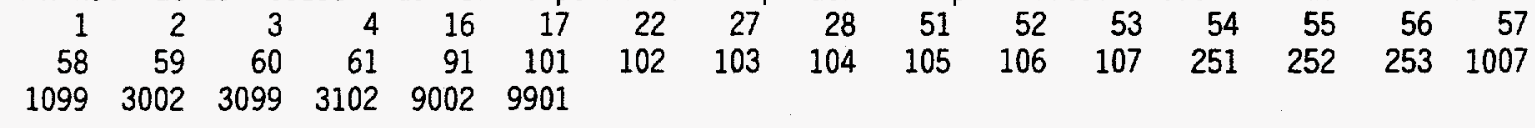

AMPX Nuclide ID 63154 has 31 temperature-independent 1-D processes. These include MT numbers:

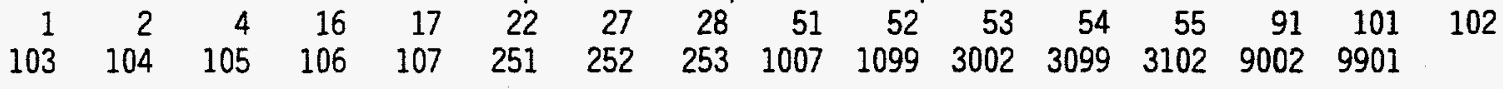


Table B-3 (continued)

AMPX Nuclide ID 63155 has 35 temperature-independent 1-D processes. These include MT numbers:

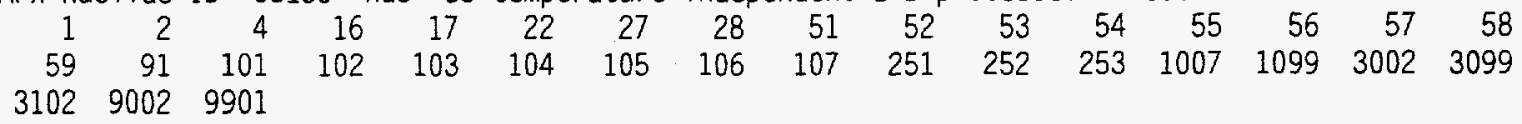

AMPX Nuclide ID 72000 has 23 temperature-independent 1-D processes. These include MT numbers:

$\begin{array}{llllllllllllllll}1 & 2 & 4 & 16 & 17 & 27 & 51 & 52 & 53 & 54 & 91 & 101 & 102 & 251 & 252 & 253\end{array}$ $1007 \quad 10993002 \quad 3099 \quad 3102 \quad 9002 \quad 9901$

AMPX Nuclide ID 72174 has 22 temperature-independent 1-D processes. These include MT numbers: $\begin{array}{rrrrrrrrrrrrrrrr}1 & 2 & 4 & 16 & 27 & 51 & 52 & 53 & 91 & 101 & 102 & 103 & 251 & 252 & 253 & 1007\end{array}$ $\begin{array}{llllll}1099 & 3002 & 3099 & 3102 & 9002 & 9901\end{array}$

AMPX Nuclide ID 72176 has 22 temperature-independent 1-D processes. These include MT numbers: $\begin{array}{rrrrrrrrrrrrrrrr}1 & 2 & 4 & 16 & 27 & 51 & 52 & 53 & 91 & 101 & 102 & 103 & 251 & 252 & 253 & 1007 \\ 1099 & 3002 & 3099 & 3102 & 9002 & 9901 & & & & & & & & & \end{array}$

AMPX Nuclide ID 72177 has 29 temperature-independent 1-D processes. These include MT numbers:

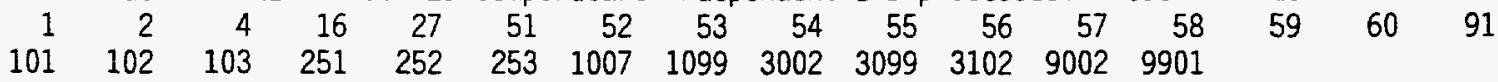

AMPX Nuclide ID 72178 has 22 temperature-independent 1-D processes. These include MT numbers: $\begin{array}{llllllllllllllll}1 & 2 & 4 & 16 & 27 & 51 & 52 & 53 & 91 & 101 & 102 & 103 & 251 & 252 & 253 & 1007\end{array}$ $\begin{array}{llllll}1099 & 3002 & 3099 & 3102 & 9002 & 9901\end{array}$

AMPX Nuclide ID 72179 has 23 temperature-independent 1-D processes. These include MT numbers: $\begin{array}{llllllllllllllll}1 & 2 & 4 & 16 & 27 & 51 & 52 & 53 & 54 & 91 & 101 & 102 & 103 & 251 & 252 & 253\end{array}$ $\begin{array}{lllllll}1007 & 1099 & 3002 & 3099 & 3102 & 9002 & 9901\end{array}$

AMPX Nuclide ID 72180 has 22 temperature-independent 1-D processes. These include MT numbers: $\begin{array}{llllllllllllllll}1 & 2 & 4 & 16 & 27 & 51 & 52 & 53 & 91 & 101 & 102 & 103 & 251 & 252 & 253 & 1007\end{array}$ $10993002 \quad 3099 \quad 3102 \quad 90029901$

AMPX Nuclide ID 73181 has 30 temperature-independent 1-D processés. These include MT numbers: $\begin{array}{llllllllllllllll}1 & 2 & 4 & 16 & 17 & 27 & 51 & 52 & 53 & 54 & 55 & 56 & 57 & 58 & 59 & 60\end{array}$ $\begin{array}{llllllllllllll}91 & 101 & 102 & 103 & 251 & 252 & 253 & 1007 & 1099 & 3002 & 3099 & 3102 & 9002 & 9901\end{array}$

AMPX Nuclide ID 73182 has 28 temperature-independent 1-D processes. These include MT numbers: $\begin{array}{rrrrrrrrrrrrrrrr}1 & 2 & 4 & 16 & 17 & 27 & 51 & 52 & 53 & 54 & 55 & 56 & 57 & 58 & 91 & 101\end{array}$ $\begin{array}{llllllllllll}102 & 107 & 251 & 252 & 253 & 1007 & 1099 & 3002 & 3099 & 3102 & 9002 & 9901\end{array}$

AMPX Nuclide ID 82000 has 55 temperature-independent 1-D processes. These include MT numbers:

$\begin{array}{rrrrrrrrrrrrrrrr}1 & 2 & 3 & 4 & 16 & 17 & 27 & 51 & 52 & 53 & 54 & 55 & 56 & 57 & 58 & 59 \\ 60 & 61 & 62 & 63 & 64 & 65 & 66 & 67 & 68 & 69 & 70 & 71 & 72 & 73 & 74 & 75 \\ 76 & 77 & 78 & 79 & 80 & 81 & 82 & 83 & 84 & 85 & 91 & 101 & 102 & 251 & 252 & 253 \\ 1007 & 1099 & 3002 & 3099 & 3102 & 9002 & 9901 & & & & & & & & & \end{array}$

AMPX Nuclide ID 83209 has 28 temperature-independent 1-D processes. These include MT numbers: $\begin{array}{llllllllllllllll}1 & 2 & 4 & 16 & 17 & 22 & 27 & 51 & 52 & 53 & 54 & 55 & 56 & 91 & 101 & 102\end{array}$ $\begin{array}{llllllllllll}103 & 107 & 251 & 252 & 253 & 1007 & 1099 & 3002 & 3099 & 3102 & 9002 & 9901\end{array}$ 
Table B-3 (continued)

AMPX Nuclide ID 90232 has 40 temperature-independent 1-D processes. These include MT numbers:

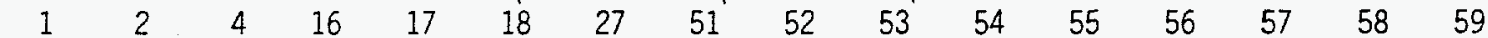

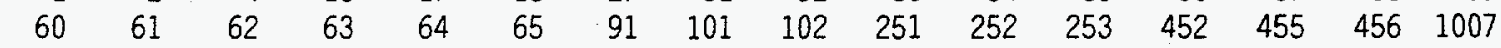

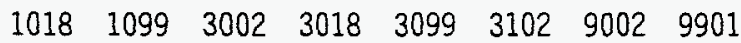

AMPX Nuclide ID 92233 has 25 temperature-independent 1-D processes. These include MT numbers:

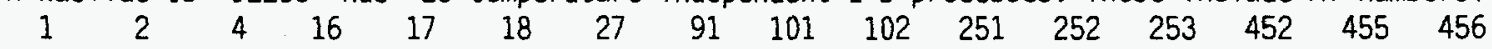

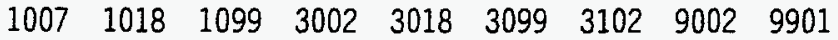

AMPX Nuclide ID 92234 has 25 temperature-independent 1-D processes. These include MT numbers:

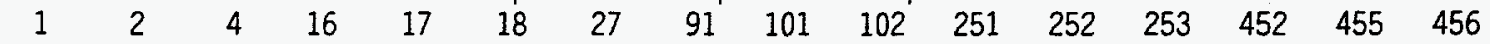

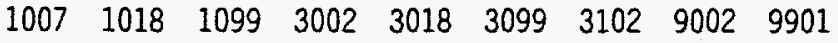

AMPX Nuclide ID 92235 has 39 temperature-independent 1-D processes. These include MT numbers:

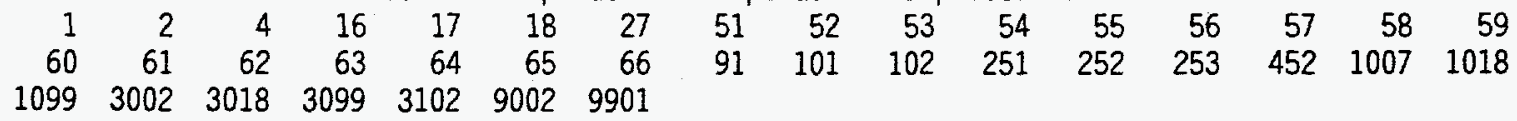

AMPX Nuclide ID 92236 has 25 temperature-independent 1-D processes. These include MT numbers:

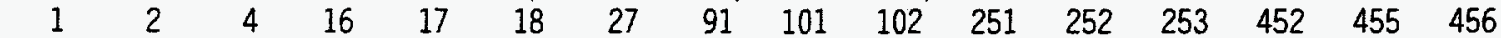

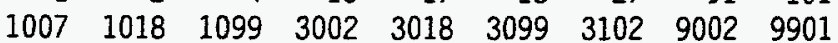

AMPX Nuclide ID 92237 has 23 temperature-independent 1-D processes. These include MT numbers:

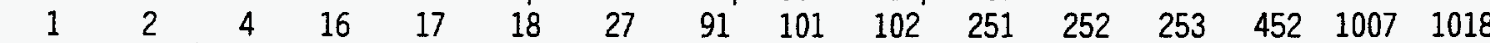

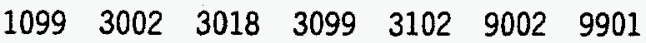

AMPX Nuclide ID 92238 has 51 temperature-independent 1-D processes. These include MT numbers:

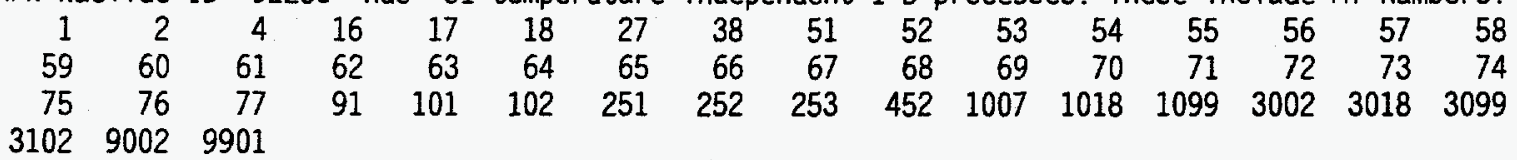

AMPX Nuclide ID 93237 has 34 temperature-independent 1-D processes. These include MT numbers:

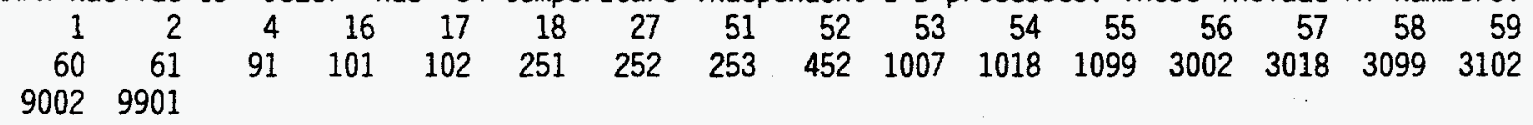

AMPX Nuclide ID 93238 has 21 temperature-independent 1-D processes. These include MT numbers:

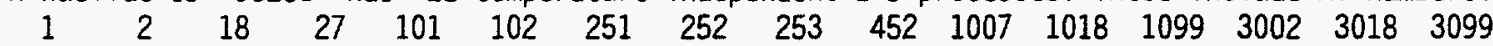
31029002945294529901

AMPX Nuclide IO 93239 has 31 temperature-independent 1-D processes. These include MT numbers:

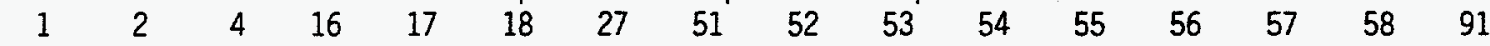

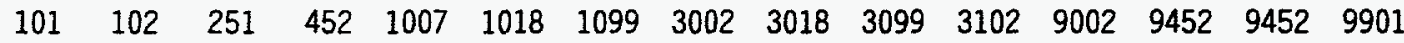

AMPX Nuclide ID 94238 has 25 temperature-independent 1-D processes. These include MT numbers:

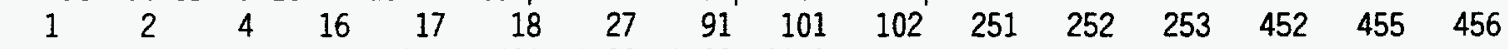

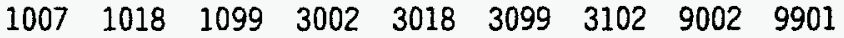


Table B-3 (continued)

AMPX Nuclide ID 96244 has 26 temperature-independent 1-D processes. These include MT numbers:

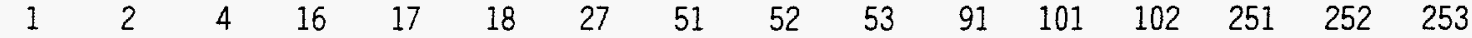

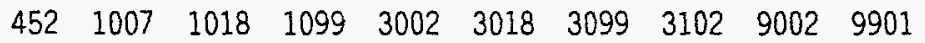

AMPX Nuclide ID 96245 has 28 temperature-independent 1-D processes. These include MT numbers:

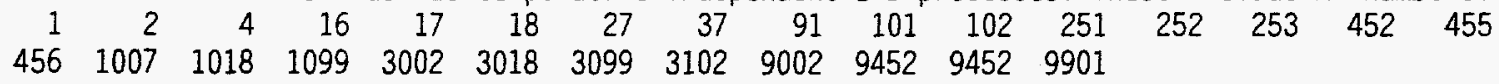

AMPX Nuclide ID 96246 has 35 temperature-independent 1-D processes. These include MT numbers:

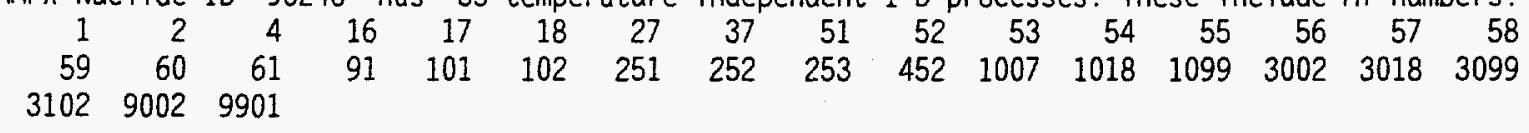

AMPX Nuclide ID 96247 has 24 temperature-independent 1-D processes. These include MT numbers:

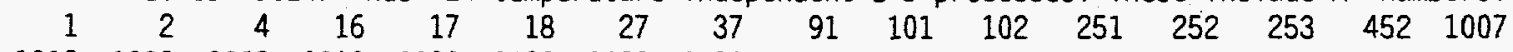

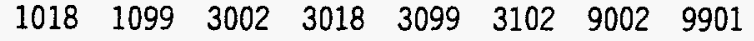

AMPX Nuclide ID 96248 has 31 temperature-independent 1-D processes. These include MT numbers:

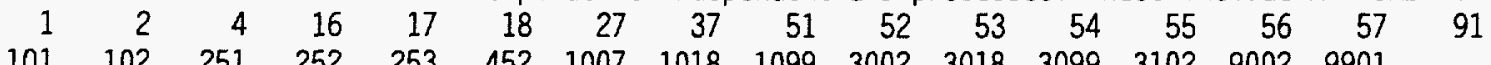

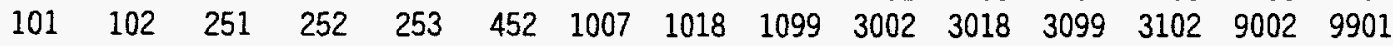

AMPX Nuclide ID 97249 has 24 temperature-independent 1-D processes. These include MT numbers:

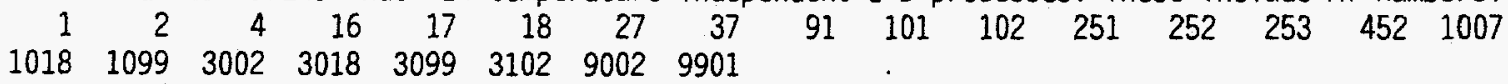

AMPX Nuclide ID 98249 has 24 temperature-independent 1-D processes. These include MT numbers:

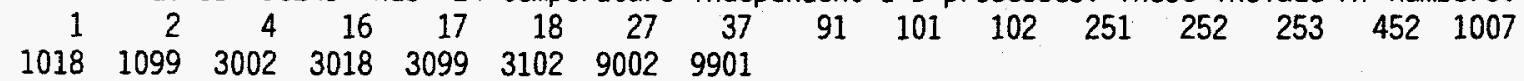

AMPX Nuclide ID 98250 has 24 temperature-independent 1-D processes. These include MT numbers:

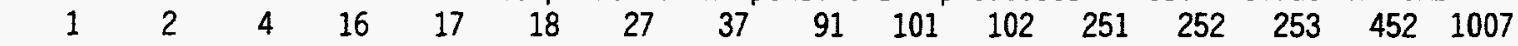

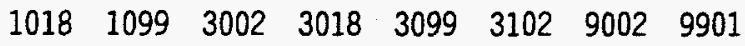

AMPX Nuclide ID 98251 has 24 temperature-independent 1-D processes. These include MT numbers:

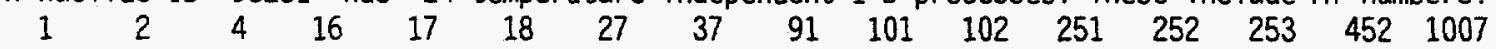

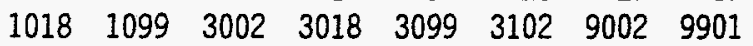

AMPX Nuclide ID 98252 has 24 temperature-independent 1-D processes. These include MT numbers:

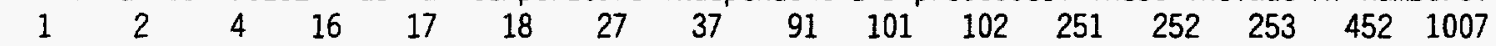

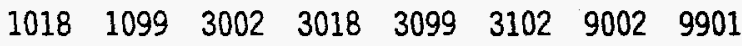

AMPX Nuclide ID 98253 has 19 temperature-independent 1-D processes. These include MT numbers:

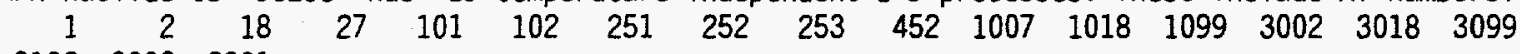
310290029901

AMPX Nuclide ID 99253 has 15 temperature-independent 1-D processes. These include MT numbers:

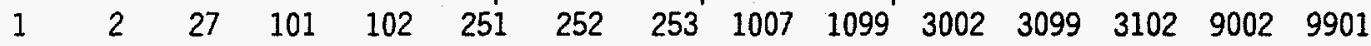

Note: The RADE output from which the above data was taken shows nuclides 1003 and 2004 as having neutron disappearance data (MT=101) and neutron absorption data $(M T=27)$, where MT(27)-MT(101)+MT(18). While these data flags do exist, all the multigroup data in the library for these two processes are zero for both of these nuclides. Likewise, the RADE output shows nuclide 3007 as having MT=82 [i.e.. inelastic ( $n . n^{\prime}$ ) data for the 32nd excited state] and nuclide 5010 as having MT=85 [i.e. inelastic $\left(n, n^{\prime}\right)$ data for the 35th excited state]. While these data flags do exist. all the multigroup data in the library for these two processes are zero for these two nuclides. 


\section{APPENDIX C}

ANSL-V LIBRARY: AMPX INPUT DATA FILES 

Table C-1. XLACS input file

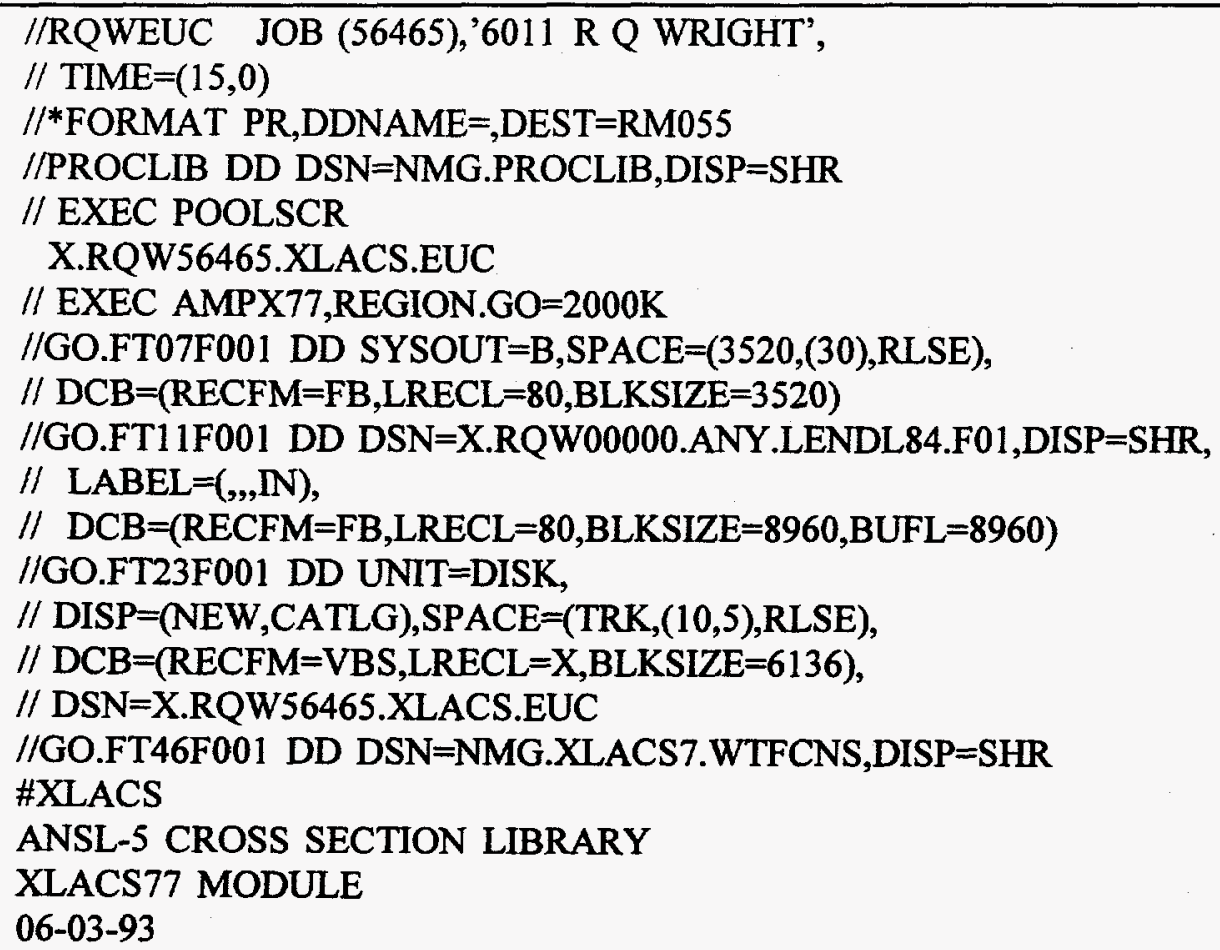


Table C-2. SMUG input file

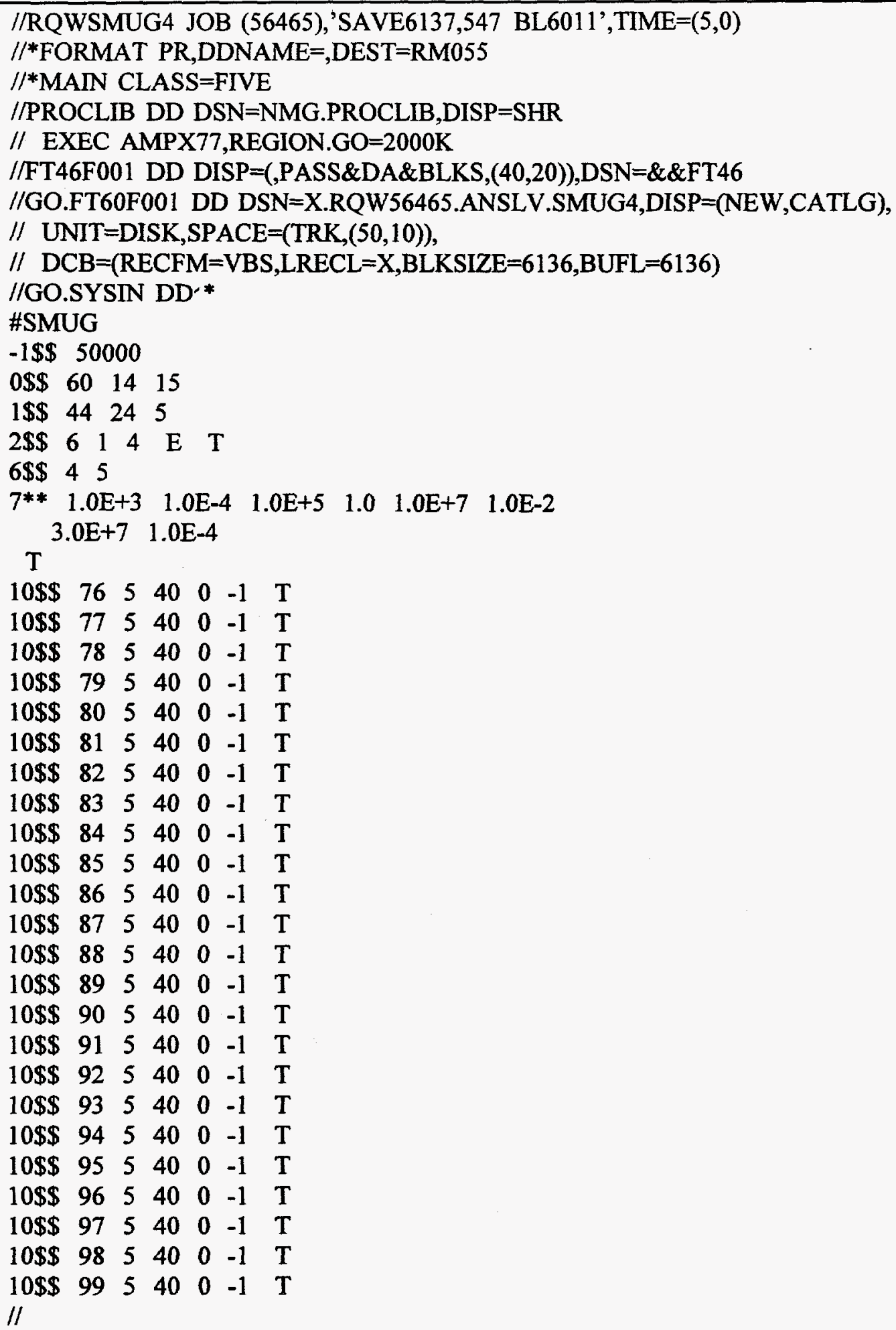


Table C-3. LAPHNGAS input file

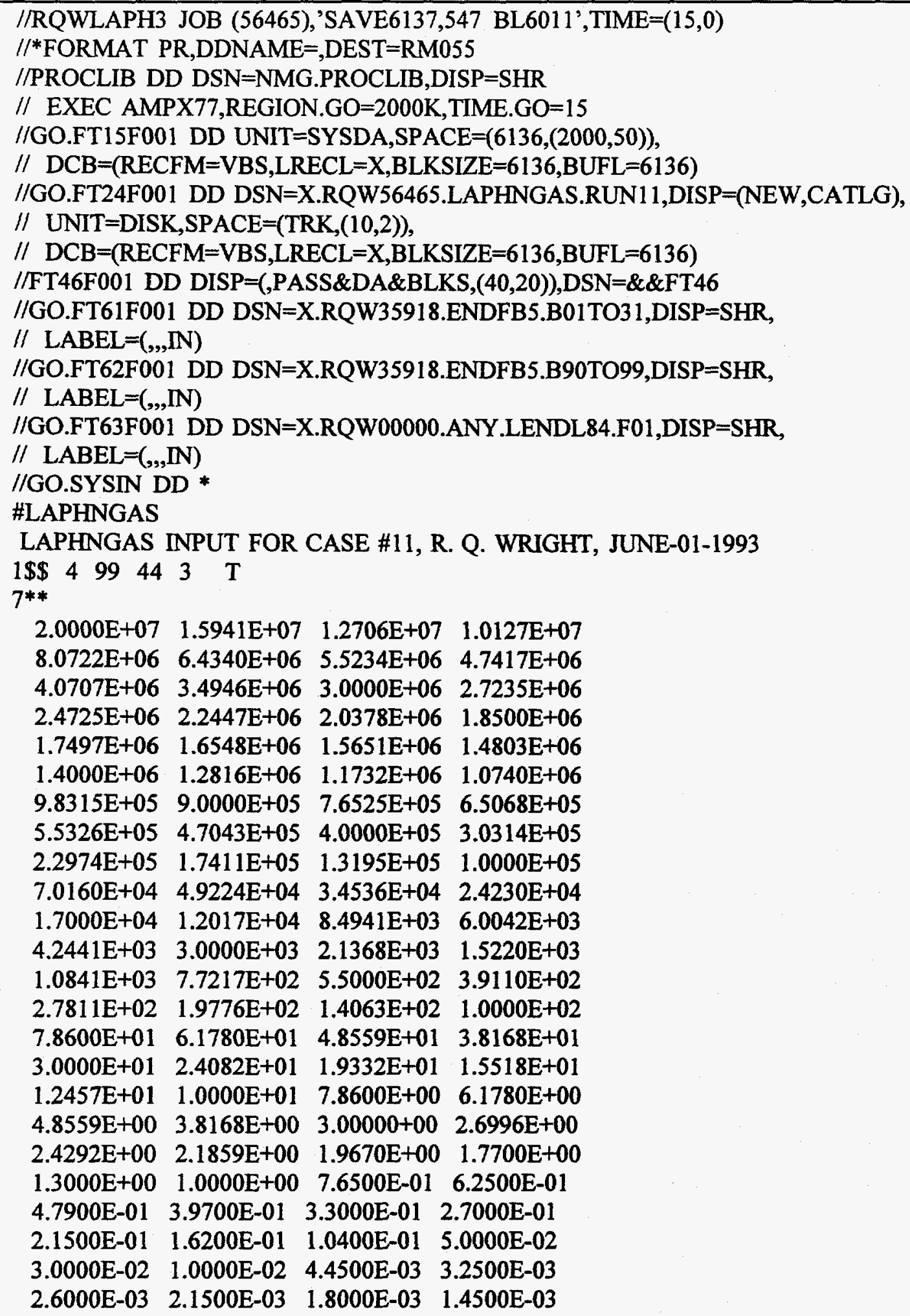


60

Table C-3 (continued)

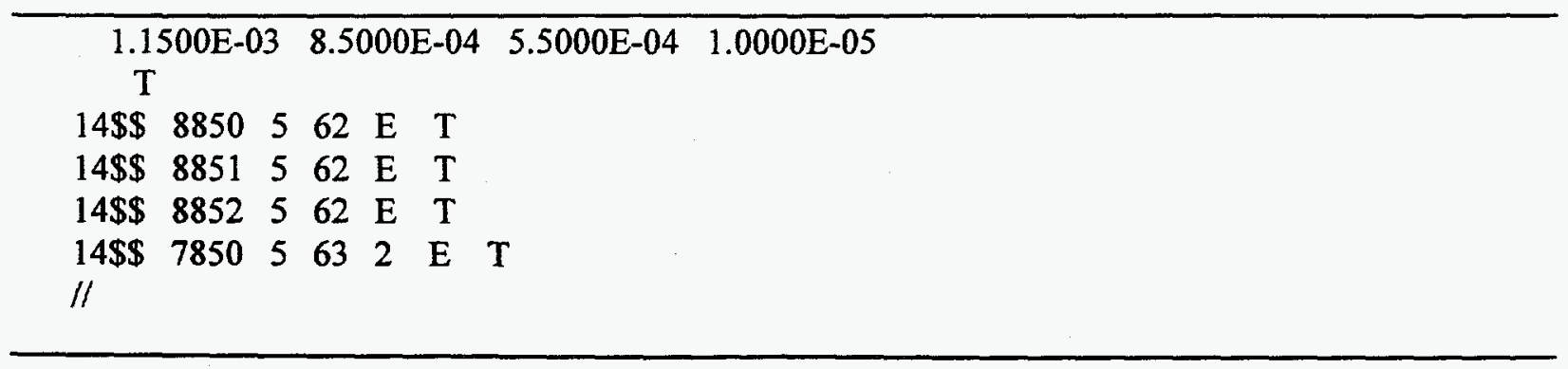


Table C-4. UNITAB input file

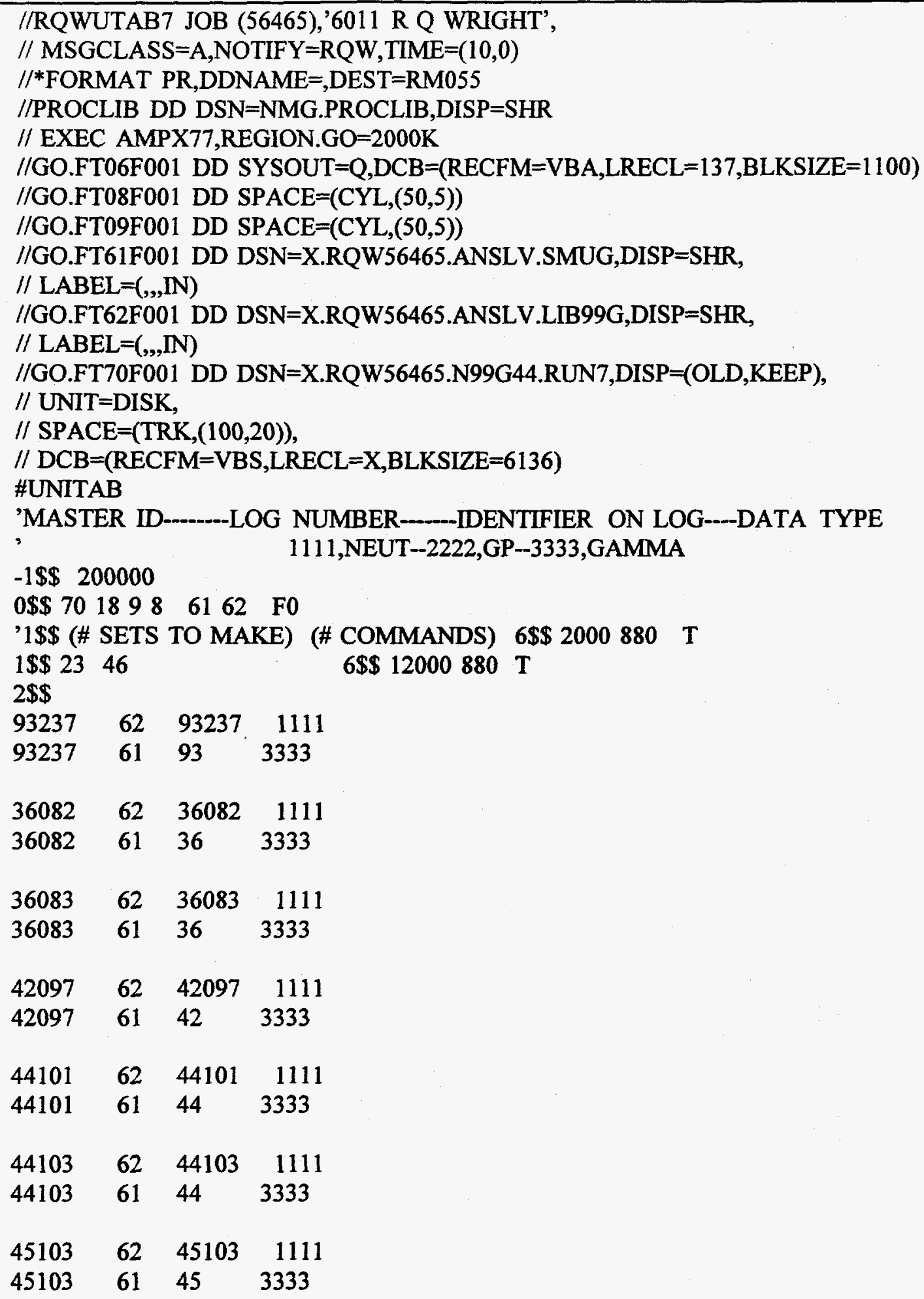


Table C-4 (continued)

\begin{tabular}{|c|c|c|c|}
\hline $\begin{array}{l}45105 \\
45105\end{array}$ & $\begin{array}{l}62 \\
61\end{array}$ & $\begin{array}{l}45105 \\
45\end{array}$ & $\begin{array}{c}1111 \\
3333\end{array}$ \\
\hline $\begin{array}{l}53135 \\
53135\end{array}$ & $\begin{array}{l}62 \\
61\end{array}$ & $\begin{array}{l}53135 \\
53\end{array}$ & $\begin{array}{c}1111 \\
3333\end{array}$ \\
\hline $\begin{array}{l}54131 \\
54131\end{array}$ & $\begin{array}{l}62 \\
61\end{array}$ & $\begin{array}{l}54131 \\
54\end{array}$ & $\begin{array}{c}1111 \\
3333\end{array}$ \\
\hline $\begin{array}{l}54133 \\
54133\end{array}$ & $\begin{array}{l}62 \\
61\end{array}$ & $\begin{array}{l}54133 \\
54\end{array}$ & $\begin{array}{c}1111 \\
3333\end{array}$ \\
\hline $\begin{array}{l}54135 \\
54135\end{array}$ & $\begin{array}{l}62 \\
61\end{array}$ & $\begin{array}{l}54135 \\
54\end{array}$ & $\begin{array}{c}1111 \\
3333\end{array}$ \\
\hline $\begin{array}{l}55133 \\
55133\end{array}$ & $\begin{array}{l}62 \\
61\end{array}$ & $\begin{array}{l}55133 \\
55\end{array}$ & $\begin{array}{c}1111 \\
3333\end{array}$ \\
\hline $\begin{array}{l}55134 \\
55134\end{array}$ & $\begin{array}{l}62 \\
61\end{array}$ & $\begin{array}{l}55134 \\
55\end{array}$ & $\begin{array}{c}1111 \\
3333\end{array}$ \\
\hline $\begin{array}{l}55135 \\
55135\end{array}$ & $\begin{array}{l}62 \\
61\end{array}$ & $\begin{array}{l}55135 \\
55\end{array}$ & $\begin{array}{c}1111 \\
3333\end{array}$ \\
\hline $\begin{array}{l}60145 \\
60145\end{array}$ & $\begin{array}{l}62 \\
61\end{array}$ & $\begin{array}{l}60145 \\
60\end{array}$ & $\begin{array}{c}1111 \\
3333\end{array}$ \\
\hline $\begin{array}{l}60147 \\
60147\end{array}$ & $\begin{array}{l}62 \\
61\end{array}$ & $\begin{array}{l}60147 \\
60\end{array}$ & $\begin{array}{c}1111 \\
3333\end{array}$ \\
\hline $\begin{array}{l}61148 \\
61148\end{array}$ & $\begin{array}{l}62 \\
61\end{array}$ & $\begin{array}{l}61148 \\
61\end{array}$ & $\begin{array}{c}1111 \\
3333\end{array}$ \\
\hline $\begin{array}{l}61601 \\
61601\end{array}$ & $\begin{array}{l}62 \\
61\end{array}$ & $\begin{array}{l}61601 \\
61\end{array}$ & $\begin{array}{c}1111 \\
3333\end{array}$ \\
\hline $\begin{array}{l}61149 \\
61149\end{array}$ & $\begin{array}{l}62 \\
61\end{array}$ & $\begin{array}{l}61149 \\
61\end{array}$ & $\begin{array}{c}1111 \\
3333\end{array}$ \\
\hline $\begin{array}{l}62151 \\
62151\end{array}$ & $\begin{array}{l}62 \\
61\end{array}$ & $\begin{array}{l}62151 \\
62\end{array}$ & $\begin{array}{c}1111 \\
3333\end{array}$ \\
\hline $\begin{array}{l}62152 \\
62152\end{array}$ & $\begin{array}{l}62 \\
61\end{array}$ & $\begin{array}{l}62152 \\
62\end{array}$ & $\begin{array}{c}1111 \\
3333\end{array}$ \\
\hline
\end{tabular}


Table C-4 (continued)

\begin{tabular}{|c|c|c|}
\hline 63155 & 62 & 63155 \\
\hline $\begin{array}{l}63155 \\
T\end{array}$ & 61 & 63 \\
\hline
\end{tabular}


Table C-5. MALOCS input file

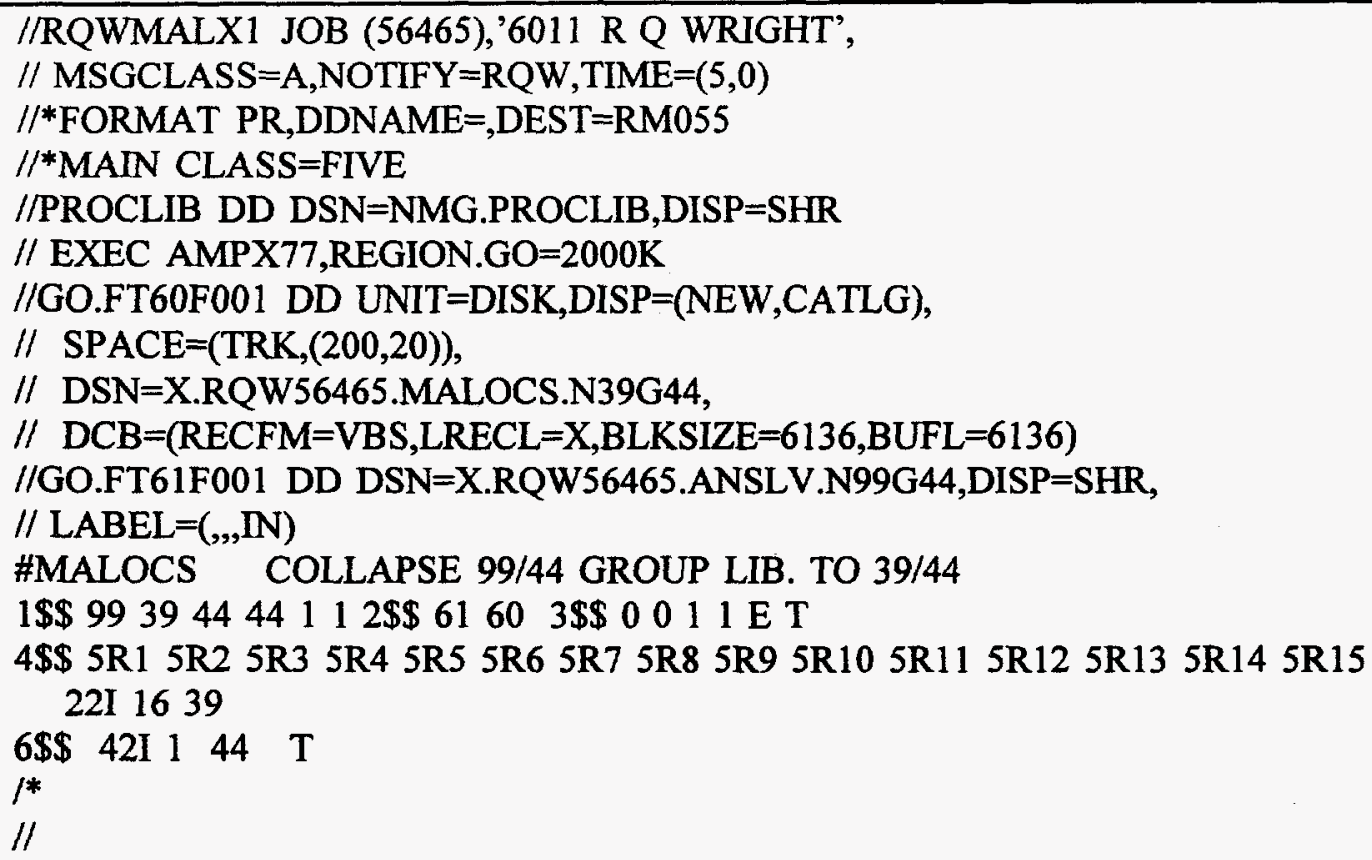


Table C-6. COMET input file

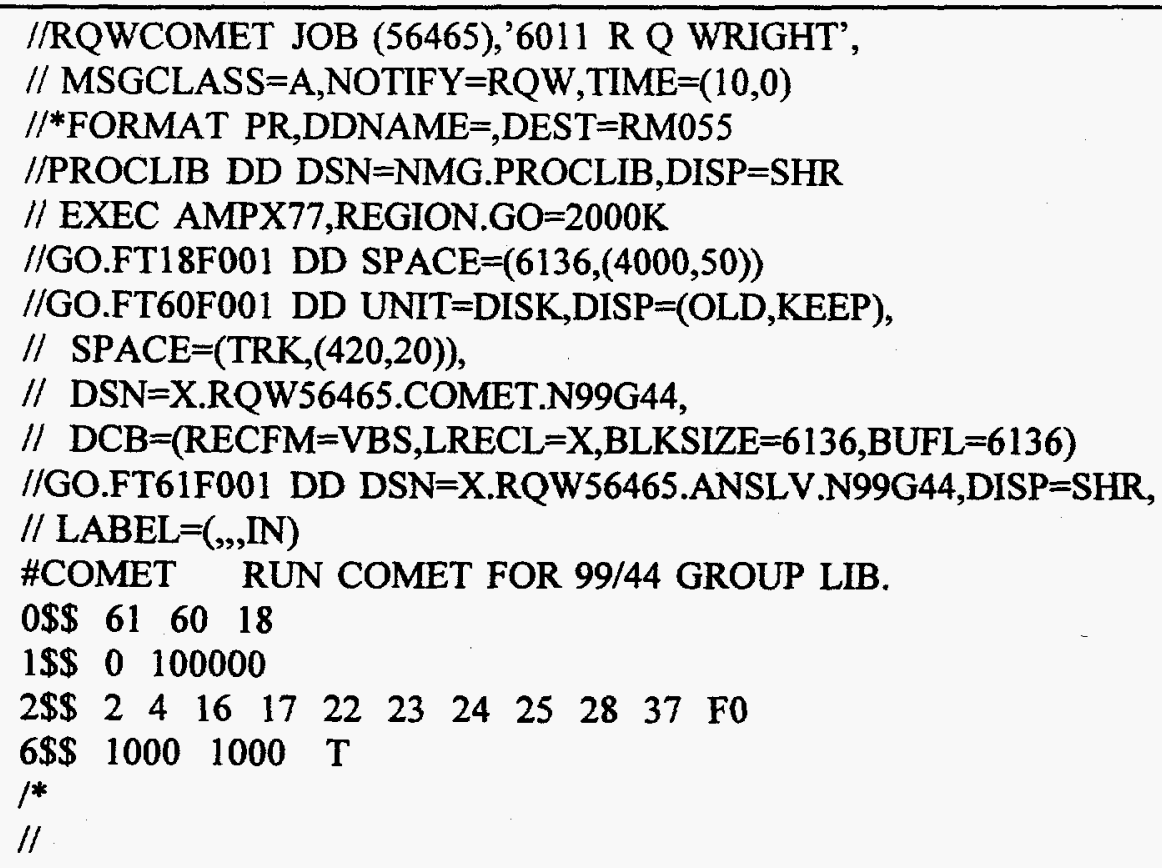


Table C-7. FRESH input file

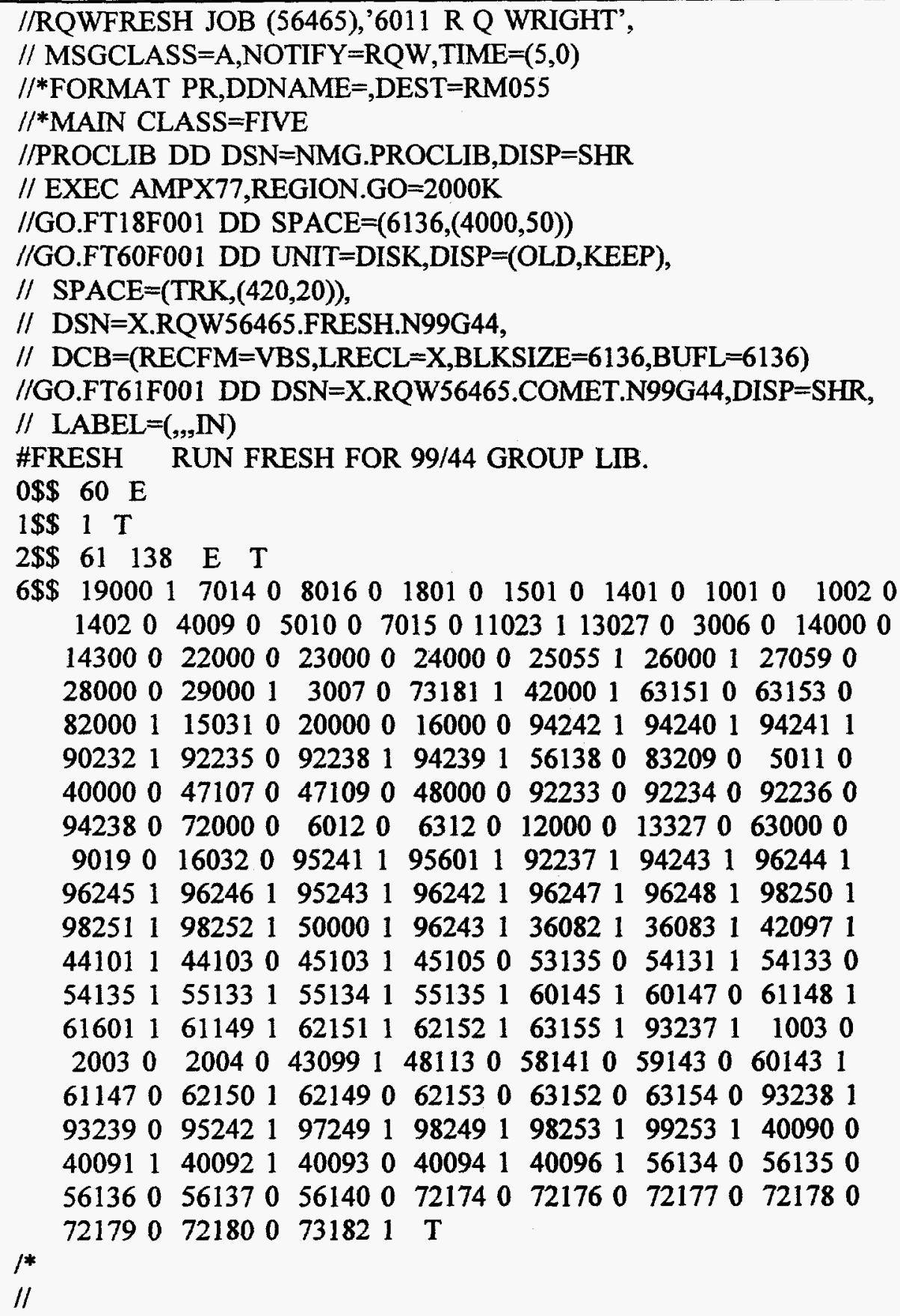


Table C-8. PERFUME input file

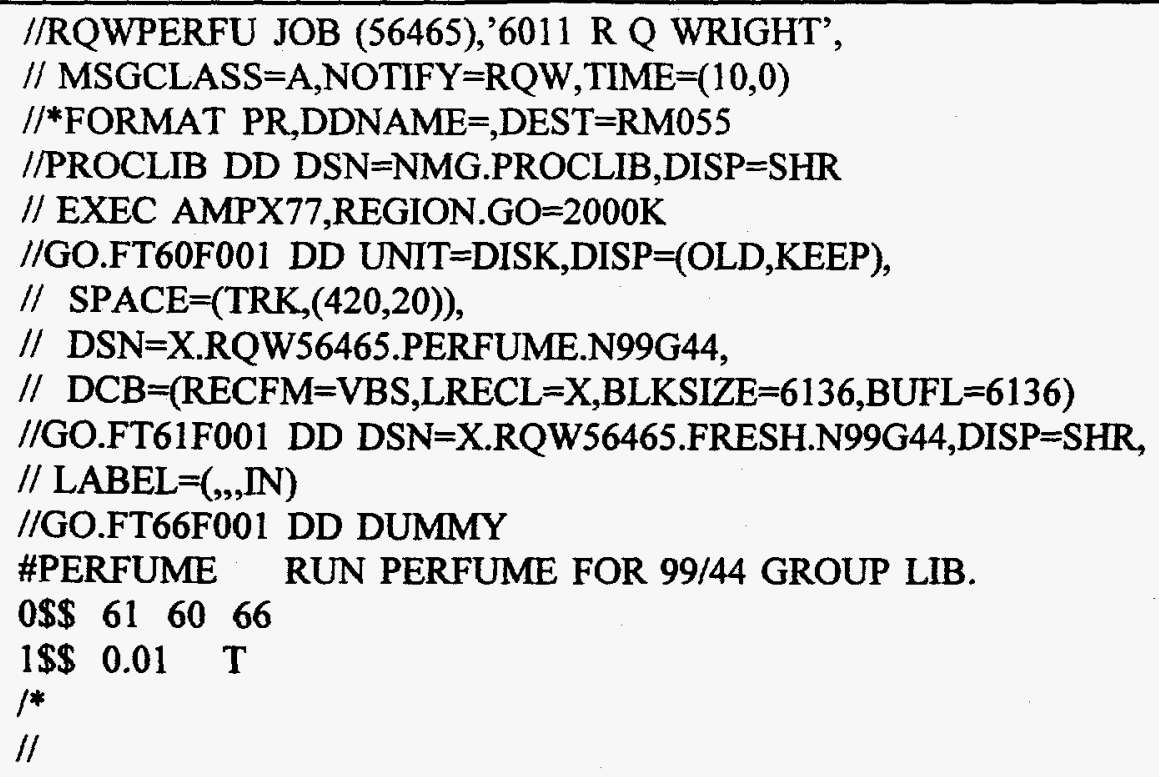


- 


\section{Internal Distribution}

1-3. J. A. Bucholz

4. J. C. Gehin

5. N. M. Greene

6-7. D. T. Ingersoll

8. M. Kuliasha

9. R. A. Lillie

10. L. F. Norris

11. C. V. Parks

12. R. T. Primm III

13. J. P. Renier

14. R. W. Roussin

15. D. L. Selby
16. C. O. Slater

17. C. D. West

18. R. M. Westfall

19-21. B. A. Worley

22-26. R. Q. Wright

27-29. RSIC

30-32. EP\&MD Reports Office

33-34. Laboratory Records Dept.

35. Central Research Library

36. Central Research Library

37. Document Reference Section

38. ORNL Patent Office

\section{External Distribution}

39. Office of the Assistant Manager for Energy Research \& Development, DOE-ORO, Oak Ridge, TN 37830

40-41. Office of Scientific and Technical Information, P.O. Box 62, Oak Ridge, TN 37830

42. B. Chalmers Frazer, Materials Sciences Division, U.S. Department of Energy, Germantown, ER-132, Washington, DC 20585

43. Ralph Fullwood, Brookhaven National Laboratory, Upton, NY 11973 
